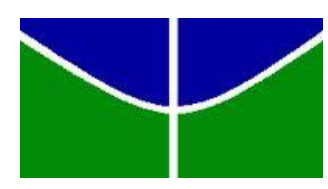

UNIVERSIDADE DE BRASÍLIA - UNB

FACULDADE DE ECONOMIA, ADMINISTRAÇÃO E CONTABILIDADE - FACE PROGRAMA DE PÓS GRADUAÇÃO EM ADMINISTRAÇÃO - PPGA

\title{
RELAÇÃO ENTRE CONDIÇÕES PARA CRIAR E ESTRATÉGIAS DE APRENDIZAGEM NO AMBIENTE DE TRABALHO
}

PEDRO CÉSAR ALVES RIBEIRO DE SOUZA

BRASÍLIA, DF 


\section{PEDRO CÉSAR ALVES RIBEIRO DE SOUZA}

\section{RELAÇÃO ENTRE CONDIÇÕES PARA CRIAR E ESTRATÉGIAS DE APRENDIZAGEM NO AMBIENTE DE TRABALHO}

Dissertação apresentada como requisito parcial para obtenção do grau de Mestre em Administração do Programa de PósGraduação em Administração da Faculdade de Economia, Administração e Contabilidade da Universidade de Brasília.

Orientadora: $\operatorname{Prof}^{\mathrm{a}}$. Dr ${ }^{\mathrm{a}}$. Catarina Cecília Odelius

BRASÍLIA, DF 


\section{PEDRO CÉSAR ALVES RIBEIRO DE SOUZA}

\section{RELAÇÃO ENTRE CONDIÇÕES PARA CRIAR E ESTRATÉGIAS DE APRENDIZAGEM NO AMBIENTE DE TRABALHO}

Dissertação submetida ao Programa de Pós-Graduação em Administração da Universidade de Brasília (PPGA/UnB) e avaliada em 25 de fevereiro de 2016 pela banca examinadora constituída por:

Prof ${ }^{\mathrm{a}}$. Dr ${ }^{\mathrm{a}}$. CATARINA CECÍLIA ODELIUS - Presidente Universidade de Brasília (UnB)

Prof. Dr. FRANCISCO ANTÔNIO COELHO JUNIOR - Membro Interno Universidade de Brasília (UnB)

Prof $^{\mathrm{a}}$. Dr ${ }^{\mathrm{a}}$. MARIA DE FÁTIMA BRUNO DE FARIA- Membro Externo Universidade Federal do Rio de Janeiro (UFRJ) 
Às minhas queridas avós que tive o prazer de conviver e amar. 


\section{AGRADECIMENTOS}

À Prof ${ }^{a}$. Catarina Odelius pela impecável orientação nestes últimos anos. Obrigado pelos ensinamentos, pela paciência e por acreditar no meu trabalho. Sou muito grato por tudo que a $\mathrm{Sr}^{\mathrm{a}}$ fez por mim.

Aos professores que tive o prazer de ter em minha banca examinadora. À Prof ${ }^{a}$. Gardênia por aceitar o convite, ao Prof $^{\circ}$ Francisco pelas inestimáveis contribuições e à Prof ${ }^{a}$ Fátima Bruno pelo mesmo apoio e carinho de que me lembro quando fui seu orientando de graduação.

Á minha família pelo apoio incondicional. Em especial aos meus pais, Alexandre e Fátima, por acreditarem no meu sucesso, às vezes, até mais do que eu. Meus irmãos Felipe, Ângela e Pâmela, obrigado por toda a ajuda de vocês.

Aos meus amigos pela compreensão e apoio, nos momentos bons e ruins, longe ou perto, até chegar aqui.

Às pessoas que me ajudaram diretamente na elaboração deste trabalho. Em especial ao Bruno Farias pela parceria nas tardes de estudos e ao Igor Guevara que agora sabe tanto de Estratégias de Aprendizagem quanto o que eu sei sobre Reputação de RH.

À FENABB e à todos os participantes da pesquisa por acreditarem na importância deste estudo. Obrigado pela oportunidade e por dedicarem tempo para a realização deste trabalho.

À todos os colegas que fazem parte do Grupo de Pesquisa APINOV pelas valiosas "cri-crizagens" que agregaram muito para este resultado.

A todos que me ajudaram, direta ou indiretamente, a chegar até aqui. Sou grato a todos. 


\section{RESUMO}

Este trabalho teve como objetivo identificar as relações existentes entre as condições para criar e o uso de estratégias de aprendizagem no ambiente de trabalho de uma rede de clubes socioesportivo de abrangência nacional. $O$ conceito de criatividade organizacional foi entendido como "a geração de ideias, processos, produtos e/ou serviços novos para aquele indivíduo, grupo ou naquele contexto que possam gerar contribuições valiosas para a organização e/ou para o bem-estar das pessoas que trabalham naquele contexto e que possuam elementos essenciais à sua implementação" e o de estratégias de aprendizagem como "práticas que as pessoas utilizam para auxiliar a aquisição de conhecimentos e habilidades em seu contexto profissional". A pesquisa foi realizada junto a 198 funcionários efetivos de diferentes unidades da rede de clubes por meio da aplicação de um questionário estruturado disponibilizado eletronicamente, que continha dois instrumentos de medida. O Indicadores de Condições para Criar no Ambiente de Trabalho (ICCAT) composto de duas escalas, sendo a primeira voltada a condições favoráveis à criatividade, composto de 36 itens e 6 fatores, e a segunda voltada a condições desfavoráveis à criatividade, com 24 itens em 3 fatores. A escala de estratégia de aprendizagem utilizada, de Brandão e Borges-Andrade (2011), é composta de 26 itens distribuídos em 5 fatores. Foram realizadas análises descritivas e exploratórias, além de técnicas multivariadas como análise fatorial e de correlação de Spearman. A identificação de evidências de validade revelou novas estruturas fatoriais para as escalas de condições favoráveis à criatividade e de estratégia de aprendizagem, passando ambas a serem compostas por 4 fatores. Verificou-se maior concordância quanto à presença das condições favoráveis à criatividade Liberdade de ação e atividades desafiantes e Características do ambiente físico enquanto que para condição desfavorável mais percebida foi Excesso de Serviço e Escassez de Tempo. As estratégias de aprendizagem indicadas como mais utilizadas foram Aplicação prática e Reflexão Ativa e Busca de Ajuda Interpessoal. Em seguida, verificou-se a associação positiva entre condições favoráveis à criatividade com as estratégias de aprendizagem, bem como a associação negativa de algumas estratégias de aprendizagem com as condições desfavoráveis à criatividade. Seis das nove hipóteses levantadas inicialmente à luz da literatura foram confirmadas empiricamente e outras oito relações não previstas também foram identificadas. Os principais resultados apontam que a estratégia de aprendizagem Busca de ajuda interpessoal está relacionada com todos os fatores de condições para criar, favoráveis ou desfavoráveis, exceto com Dificuldade de comunicação e rigidez das normas e regras na organização, que não teve relação com nenhuma estratégia de aprendizagem. As relações de maior efeito são do fator de condições favoráveis Liberdade de ação e atividades desafiantes com as estratégias de aprendizagem Aplicação prática e reflexão ativa, Busca de ajuda interpessoal e Busca de ajuda em material escrito. O aspecto de condição favorável à criatividade Estímulos a novas ideias por colegas, chefes e ações organizacionais está relacionado com todas as estratégias de aprendizagem.

Palavras chave: estratégias de aprendizagem no trabalho, aprendizagem informal criatividade nas organizações condições para criar. 


\begin{abstract}
This study aimed to identify the relationship between the conditions to create and use learning strategies in the workplace of a network of social and sports clubs nationwide. The concept of organizational creativity was understood as "the generation of ideas, processes, products and/or new services for that individual, group, or in that context that can generate valuable contributions to the organization and/or for the welfare of the people working in that context and that have essential elements to their implementation" and the concept of learning strategies as" practices that people use to support the acquisition of knowledge and skills in their professional context". The survey was conducted with 198 permanent employees from different units of the network of clubs through the application of a structured questionnaire available electronically, containing two instruments measure. The Indicators of Conditions to Create in the Workplace (ICCW) composed of two scales, being the first dedicated to favorable conditions for creativity, consisting of 36 items and 6 factors, and the second dedicated to unfavorable conditions for creativity, with 24 items on 3 factors. The learning strategy scale used, made by Brandão and Andrade-Borges (2011), consists of 26 items distributed on 5 factors. Descriptive and exploratory analyzes were performed, and multivariate techniques such as factor analysis and Spearman correlation. The identification of evidence of validity revealed new factor structures for the scales of favorable conditions for creativity and learning strategy, passing both to be composed by four factors. There was more agreement on the presence of favorable conditions for creativity freedom of action and challenging activities and characteristics of the physical environment while for unfavorable condition was Excess Service and lack of time. Learning strategies indicated as more used were Practical application and active reflection and Interpersonal Help Seeking. Then, the positive association between favorable conditions for creativity with the learning strategies was found, as well as the negative association of some learning strategies with unfavorable conditions for creativity. Six of the nine first hypotheses formulated based on the literature have been confirmed empirically and eight other unforeseen relations have also been identified. The main results show that learning strategy interpersonal help Search is related to all the factors of conditions to create, Favorable or unfavorable, except with Communication difficulty and rigidity of rules and regulations in the organization, that had no relation to any learning strategy. The greatest effect relationships are the factor of favorable conditions Freedom of action and challenging activities with the learning strategies Practical application and active reflection, Interpersonal help seeking and Seeking help from written material. The favorable condition for creativity Stimulus to new ideas from colleagues, bosses and organizational actions is related to all learning strategies.
\end{abstract}

Keywords: Learning strategies in workplace, informal learning creativity in organizations Creative conditions . 


\section{LISTA DE QUADROS}

Quadro 1 - Estratégias de Aprendizagem propostas por Warr e Allan (1998) .22

Quadro 2 - Estratégias de Aprendizagem de Warr e Allan (1998), Warr e Downing (2000) e Holman, Epitropaki e Fernie (2001). .23

Quadro 3 - Estudos Empíricos de Construção e Validação de Medidas de Estratégias de Aprendizagem . 26

Quadro 4 - Relação de Periódicos e Classificações 31

Quadro 5 - Objetivos com o estudo de Estratégias de Aprendizagem .34

Quadro 6 - Características de Contextos Utilizados no Estudo com Escalas de Estratégias de Aprendizagem 38

Quadro 7 - Escalas de Estratégias de Aprendizagem no Trabalho 40

Quadro 8 - Trabalhos Nacionais Levantados sobre Criatividade nas Organizações ..... 45

Quadro 9 - Principais Fatores Influenciadores da Criatividade .54

Quadro 10 - Perfil da População .73

Quadro 11 - Relações entre Condições para Criar e Estratégias de Aprendizagem. 116

\section{LISTA DE GRÁFICOS}

Gráfico 1 - Ano de Publicação dos trabalhos identificados .29

Gráfico 2 - Frequência da Amostra por Faixa de Idade (Em Anos) .81

Gráfico 3 - Frequência da Amostra por Faixa de Tempo de Empresa (Em Anos) 81

\section{LISTA DE FIGURAS}

Figura 1 - Inter-relação entre Autores por Publicações ....................................... 33

Figura 2 - Rede de Construção de Escalas de Estratégias de Aprendizagem.....................37

Figura 3 - Modelo Multinível de Criatividade Organizacional........................................50

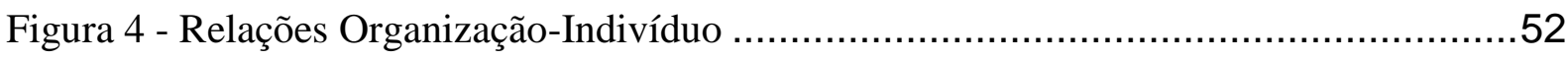

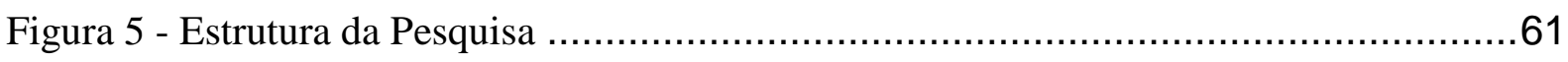

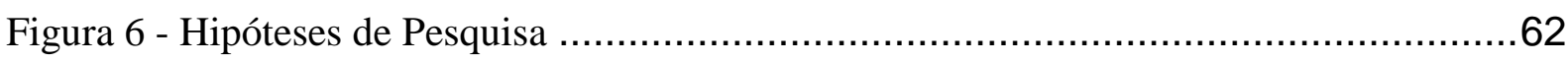

Figura 7 - Modelo de Estrutura Hierárquica de uma AABB ...................................72

Figura 8 - Hipóteses de Pesquisa na Nova Estrutura Fatorial.......................................105

Figura 9 - Hipóteses Iniciais e Novas Relações ....................................................115 


\section{LISTA DE TABELAS}

Tabela 1 - Fatores e Itens do Instrumento sobre Estratégias de Aprendizagem no Trabalho..75 Tabela 2 - Fatores e Itens do Instrumento Indicador de Condições para Criar no Ambiente de

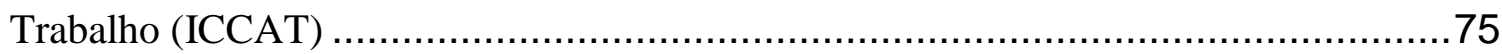

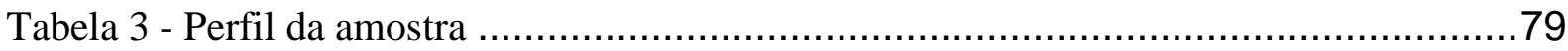

Tabela 4 - KMO e Teste de Bartlett da Matriz de Correlação da Escala de Condições Favoráveis à Criatividade .90

Tabela 5 - Estrutura Fatorial da Escala de Condições Favoráveis à Criatividade .90

Tabela 6 - Matriz de Correlação entre Fatores da Escala de Condições Favoráveis à

Criatividade .94

Tabela 7 - KMO e Teste de Bartlett da Matriz de Correlação da Escala de Condições Desfavoráveis à Criatividade .95

Tabela 8 - Estrutura Fatorial da Escala de Condições Desfavoráveis à Criatividade .96

Tabela 9 - Matriz de Correlação entre Fatores da Escala de Condições Desfavoráveis à Criatividade .98

Tabela 10 - KMO e Teste de Bartlett da Matriz de Correlação da Escala de Condições Desfavoráveis à Criatividade .98

Tabela 11 - Estrutura Fatorial da Escala de Estratégias de Aprendizagem 99

Tabela 12 - Matriz de Correlação entre Fatores da Escala de Estratégias de Aprendizagem 102 Tabela 13 - Média e Desvio Padrão dos fatores de Condições Favoráveis e Desfavoráveis à Criatividade no Ambiente de Trabalho 102

Tabela 14 - Média e Desvio Padrão dos fatores de Estratégias de Aprendizagem no Trabalho 104

Tabela 15 - Correlação entre os fatores de Condições Favoráveis à Criatividade e Estratégias de Aprendizagem. 107

Tabela 16 - Correlação entre os fatores de Condições Desfavoráveis à Criatividade e Estratégias de Aprendizagem. .112 


\section{SUMÁRIO}

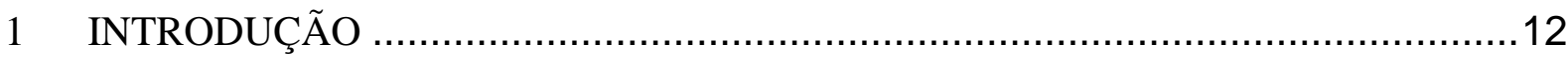

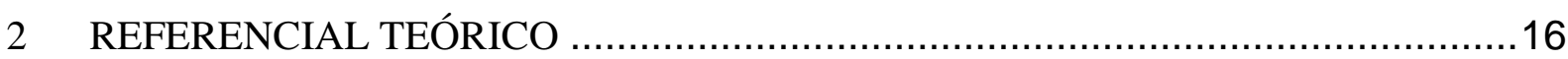

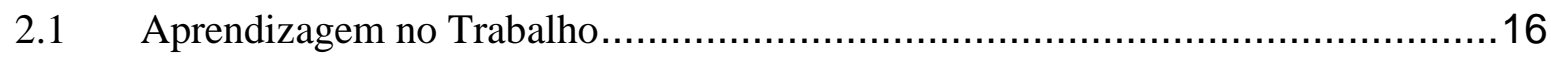

2.1.1 Estratégias de Aprendizagem no Trabalho ………………….................18

2.1.2 Medidas de Estratégias de Aprendizagem no Trabalho ...............................24

2.2 Criatividade e o Ambiente de Trabalho …..................................................... 42

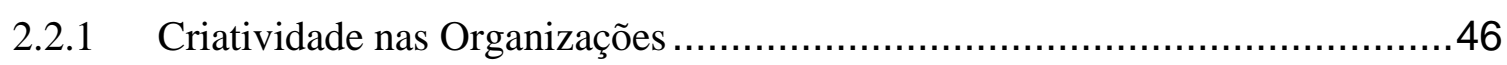

2.2.2 Condições para Criar no Ambiente de Trabalho ...........................................52

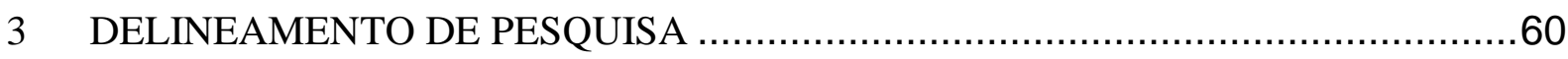

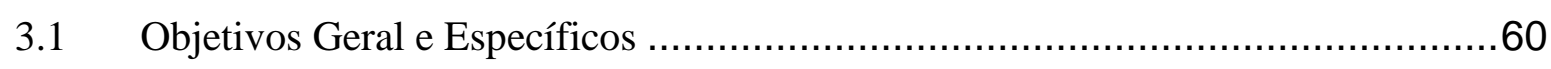

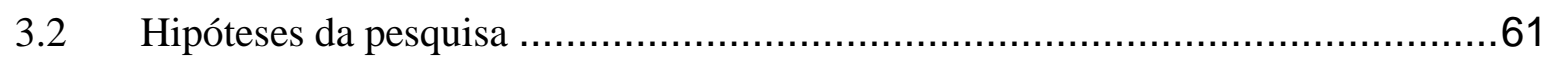

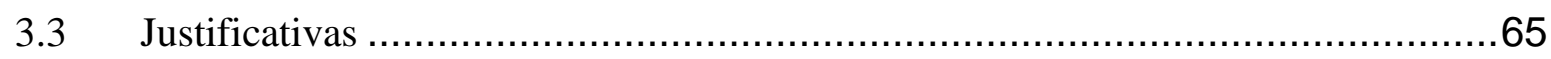

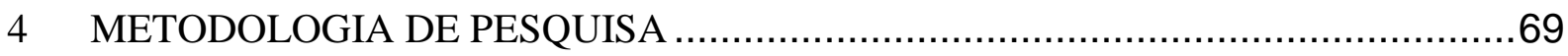

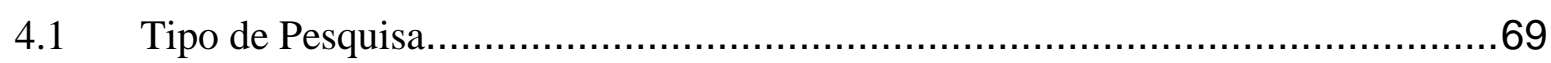

4.2 Caracterização da Organização ..............................................................70

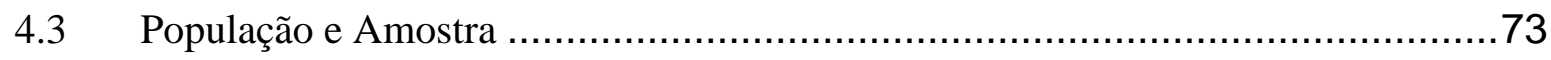

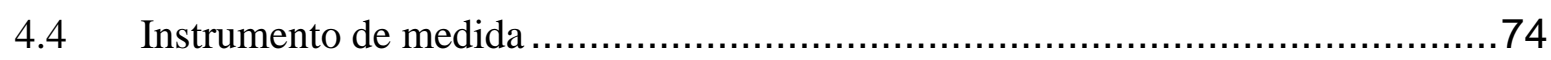

4.5 Procedimentos de coleta de dados .......................................................

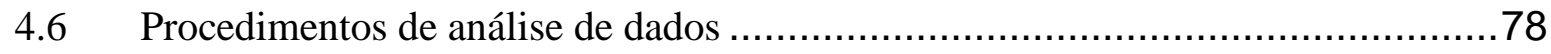

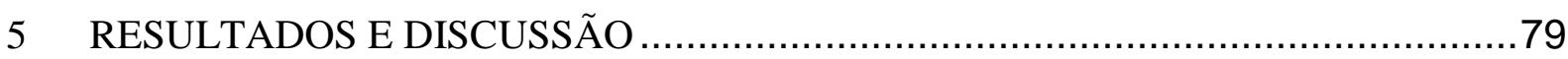

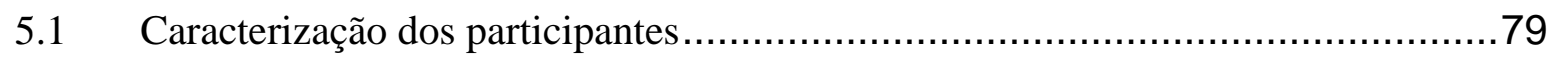

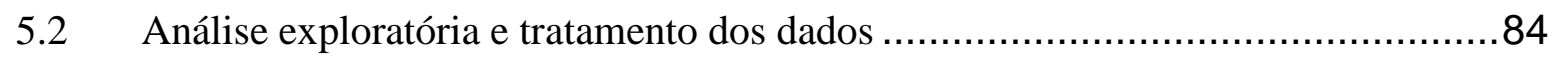

5.3 Evidências de validade dos instrumentos de medida ......................................86

5.3.1 Análise fatorial e consistência interna da escala de Condições Favoráveis à Criatividade .89

5.3.2 Análise fatorial e consistência interna da escala de Condições Desfavoráveis à Criatividade .95

5.3.3 Análise fatorial e consistência interna da escala de Estratégias de Aprendizagem 98

5.4 Condições para Criar e Estratégias de Aprendizagem percebidas 102 
5.5 Relação entre Condições para Criar e Estratégias de Aprendizagem ...................105

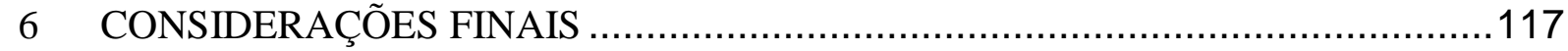

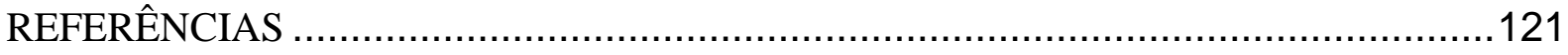

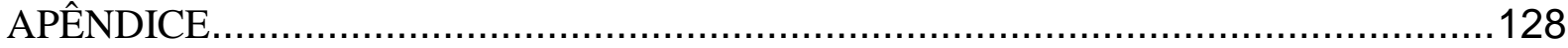




\section{INTRODUÇÃO}

Hoje, mais do que nunca, as organizações precisam de ações adequadas em resposta às condições que lhe são impostas pelo ambiente cada vez mais complexo e dinâmico. Inevitavelmente, é preciso recorrer às suas capacidades internas para superar as adversidades e alcançar seus objetivos. Nesse contexto, se destaca o papel dos indivíduos que, segundo Coelho Junior e Mourão (2011), pode proporcionar vantagens competitivas para as organizações, seja no estímulo contínuo à aprendizagem ou na busca pela inovação contínua, maximizando o desempenho, enriquecendo seu cargo e agregando valor a seu trabalho. Assim, estudos sobre atributos dos indivíduos que possam contribuir positivamente para os resultados organizacionais tem sido foco em estudos em Administração.

Estudos sobre a aprendizagem do indivíduo no contexto organizacional vêm sendo objeto de muitos trabalhos que buscam compreender fenômenos que impactam no desempenho e alcance de objetivos organizacionais. Coelho Junior e Borges Andrade (2008) destacam que ações de aprendizagem vêm sendo historicamente aplicadas no contexto das organizações com o objetivo último de maximizar seus resultados.

Dentre os múltiplos contextos onde ocorre a aprendizagem, Moraes e BorgesAndrade (2010a) afirmam que o ambiente de trabalho é provavelmente aquele em que se faz mais clara a demanda por mais e melhores resultados de aprendizagem entre todos os espaços da atividade humana. Tal importância passou inclusive a ser não exclusivamente de interesse das organizações como também de seus próprios colaboradores. Passou-se a fazer uso de procedimentos, práticas e ações de aprendizagem com vistas à garantia da empregabilidade dos indivíduos, bem como de sustentabilidade das organizações (COELHO JUNIOR; BORGES-ANDRADE, 2008). Zerbini, Carvalho e Abbad (2005) explicam que as empresas e organizações desenvolvem diversas estratégias educacionais para capacitar seus funcionários com o intuito de adequá-los às novas exigências do mercado. Os indivíduos, por sua vez, buscam alternativas de estudo para aperfeiçoarem seus conhecimentos.

Nesse sentido, pesquisas sobre a aprendizagem formal e informal são amplamente difundidos na área organizacional. Segundo Coelho Junior e Borges-Andrade (2008), ambos os tipos de aprendizagem são amplamente recomendados e devem ser utilizados de acordo com as principais demandas da organização, reforçando-se a necessidade de melhoria contínua do desempenho dos indivíduos. Entretanto, seguindo a nova cultura da aprendizagem que cresce no contexto organizacional, Beviláqua-Chaves (2007) explica que são necessárias 
ações voluntárias, individuais, que promovam o aumento ou a melhoria do conhecimento. $\mathrm{O}$ foco desloca-se para formas de aprendizagem menos estruturadas e iniciadas pelos próprios empregados, com ou sem suporte da organização, para dar conta da complexidade das demandas próprias da era do conhecimento (MORAES; BORGES-ANDRADE, 2010b).

Com isso, as estratégias de aprendizagem no trabalho emergem como um dos elementos decisivos à otimização dos processos de aprendizagem dos indivíduos em meios organizacionais (PANTOJA; BORGES-ANDRADE, 2009). Segundo Holman, Epitropaki e Fernie (2001), estratégias de aprendizagem no trabalho podem ser entendidas como práticas que as pessoas utilizam para auxiliar a aquisição de conhecimentos e habilidades em seu contexto profissional.

Pantoja (2004) argumenta que estudos focalizando estratégias de aprendizagem no trabalho são especialmente relevantes porque podem gerar conhecimentos, métodos e procedimentos que auxiliem tanto o indivíduo a melhor aprender, quanto à organização no delineamento de contexto de suporte e apoio ao desenvolvimento e manutenção de estratégias em contextos organizacionais complexos.

Segundo Holman, Epitropaki e Fernie (2001) mais estudos são necessários para entender a associação entre estratégias de aprendizagem e resultados, performance, ganhos de conhecimento, diferenças qualitativas na compreensão e inovação. Este último, segundo Alencar (1995) é, ao mesmo tempo, uma necessidade e um grande desafio. Organizações buscam na inovação uma saída para não se tornarem obsoletas e defasadas. Para tanto, surge a preocupação com outro fenômeno importante em estudos de Administração, a criatividade nas organizações. Sua importância, segundo Moraes e Lima (2009), se dá por trazer à tona aspectos que subsidiariamente favoreçam a ocorrência da inovação e, por conseguinte, auxiliem as organizações a lidar melhor com os desafios impostos pela instabilidade vigente.

Quando se fala de criatividade na organização, está se falando também do potencial criativo de seus participantes e da necessidade de aproveitar da melhor forma possível esse atributo. Segundo Bruno-Faria (1996), a criatividade ocupa um lugar de destaque, dado que para atender as demandas do mercado, as organizações precisam contar com funcionários que possam fazer uso constante de seu potencial criativo. Adicionalmente, de acordo com Tudda e Santos (2011), o fenômeno da criatividade tem mobilizado o interesse nas organizações em razão das mudanças acompanhadas pelo desenvolvimento e aplicação de novos conhecimentos e pela valorização de atributos humanos de maneira mais abrangente, que 
inclui a criatividade em adição às competências técnicas e comportamentais demandadas pelas organizações.

Contar com funcionários criativos que buscam aprimorar o desempenho de suas atividades e gerar resultados que levem a empresa a ser altamente competitiva é o objetivo de organizações que valorizam o potencial criativo dos seus funcionários. Dessa forma, Alencar (1998) aponta que dado esse papel decisivo da criatividade para o êxito das organizações, se faz necessário que os dirigentes estejam atentos às condições prevalecentes no seu ambiente de trabalho, no sentido de desfazer possíveis barreiras à criatividade, maximizando as oportunidades para sua expressão. Trata-se aqui, então, de gerir as condições para criar no ambiente de trabalho das organizações.

Analisando ambos os fenômenos, tanto as práticas de aprendizagem executadas pelos indivíduos da organização como a expressão da criatividade no contexto de trabalho, percebese uma convergência no sentido de capacidades dos indivíduos que podem contribuir para o alcance dos objetivos organizacionais e que, portanto, devem ter a atenção de gestores e estudiosos na área. Alencar (1995) explica que o que importa é promover condições para o desenvolvimento das potencialidades presentes em todo ser humano e despertar a consciência das organizações para as faculdades dos profissionais que atuam na organização.

Investigando a relação entre os dois fenômenos a partir dos estudos sobre a aprendizagem no trabalho, tem-se que a criatividade, dentro do conjunto de competências atribuídas aos indivíduos, está relacionada nos processos de aprendizagem empregados por estes para alcançar o desempenho desejado e esperado pela organização. Pantoja e BorgesAndrade (2009) explicam que se espera da aprendizagem no trabalho o desenvolvimento contínuo de novas competências, tais como a criatividade, proatividade, flexibilidade, comprometimento, capacidade de aprender a aprender, entre outras (PANTOJA; BORGESANDRADE, 2009, grifo nosso).

Preocupados com a compreensão de um suporte à aprendizagem informal no trabalho, Coelho Junior e Mourão (2011), citando os trabalhos de Andersen e Andersen (2007) e Pentland (1995), explicitam, de forma bem clara, que a aprendizagem contínua dos empregados e a posterior aplicação de novas habilidades necessitam de apoio organizacional à inovação, criatividade e experimentação. Nesse contexto, seria necessário identificar os fatores facilitadores de novos desempenhos no ambiente de trabalho (COELHO JUNIOR; MOURÃO, 2011). 
Já pelos estudos sobre criatividade e condições que influenciam sua expressão no contexto do trabalho, o fator aprendizagem se mostra relevante e relacionado como explica Pereira, Mussi e Knabben (1999), que reforçam a ideia de que elementos que compõem as condições para a organização que almeja ser criativa devem estar focados no empenho e na capacidade de aprendizagem das pessoas. Segundo os autores, pessoas que revelam potencial criativo tendem a ser mais abertas à aprendizagem e, portanto, mais interessadas e motivadas (PEREIRA; MUSSI; KNABBEN, 1999).

Ainda assim, não foram identificados estudos empíricos preocupados com a compreensão da relação entre as práticas de aprendizagem empregadas pelos indivíduos da organização e as condições favoráveis e desfavoráveis à expressão da criatividade no ambiente de trabalho. Segundo um dos trabalhos mais referenciados nos estudos sobre estratégias de aprendizagem no ambiente de trabalho, conduzidos por Holman, Epitropaki e Fernie (2001), entender as relações existentes entre estratégias de aprendizagem e a criatividade é um importante direcionamento para pesquisas futuras sobre o tema.

Diante disso, este trabalho tem como objetivo geral identificar as relações existentes entre condições para criar e o uso de estratégias de aprendizagem no ambiente de trabalho.

Para dar suporte a esse objetivo geral, o presente estudo encontra-se estruturado em sete capítulos, incluindo esta apresentação introdutória como primeiro capítulo. O segundo capítulo apresenta o referencial teórico dividido em duas partes. A primeira estuda a aprendizagem partindo dos entendimentos gerais sobre o tema no contexto do trabalho, até as medidas de estratégias de aprendizagem utilizadas para medir essa variável nesse tipo de contexto. Já na segunda parte do referencial, o tema criatividade é abordado partindo da análise conceitual até sua relação com o ambiente organizacional. No terceiro capítulo é feito o delineamento da pesquisa onde são detalhados os objetivos, hipóteses da pesquisa e as justificativas de realização do estudo. No quarto capítulo é apresentada a metodologia proposta para o estudo com tipificação da pesquisa, caracterização da população e amostra, além dos procedimentos adotados para coleta e análise dos dados. Em seguida, no capítulo cinco são apresentados os resultados e discussões geradas a partir da pesquisa realizada. Por fim, são tecidas as considerações finais no sexto capítulo. 


\section{REFERENCIAL TEÓRICO}

Este Capítulo destina-se à revisão da literatura sobre estratégias de aprendizagem e as condições para expressão da criatividade no contexto das organizações. O capítulo foi dividido em duas seções, uma para cada assunto. Sobre aprendizagem, a seção está dividida em: Estratégias de Aprendizagem no Trabalho, onde serão apresentadas algumas linhas conceituais sobre o objeto dentro do contexto de trabalho; e Medidas de Estratégias de Aprendizagem no Trabalho, em que é apresentada uma análise sobre medidas desenvolvidas e utilizadas em estudos na área. Sobre criatividade, a seção está dividida em: Criatividade nas Organizações, onde são discutidos conceitos sobre a criatividade no trabalho e sua relação com a inovação; e Condições para Criar no Ambiente de Trabalho, onde é discutido o papel do ambiente na expressão da criatividade do indivíduo em seu contexto profissional.

\subsection{Aprendizagem no Trabalho}

Segundo Brandão e Borges-Andrade (2011), a aprendizagem implica mudar ou desenvolver conhecimentos, habilidades e atitudes podendo, por conseguinte, promover o desenvolvimento de competências profissionais. Para Freitas e Brandão (2006), a aquisição de conhecimentos, habilidades e atitudes, entendidas como competências do indivíduo, é decorrente do processo de aprendizagem.

A aprendizagem representaria o processo pelo qual se adquire a competência, enquanto o desempenho da pessoa no trabalho refletiria uma expressão de suas competências (FREITAS; BRANDÃO, 2006). Coelho Junior e Borges-Andrade (2008) explicam que o empreendimento do indivíduo em ações de aprendizagem no âmbito das organizações é impulsionado, principalmente, pela necessidade do mesmo em manifestar conhecimentos e habilidades requisitados pelo desempenho em uma dada atividade, atrelando-se ao aperfeiçoamento de seu próprio repertório atual de competências.

As pesquisas referentes a aspectos relacionados à aprendizagem, geralmente são realizadas em contextos escolares e universitários (ZERBINI; CARVALHO; ABBAD, 2005). Entretanto, o fenômeno da aprendizagem pode ocorrer em múltiplos contextos, principalmente em se tratando da aprendizagem de adultos que, segundo Warr e Downing 
(2000), aprendem em contextos não acadêmicos que permitam interações com outras pessoas e proporcionam a oportunidade de buscas próprias por informações e atividades práticas.

No contexto do trabalho, estudos sobre aprendizagem vêm sendo associados usualmente a processos formais de treinamento, desenvolvimento e educação (TD\&E) (PANTOJA; BORGES-ANDRADE, 2009). Esse tipo de aprendizagem, induzido e proposital, ocorre por meio de programas e ações sistematizadas, planejados previamente e de forma que há métodos e técnicas previamente criadas para o alcance de objetivos desejados de capacitação pela organização (COELHO JUNIOR; BORGES-ANDRADE, 2008).

Entretanto, em contextos de trabalho, nem todas as situações que geram aprendizagem constituem ações formais de TD\&E. Moraes e Borges-Andrade (2010b) destacam, por exemplo, a relevância do estudo das variáveis envolvidas na aprendizagem que ocorre entrelaçada ao exercício do trabalho. Segundo Coelho Junior e Borges-Andrade (2008), nesses casos a aprendizagem ocorre de maneira mais natural ou não planejada no trabalho e acontece provavelmente em virtude de alguma demanda emergencial e espontânea por parte do indivíduo. As pessoas aprendem o tempo todo no trabalho e nessa perspectiva se insere a noção de aprendizagem informal (NEIVA; PANTOJA, 2011; FERNANDEZ, 2012).

Pozo (2002) e Sonnentag et al. (2004), citados por Brandão e Borges-Andrade (2011), classificam a aprendizagem informal nas organizações como explícita, decorrente de uma atividade deliberada e consciente do indivíduo e não estruturada, constituída a partir da iniciativa do próprio empregado, com ou sem o apoio da organização. Outras características citadas por Fernandez (2012) apontam ainda a inexistência de um vínculo prévio relativo ao alcance de resultados, além da incapacidade de controle do conteúdo a ser aprendido por parte da organização. Coelho Junior e Borges-Andrade (2008) argumentam ainda que, tanto a aprendizagem formal quanto a informal, podem ser diretas ou indiretas: direta quando a aprendizagem está diretamente ligada às tarefas e rotinas organizacionais do indivíduo, ou indiretas, quando não é necessariamente aplicável ao trabalho, mas não deixa de ser aprendida.

Pantoja e Borges-Andrade (2009) destacam quatro aspectos razoavelmente consolidados na literatura acerca dos processos de aprendizagem informal no trabalho:

- São ações específicas, pontuais e condicionadas aos interesses do indivíduo;

- Não constituem ações sistematicamente programadas, tampouco há controle por parte da organização acerca do que será aprendido; 
- Sua ocorrência pode estar ou não articulada aos objetivos organizacionais e do trabalho; e

- Não estão direcionadas ao alcance de resultados específicos previamente delineados pela organização.

De acordo com Coelho Junior e Borges-Andrade (2008), a aprendizagem informal tende a ser mais intrínseca ao indivíduo, quando há manifestação de interesse em aprofundamento em determinado tema ou assunto, e o decorrente empreendimento de estratégias voltadas a tal, o que aumenta a probabilidade de aquisição, retenção e aplicação. Em se tratando desse tipo de aprendizagem intrínseca informal empenhada pelos indivíduos, estudos vem sendo feitos sobre as estratégias de aprendizagem no âmbito do trabalho.

Segundo Beviláqua-Chaves (2007), investigações sobre estratégias de aprendizagem vêm sendo realizadas principalmente em contextos formais de ensino, tais como escolas e universidades. Os estudos em contextos de trabalho e de aprendizagem informal têm se tornado mais comuns devido a avanços tecnológicos e às novas demandas profissionais exigidas pelo mercado. Destacando as diferenças que levam estudantes e profissionais à utilizar estratégias de aprendizagem, Warr e Allan (1998 apud PANTOJA, 2004) argumentam que atividades de diferentes naturezas e complexidades exigem a adoção de diferentes estratégias de aprendizagem e indivíduos em ambiente de trabalho provavelmente apresentam motivações e ansiedades diversas daquelas manifestadas por estudantes em ambientes estritamente acadêmicos.

A seção a seguir tratará dos estudos sobre estratégias de aprendizagem no contexto do trabalho identificados na pesquisa bibliográfica descrita em detalhes na seção 2.1.2.

\subsubsection{Estratégias de Aprendizagem no Trabalho}

Segundo Beviláqua-Chaves (2007), o termo estratégias de aprendizagem foi originalmente criado provavelmente na área educacional em estudos preocupados em identificar a melhor forma de ensinar os alunos a aprender o conteúdo a ser transmitido. O uso da expressão se popularizou nos estudos sobre a psicologia cognitiva e em pressupostos do modelo de processamento de informações (BEVILÁQUA-CHAVES, 2007). Analisado no nível do indivíduo e suas capacidades cognitivas, as estratégias de aprendizagem se relacionam aos processos de controle executivo e expectativas que são as capacidades 
aprendidas pelo indivíduo ao longo do tempo em sua experiência. Por meio destes, o indivíduo pode regular as diferentes etapas de sua aprendizagem (FERNANDEZ, 2012). O foco de análise recai sobre as capacidades ou estratégias utilizadas pelos indivíduos nas etapas dos processos informais de aprendizagem no contexto do trabalho como codificar, armazenar, lembrar e transferir informações (PANTOJA; BORGES-ANDRADE, 2009).

Segundo Carvalho-Silva (2008), é esperado durante o processo de escolarização que o indivíduo adquira estratégias que facilitem seu processo de aprendizagem. No entanto, quando entram no mercado de trabalho e são induzidos a adquirir novas competências, acredita-se que surjam condições de aprender estratégias diferentes daquelas adquiridas no contexto educacional.

Um dos conceitos mais utilizados pelos autores da área sobre estratégia de aprendizagem foi atribuído por Warr e Allan (1998) como sendo um conjunto de capacidades cognitivas, habilidades comportamentais e de autocontrole emocional utilizado pelo aprendiz para controlar os próprios processos psicológicos de aprendizagem, como atenção, aquisição, memorização e transferência.

Outros autores destacam como elemento-chave das estratégias de aprendizagem o suporte à aprendizagem. Carvalho-Silva (2008) conceitua estratégias de aprendizagem como o conjunto de atividades de processamento de informações, usadas pelos aprendizes com a finalidade de facilitar a aquisição, codificação, armazenagem e subsequente recuperação da informação. Ampliando o conceito, Moraes e Borges-Andrade (2010b) acrescentam que estratégias de aprendizagem são esforços empreendidos pelo indivíduo para realizar a aprendizagem.

As estratégias de aprendizagem partem de uma iniciativa consciente do indivíduo e podem ser aprendidas. Em uma análise sobre o termo "Estratégia" e sua associação com "aprendizagem", Beviláqua-Chaves (2007) sugere que essas ações são voluntárias, organizadas individualmente ou por meio de treinamento, que direcionam o indivíduo ao alcance de objetivos que podem modificar o comportamento de forma permanente, agregando conhecimento à experiência individual.

Pantoja e Borges-Andrade (2009, p.47) caracterizam as estratégias de aprendizagem de acordo com três aspectos principais:

(a) Compreendem atividades de processamento de informações facilitadoras da aquisição, retenção, recuperação e uso posterior de novas informações; (b) englobam comportamentos adotados pelo indivíduo direcionados à aprendizagem e utilização de novos conhecimentos e habilidades; e (c) podem contribuir tanto para a 
aquisição, retenção e recuperação das novas informações, como também para sua aplicação em diferentes contextos.

Em se tratando das estratégias de aprendizagem no contexto de trabalho, Zerbini e Abbad (2008) argumentam que não existe muita discordância entre os pesquisadores quanto à definição de estratégias de aprendizagem. Para Holman, Epitropaki e Fernie (2001) elas podem ser entendidas como práticas que as pessoas utilizam para auxiliar a aquisição de conhecimentos e habilidades em seu contexto profissional. De forma semelhante, Sonnentag, Niessen e Ohly (2004) e Pantoja e Borges-Andrade (2009) conceituam como práticas informais que os indivíduos utilizam para auxiliar a aquisição de conhecimentos e habilidades em seu próprio local de trabalho. Para este trabalho será adotado o conceito de estratégia de aprendizagem no trabalho definido por Holman, Epitropaki e Fernie (2001).

Com relação ao conceito de estratégia de aprendizagem, Pantoja (2004) e Zerbini e Abbad (2008) advertem sobre a existência de outros conceitos correlatos ao de estratégias que podem gerar dúvidas ou mesmo serem utilizadas equivocadamente como sinônimos como hábitos de estudo e estilos de aprendizagem. Baseado na descrição de Warr e Allan (1998), as autoras procuram diferenciar hábitos de estudo, estilos de aprendizagem e estratégias de aprendizagem (ZERBINI; ABBAD, 2008; PANTOJA, 2004), conforme a seguir.

- Hábitos de estudo envolvem os procedimentos utilizados pelo aluno para integrar os melhores aspectos contextuais e maneiras de estudo com o objetivo de melhorar a aquisição e retenção da aprendizagem. São ferramentas específicas, como por exemplo: habilidades de leitura, gerenciamento do tempo, uso efetivo de biblioteca, procedimentos de revisão, uso de anotações, entre outros. Dificilmente se referem à maneira ou forma como o aluno diretamente adquire novas informações e habilidades, que são o foco das estratégias de aprendizagem. São procedimentos relativamente focados, seja quanto ao contexto ou atividades de aprendizagem do indivíduo.

- Estratégias de aprendizagem são procedimentos utilizados pelos indivíduos durante as atividades de aprendizagem para serem bem-sucedidos. Apresentam certa maleabilidade e abertura a mudanças por meio de treinamento. São mais focalizadas e específicas a uma determinada situação de aprendizagem. São procedimentos relativamente focados nas atividades de aprendizagem do indivíduo. 
- Estilos de aprendizagem se referem a aspectos gerais, de natureza mais estável do que estratégias. São as preferências do estudante relativas a aspectos contextuais e a maneiras de estudo. Compreendem a preferência dos indivíduos por determinadas estratégias de aprendizagem e por aspectos do contexto em que esta ocorre. Exemplos: nível de ruído e temperatura do ambiente ao estudar, horário de preferência de estudo, forma de estudo (individual, em grupo), maneira de adquirir e processar as informações (pedir ajuda a colegas, consultar o material). Em suma, são preferências quanto ao contexto e às atividades de aprendizagem relativamente gerais do indivíduo.

Procurando categorizar e medir diferentes estratégias de aprendizagem utilizadas pelas pessoas, Brandão e Borges-Andrade (2011) indicam que alguns autores têm sugerido classificações específicas. Dentre eles, o ensaio teórico de Warr e Allan (1998) é reconhecido como precursor na categorização dessas estratégias de aprendizagem no campo organizacional fazendo uma transição a partir do campo educacional. Zerbini, Carvalho e Abbad (2008), destacam a relevância do trabalho de Warr e Allan (1998) por ter fundamentado teoricamente e orientado a realização de pesquisas nacionais e internacionais. Pantoja (2004) argumenta que a classificação desenvolvida pelos autores integra conceitos das áreas da Educação, da Psicologia Cognitiva e Psicologia Organizacional. O Quadro 1 apresenta as estratégias propostas por Warr e Allan (1998) enquadradas em perspectivas cognitivas, comportamentais e de auto regulação identificadas no processo de aprendizagem. 
Quadro 1 - Estratégias de Aprendizagem propostas por Warr e Allan (1998)

\begin{tabular}{|c|c|c|}
\hline Categorias & Estratégias & Descrição \\
\hline \multirow[t]{3}{*}{$\begin{array}{l}\text { Estratégias } \\
\text { Cognitivas }\end{array}$} & Repetição & $\begin{array}{l}\text { Procedimentos de repetir para si o conteúdo que está sendo } \\
\text { aprendido. }\end{array}$ \\
\hline & Organização & $\begin{array}{l}\text { Procedimentos de identificação de questões chaves, e criação de } \\
\text { estruturas mentais que agrupem e inter-relacionem elementos do } \\
\text { que está sendo aprendido. }\end{array}$ \\
\hline & Elaboração & $\begin{array}{l}\text { Procedimentos de examinar implicações, e fazer conexões } \\
\text { mentais entre o conteúdo que está sendo aprendido e o } \\
\text { conhecimento existente. }\end{array}$ \\
\hline \multirow[t]{3}{*}{$\begin{array}{l}\text { Estratégias } \\
\text { Comportamentais }\end{array}$} & $\begin{array}{l}\text { Busca de ajuda } \\
\text { interpessoal }\end{array}$ & Procedimentos de obter ajuda de outras pessoas \\
\hline & $\begin{array}{l}\text { Busca de ajuda em } \\
\text { material escrito }\end{array}$ & $\begin{array}{l}\text { Procedimentos de obter informações de documentos, manuais, } \\
\text { programas de computador e outros recursos não sociais. }\end{array}$ \\
\hline & Aplicação Prática & $\begin{array}{l}\text { Procedimentos para aumentar o conhecimento testando-o em } \\
\text { prática. }\end{array}$ \\
\hline \multirow[t]{3}{*}{$\begin{array}{l}\text { Estratégias de } \\
\text { Auto Regulação }\end{array}$} & Controle Emocional & $\begin{array}{l}\text { Procedimentos de afastar a ansiedade e prevenir falhas de } \\
\text { concentração causadas por pensamentos ligados a ansiedade. }\end{array}$ \\
\hline & $\begin{array}{l}\text { Controle } \\
\text { Motivacional }\end{array}$ & $\begin{array}{l}\text { Procedimentos de manter-se motivado e atento apesar de um } \\
\text { interesse limitado na tarefa. }\end{array}$ \\
\hline & $\begin{array}{l}\text { Monitoramento da } \\
\text { compreensão }\end{array}$ & $\begin{array}{l}\text { Procedimentos de avaliar o grau em que os objetivos de } \\
\text { aprendizagem são alcançados e modificar o comportamento de } \\
\text { aprendizagem se necessário. }\end{array}$ \\
\hline
\end{tabular}

Fonte: Elaborado pelo autor com base em Warr e Allan (1998) e Warr e Downing (2000)

Com o objetivo de aplicar empiricamente a categorização proposta por Warr e Allan (1998), Warr e Downing (2000) desenvolveram um instrumento composto por 45 itens que descrevem as nove estratégias cognitivas, comportamentais e de auto regulação sugeridas no ensaio teórico anterior. A pesquisa foi aplicada junto a 190 estudantes universitários de cursos de artes e ciências e 288 participantes de um curso preparatório na área de mecânica de automóveis. Após analisar os resultados, a medida apresentou uma estrutura composta de oito fatores. As estratégias organização e elaboração formaram um único fator denominado reflexão ativa. Os demais fatores se mantiveram como a categorização proposta por Warr e Allan (1998). As estratégias de auto regulação apresentaram associação negativa à obtenção de aprendizagem, ou seja, a utilização dessas estratégias não resultaria, necessariamente, em uma melhoria da aprendizagem (BRANDÃO, 2009; WARR; DOWNING, 2000).

O instrumento desenvolvido por Warr e Downing (2000) constitui um dos primeiros passos para o desenvolvimento de medidas sobre Estratégias de Aprendizagem voltadas para o campo organizacional. Segundo os autores, deveria ser possível utilizá-lo em uma variedade de configurações para além das escolas e faculdades em que as estratégias de aprendizagem 
têm sido tipicamente estudadas (WARR; DOWNING, 2000). Nesse sentido, Holman, Epitropaki e Fernie (2001) realizaram um estudo envolvendo 628 técnicos da um call center de um banco britânico. O objetivo deste estudo foi analisar as estratégias de aprendizagem em um ambiente de trabalho não educacional. A escala desenvolvida considerou as estratégias cognitivas e comportamentais propostas por Warr e Downing (2000). Em seus resultados, novamente as categorias organização e elaboração sofreram alterações e seus itens combinados deram origem a dois outros fatores distintos sobre a reflexão do indivíduo. A reflexão intrínseca se concentra sobre a relação que o aprendiz faz entre o que é aprendido e as partes componentes do próprio trabalho e a reflexão extrínseca se concentra sobre a relação feita entre os diferentes aspectos da organização e o trabalho do indivíduo (HOLMAN; EPITROPAKI; FERNIE, 2001).

No Quadro 2 são apresentados os resultados encontrados na estrutura fatorial e de categorização das estratégias de aprendizagem dos estudos de Warr e Allan (1998), Warr e Downing (2000) e Holman, Epitropaki e Fernie (2001).

Quadro 2 - Estratégias de Aprendizagem de Warr e Allan (1998), Warr e Downing (2000) e Holman, Epitropaki e Fernie (2001)

\begin{tabular}{|c|c|c|c|}
\hline Categorias & $\begin{array}{c}\text { Warr e Allan (1998) } \\
\text { (Teórico) }\end{array}$ & $\begin{array}{c}\text { Warr e Downing (2000) } \\
\text { (Empírico) }\end{array}$ & $\begin{array}{c}\text { Holman, Epitropaki e } \\
\text { Fernie (2001) } \\
\text { (Empírico) }\end{array}$ \\
\hline \multirow{3}{*}{$\begin{array}{l}\text { Estratégias } \\
\text { Cognitivas }\end{array}$} & 1. Repetição & 1. Repetição & 1. Reprodução \\
\hline & 2. Organização & \multirow[t]{2}{*}{ 2. Reflexão Ativa } & 2. Reflexão Intrínseca \\
\hline & 3. Elaboração & & 3. Reflexão Extrínseca \\
\hline \multirow[t]{3}{*}{$\begin{array}{l}\text { Estratégias } \\
\text { Comportamentais }\end{array}$} & $\begin{array}{l}\text { 4. Busca de ajuda } \\
\text { interpessoal }\end{array}$ & $\begin{array}{l}\text { 3. Busca de ajuda } \\
\text { interpessoal }\end{array}$ & $\begin{array}{l}\text { 4. Busca de ajuda } \\
\text { interpessoal }\end{array}$ \\
\hline & $\begin{array}{l}\text { 5. Busca de ajuda em } \\
\text { material escrito }\end{array}$ & $\begin{array}{l}\text { 4. Busca de ajuda em } \\
\text { material escrito }\end{array}$ & $\begin{array}{l}\text { 5. Busca de ajuda em } \\
\text { material escrito }\end{array}$ \\
\hline & 6. Aplicação Prática & 5. Aplicação Prática & 6. Aplicação Prática \\
\hline \multirow{3}{*}{$\begin{array}{l}\text { Estratégias de } \\
\text { Auto Regulação }\end{array}$} & 7. Controle Emocional & 6. Controle Emocional & \\
\hline & 8. Controle Motivacional & 7. Controle Motivacional & \\
\hline & $\begin{array}{l}\text { 9. Monitoramento da } \\
\text { compreensão }\end{array}$ & $\begin{array}{l}\text { 8. Monitoramento da } \\
\text { compreensão }\end{array}$ & \\
\hline
\end{tabular}

Fonte: Elaborado pelo Autor

A partir desses trabalhos de Warr e Allan (1998), Warr e Downing (2000) e Holman, Epitropaki e Fernie (2001), um crescente interesse nos estudos sobre estratégias de 
aprendizagem no trabalho pode ser observado nas produções nacionais. Sob influencia desses trabalhos, outros autores passaram a construir e validar escalas com a finalidade de identificar empiricamente as estratégias de aprendizagem em diferentes contextos de trabalho e correlacioná-las com outros constructos. A seção a seguir se dedica a apresentação e análise dos principais trabalhos produzidos. Antes porem é feito um breve relato dos achados internacionais sobre o tema.

\subsubsection{Medidas de Estratégias de Aprendizagem no Trabalho}

$\mathrm{Na}$ busca por trabalhos internacionais dedicados ao tema de estratégias de aprendizagem nas áreas de administração e psicologia organizacional, foram identificados poucos relatos sobre o tema nos mesmos termos utilizados nesta pesquisa (learning strategies) e mais escasso ainda foram os trabalhos que envolvessem instrumentos de medida.

Revisando a produção internacional sobre práticas metodológicas em pesquisas sobre aprendizagem no trabalho (on-the-job learning), Berings, Doorrnbos e Simons (2006) levantam uma relação de instrumentos, entre questionários e roteiros de entrevista, desenvolvidos para mediar aspectos diversos da aprendizagem no trabalho como aprendizagem explícita e planejado, aprendizagem emergente, autoaprendizagem, aprendizagem experiencial, estratégias de aprendizagem, aprendizado em equipe, aprendizagem inovadora, dentre outras. Segundo os autores, os estudos sobre os diferentes tipos de processos de aprendizagem no trabalho possuem diferentes perspectivas na operacionalização de seus conceitos com foco na aprendizagem deliberada e/ou espontânea (BERINGS; DOORNBOS; SIMONS, 2006).

Como principal resultado da pesquisa, os autores apontam que

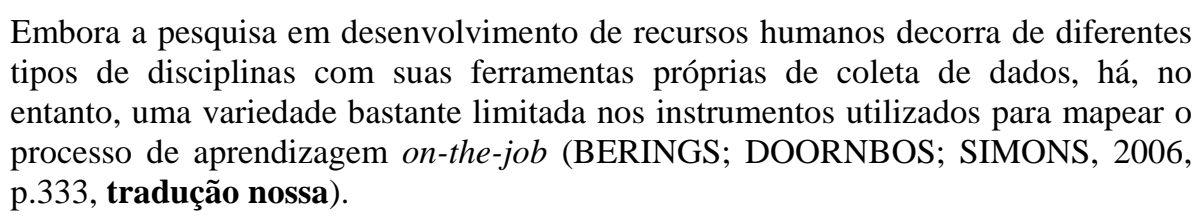

Com base nessa revisão, observou-se que os instrumentos utilizados mensuram diferentes tipos de aprendizagem que podem ou não representar as estratégias de aprendizagem tratadas neste trabalho. Uma investigação futura mais aprofundada sobre esses 
tipos de aprendizagem poderia trazer esclarecimentos importantes sobre o direcionamento de estudos no tema.

Investigando os trabalhos realizados pelos autores seminais da área, Peter Warr e David Holman, não foram identificadas pesquisas que dessem continuidade aos estudos sobre os instrumentos propostos. Apenas no trabalho de Holman et al. (2012), o autor resgata a escala desenvolvida em 2001 para realizar um estudo que procurou analisar como as estratégias de aprendizagem podem mediar a relação entre o design do trabalho e a capacidade de inovação do empregado.

Procurando identificar citações ou referências sobre trabalhos internacionais que tratam de estratégias de aprendizagem no ambiente de trabalho, foram analisados os referenciais de todos os trabalhos encontrados e detalhados a seguir. Em nenhum dos casos foram encontradas referências internacionais que tratassem do tema. Excluindo-se os trabalhos seminais, a produção nacional sobre o tema se mostra nutrida pelo próprio conhecimento gerado no país.

Dada essa limitação na produção científica internacional sobre o tema, esta pesquisa se dedicou a investigação da produção nacional sobre estratégias de aprendizagem.

Estudos teóricos e empíricos preocupados com a construção e/ou validação de medidas de estratégias de aprendizagem no trabalho vêm sendo analisados de forma agregada por diferentes autores na área. Esquematizado inicialmente por Pantoja (2004) entre os anos de 1998 e 2004 e ampliado por Morais e Borges-Andrade (2010) entre 2004 e 2010 e em seguida por Fernandez (2012) de 2010 a 2011, o Quadro 3 apresenta uma síntese dos resultados de estudos voltados à utilização de escalas de estratégias de aprendizagem no trabalho. Esse quadro resumo, revisado neste trabalho, considerou os levantamentos já realizados de 1998 a 2011 e foi atualizado até 2014. A metodologia de pesquisa adotada, bem como as devidas descrições e justificativas são detalhadas em seguida. 
Quadro 3 - Estudos Empíricos de Construção e Validação de Medidas de Estratégias de Aprendizagem

\begin{tabular}{|c|c|c|}
\hline Autor & Amostra & Resultados \\
\hline $\begin{array}{l}\text { Warr e } \\
\text { Downing } \\
(2000)\end{array}$ & $\begin{array}{l}288 \text { participantes de curso } \\
\text { preparatório na área de } \\
\text { mecânica de automóveis e } \\
190 \text { Estudantes } \\
\text { universitários de cursos de } \\
\text { Artes e Ciências. }\end{array}$ & $\begin{array}{l}\text { Análise fatorial exploratória: } \\
\text { Estrutura empírica composta de oito fatores: Repetição, } \\
\text { Reflexão Ativa, Busca de Ajuda Interpessoal, Busca de } \\
\text { Ajuda em Material Escrito, Controle Emocional, Controle da } \\
\text { Motivação e Monitoramento da Compreensão. Todos os } \\
\text { fatores apresentaram índices de confiabilidade razoáveis e } \\
\text { bons que variaram de } 0,73 \text { a } 0,90 \text {. }\end{array}$ \\
\hline $\begin{array}{l}\text { Holman, } \\
\text { Epitropaki e } \\
\text { Fernie } \\
(2001)\end{array}$ & $\begin{array}{l}\text { Amostra Total: } 628 \text { técnicos } \\
\text { de call center. Realizada } \\
\text { validação cruzada } \\
\text { considerando, para a análise } \\
\text { exploratória, uma amostra de } \\
399 \text { e, depois, para a análise } \\
\text { confirmatória, uma amostra } \\
\text { de } 319 \text { profissionais. }\end{array}$ & $\begin{array}{l}\text { Análise fatorial exploratória: } \\
\text { Estrutura empírica composta de seis fatores: Reprodução, } \\
\text { Reflexão Intrínseca, Reflexão Extrínseca, Busca de Ajuda } \\
\text { Interpessoal, Busca de Ajuda em Material Escrito e } \\
\text { Aplicação Prática. Os fatores apresentaram índices de } \\
\text { confiabilidade razoáveis e bons, variando de } 0,72 \text { a } 0,82 \text {. } \\
\text { Análise fatorial confirmatória: } \\
\text { Os seis fatores de primeira ordem foram explicados por dois } \\
\text { constructos latentes denominados estratégias cognitivas e } \\
\text { comportamentais. -Qui-quadrado }(182, \mathrm{n}=319)=365,73 \text {, } \\
\text { NNFI }=0,94, \mathrm{CFI}=0,95, \mathrm{RMSEA}=0,06 \text {. }\end{array}$ \\
\hline $\begin{array}{l}\text { Pantoja, } \\
\text { Borges- } \\
\text { Andrade e } \\
\text { Lopes-Ribeiro } \\
\text { (2003) }\end{array}$ & $\begin{array}{l}380 \text { profissionais de } \\
\text { organizações que atuavam } \\
\text { em diferentes segmentos: } \\
\text { telecomunicações, hotelaria, } \\
\text { energia elétrica, mobiliário e } \\
\text { financeiro. }\end{array}$ & $\begin{array}{l}\text { Análise fatorial exploratória: } \\
\text { Estrutura empírica composta de seis fatores: Reprodução, } \\
\text { Reflexão Intrínseca, Reflexão Extrínseca, Busca de Ajuda } \\
\text { Interpessoal, Busca de Ajuda em Material Escrito e } \\
\text { Aplicação Prática. Todos os fatores apresentaram índices de } \\
\text { confiabilidade razoáveis e bons que variaram de } 0,65 \text { a } 0,86 \text {. }\end{array}$ \\
\hline $\begin{array}{l}\text { Zerbini } \\
\text { (2003) }\end{array}$ & $\begin{array}{l}1860 \text { gestores de pequenas e } \\
\text { médias empresas. }\end{array}$ & $\begin{array}{l}\text { Análise fatorial exploratória: } \\
\text { Estrutura fatorial composta de } 3 \text { fatores: Busca de Ajuda } \\
\text { Interpessoal; Elaboração e Aplicação prática; e Reprodução, } \\
\text { Organização e Busca de Ajuda em Material Escrito. Os } \\
\text { índices de confiabilidade variaram de } 0,75 \text { a } 0,85 \text {. }\end{array}$ \\
\hline $\begin{array}{l}\text { Pantoja } \\
(2004)\end{array}$ & $\begin{array}{l}906 \text { profissionais de } \\
\text { diferentes áreas e níveis de } \\
\text { atuação. }\end{array}$ & $\begin{array}{l}\text { Análise fatorial exploratória: } \\
\text { Estrutura fatorial composta de } 5 \text { fatores: Busca de Ajuda em } \\
\text { Material Escrito, Reprodução, Busca de Ajuda Interpessoal, } \\
\text { Reflexão Extrínseca, Aplicação Prática e Reflexão } \\
\text { Intrínseca. Índices de confiabilidade variaram entre } 0,80 \text { e } \\
0,87 \text {. }\end{array}$ \\
\hline $\begin{array}{l}\text { Lopes-Ribeiro } \\
\text { (2005) }\end{array}$ & $\begin{array}{l}\text { Total de } 1007 \text { alunos de pós- } \\
\text { graduação, de diferentes } \\
\text { áreas de atuação, formação } \\
\text { acadêmica e cargos, } \\
\text { utilizando duas sub-amostras } \\
\text { em validação cruzada. }\end{array}$ & $\begin{array}{l}\text { Análise fatorial confirmatória: } \\
\text { Estrutura fatorial composta de } 1 \text { fator geral primário } \\
\text { contendo e } 5 \text { fatores de segunda ordem: Busca de Ajuda em } \\
\text { Material Escrito, Busca de Ajuda Interpessoal, Reflexão } \\
\text { Extrínseca, Aplicação Prática e Reflexão Intrínseca. Índices } \\
\text { de confiabilidade variaram entre } 0,76 \text { e } 0,87 \text {. }\end{array}$ \\
\hline $\begin{array}{l}\text { Zerbini, } \\
\text { Carvalho e } \\
\text { Abbad } \\
(2005)\end{array}$ & $\begin{array}{l}1860 \text { participantes de curso } \\
\text { técnico a distância. }\end{array}$ & $\begin{array}{l}\text { Análise fatorial exploratória: } \\
\text { Estrutura fatorial composta de } 3 \text { fatores: Busca de Ajuda } \\
\text { Interpessoal; Elaboração e Aplicação Prática do Conteúdo; e } \\
\text { Repetição, Organização e Ajuda do Material. Índices de } \\
\text { confiabilidade variaram entre } 0,75 \text { e } 0,85 \text {. }\end{array}$ \\
\hline $\begin{array}{l}\text { Zerbini, e } \\
\text { Abbad } \\
\text { (2005) }\end{array}$ & $\begin{array}{l}1860 \text { participantes de curso } \\
\text { técnico a distância. }\end{array}$ & $\begin{array}{l}\text { Análise fatorial exploratória: } \\
\text { Estrutura fatorial composta de } 3 \text { fatores: Busca de Ajuda } \\
\text { Interpessoal; Elaboração e Aplicação Prática do Conteúdo; e } \\
\text { Repetição, Organização e Ajuda do Material. Índices de } \\
\text { confiabilidade variaram entre } 0,75 \text { e } 0,85 \text {. }\end{array}$ \\
\hline $\begin{array}{l}\text { Beviláqua- } \\
\text { Chaves } \\
(2007)\end{array}$ & $\begin{array}{l}\text { 467servidores de } 4 \\
\text { organizações públicas. }\end{array}$ & $\begin{array}{l}\text { Análise fatorial confirmatória: } \\
\text { Estrutura fatorial composta de } 5 \text { fatores: Busca de Ajuda em } \\
\text { Material Escrito, Reprodução, Busca de Ajuda Interpessoal, } \\
\text { Reflexão Extrínseca, Aplicação Prática e Reflexão } \\
\text { Intrínseca. Índices de confiabilidade variaram entre } 0,78 \text { e }\end{array}$ \\
\hline
\end{tabular}




\begin{tabular}{|c|c|c|}
\hline Autor & Amostra & Resultados \\
\hline & & 0,81 \\
\hline $\begin{array}{l}\text { Zerbini e } \\
\text { Abbad } \\
\text { (2008) }\end{array}$ & $\begin{array}{l}993 \text { participantes de curso } \\
\text { técnico a distância. }\end{array}$ & $\begin{array}{l}\text { Análise fatorial exploratória: } \\
\text { Estrutura fatorial composta de } 7 \text { fatores: Controle da } \\
\text { Emoção; Busca de Ajuda Interpessoal; Repetição e } \\
\text { Organização; Controle da Motivação; Elaboração; Busca de } \\
\text { Ajuda ao Material Didático; Monitoramento da } \\
\text { Compreensão. Índices de confiabilidade variaram entre } 0,75 \\
\text { e } 0,89 \text {. }\end{array}$ \\
\hline $\begin{array}{l}\text { Carvalho- } \\
\text { Silva } \\
(2008)\end{array}$ & $\begin{array}{l}394 \text { participantes de empresa } \\
\text { pública federal e servidores } \\
\text { de órgão da administração } \\
\text { direta federal. }\end{array}$ & $\begin{array}{l}\text { Análise fatorial exploratória: } \\
\text { Estrutura empírica composta de } 6 \text { fatores: Busca de Ajuda } \\
\text { Interpessoal e em Material Escrito, Reflexão Extrínseca, } \\
\text { Reprodução, Reflexão Intrínseca/ Aplicação Prática. Os } \\
\text { fatores apresentaram índices de confiabilidade razoáveis e } \\
\text { bons, variando de } 0,73 \text { a } 0,88 \text {. } \\
\text { Análise fatorial confirmatória: } \\
\text { Os cinco fatores de primeira ordem foram explicados por um } \\
\text { constructo latente denominado Estratégias Gerais de } \\
\text { Aprendizagem no Trabalho. Qui-quadrado }=0,80 \text { com } \\
\text { cargas fatoriais variando de } 0,55 \text { a } 0,88 \text {. }\end{array}$ \\
\hline $\begin{array}{l}\text { Brandão } \\
(2009)\end{array}$ & $\begin{array}{l}\text { Análise fatorial exploratória: } \\
311 \text { gestores de instituição } \\
\text { bancária } \\
\text { Análise fatorial } \\
\text { confirmatória: } 926 \text { gestores } \\
\text { de instituição bancária. }\end{array}$ & $\begin{array}{l}\text { Análise fatorial exploratória: } \\
\text { Estrutura fatorial composta de } 6 \text { fatores: Reflexão Intrínseca } \\
\text { e Reflexão Extrínseca, Busca de Ajuda Interpessoal, Busca } \\
\text { de Ajuda em Material Escrito e Aplicação Prática, } \\
\text { Reprodução1 e, Reprodução2. Índices de confiabilidade } \\
\text { superiores a } 0,70 . \\
\text { Análise fatorial confirmatória: } \\
\text { Estrutura fatorial composta de } 5 \text { fatores: Reflexão Intrínseca } \\
\text { e Reflexão Extrínseca, Busca de Ajuda Interpessoal, Busca } \\
\text { de Ajuda em Material Escrito e Aplicação Prática, } \\
\text { Reprodução. Índice de confiabilidade variando de } 0,79 \text { a } \\
0,92 \text {. }\end{array}$ \\
\hline $\begin{array}{l}\text { Souza } \\
(2009)\end{array}$ & $\begin{array}{l}789 \text { trabalhadores de } \\
\text { organização de pesquisa e } \\
\text { desenvolvimento de } \\
\text { tecnologias para o } \\
\text { agronegócio. }\end{array}$ & $\begin{array}{l}\text { Análise fatorial exploratória: } \\
\text { Estrutura fatorial composta por } 4 \text { fatores: Reflexão Intrínseca } \\
\text { e Extrínseca, Busca de Ajuda Interpessoal, Busca de Ajuda } \\
\text { em Material Escrito e Reprodução. Índice de confiabilidade } \\
\text { variando entre } 0,70 \text { e } 0,91 \text {. }\end{array}$ \\
\hline Lins (2009) & $\begin{array}{l}403 \text { servidores que } \\
\text { realizaram atividades de } \\
\text { fiscalização, atividade típica } \\
\text { da área-fím do TCU. }\end{array}$ & $\begin{array}{l}\text { Análise fatorial exploratória: } \\
\text { Estrutura fatorial composta de } 6 \text { fatores: Reflexão Intrínseca, } \\
\text { Reflexão Extrínseca, Reprodução, Busca de Ajuda } \\
\text { Interpessoal, Busca de Ajuda em Material Escrito e } \\
\text { Aplicação Prática. Índices de confiabilidade variando de } 0,73 \\
\text { a } 0,93 \text {. }\end{array}$ \\
\hline $\begin{array}{l}\text { Moraes e } \\
\text { Borges- } \\
\text { Andrade } \\
(2010 b)\end{array}$ & $\begin{array}{l}90 \text { Prefeitos(as) e } 365 \\
\text { Secretários(as) de } \\
\text { municípios brasileiros. }\end{array}$ & $\begin{array}{l}\text { Análise fatorial exploratória: } \\
\text { Estrutura fatorial composta de } 5 \text { fatores: Reflexão Intrínseca } \\
\text { e Extrínseca, Busca de Ajuda Interpessoal, Busca de Ajuda } \\
\text { em Material Escrito, Aplicação Prática e, Reprodução. } \\
\text { Índices de confiabilidade variando de } 0,65 \text { a } 0,88 \text {. }\end{array}$ \\
\hline $\begin{array}{l}\text { Abbad, } \\
\text { Corrêa e } \\
\text { Meneses } \\
(2010)\end{array}$ & $\begin{array}{l}216 \text { participantes de } 5 \text { cursos } \\
\text { a distância de uma } \\
\text { organização pública. }\end{array}$ & $\begin{array}{l}\text { Análise fatorial exploratória: } \\
\text { Estrutura fatorial composta de } 3 \text { fatores:Busca de Ajuda } \\
\text { Interpessoal, Elaboração e Aplicação Prática do Conteúdo e } \\
\text { Organização e Ajuda do Material. Índices de confiabilidade } \\
\text { variando de } 0,86 \text { a } 0,94 \text {. }\end{array}$ \\
\hline $\begin{array}{l}\text { Isidro Filho } \\
\text { (2010) }\end{array}$ & $\begin{array}{l}425 \text { empregados de } \\
\text { diferentes setores de } 3 \\
\text { hospitais privados. }\end{array}$ & $\begin{array}{l}\text { Análise fatorial exploratória: } \\
\text { Estrutura fatorial composta de } 4 \text { fatores: Reflexão Intrínseca } \\
\text { e Extrínseca, Reprodução, Busca de Ajuda Interpessoal e } \\
\text { Aplicação Prática e Busca de Ajuda em Material Escrito. }\end{array}$ \\
\hline
\end{tabular}




\begin{tabular}{|c|c|c|}
\hline Autor & Amostra & Resultados \\
\hline $\begin{array}{l}\text { Brandão e } \\
\text { Borges- } \\
\text { Andrade } \\
(2011)\end{array}$ & $\begin{array}{l}926 \text { gestores de agências de } \\
\text { um banco público brasileiro, } \\
\text { atuante em todas as regiões } \\
\text { do Brasil e no exterior. }\end{array}$ & $\begin{array}{l}\text { Análise fatorial exploratória: } \\
\text { Estrutura fatorial composta de } 5 \text { fatores: Reflexão Ativa, } \\
\text { Busca de Ajuda Interpessoal, Busca de Ajuda em Material } \\
\text { Escrito, Reprodução e, Aplicação Prática. Índices de } \\
\text { confiabilidade acima de } 0,78\end{array}$ \\
\hline Lins (2011) & $\begin{array}{l}377 \text { gestores de três órgãos } \\
\text { da Administração Pública } \\
\text { Federal e } 692 \text { integrantes de } \\
\text { equipes de trabalho. }\end{array}$ & $\begin{array}{l}\text { Análise fatorial exploratória: } \\
\text { Estrutura fatorial composta de } 5 \text { fatores: Reflexão Intrínseca } \\
\text { e Extrínseca, Reprodução, Busca de Ajuda Interpessoal, } \\
\text { Busca de Ajuda em Material Escrito e Aplicação Prática. } \\
\text { Índices de confiabilidade variando de } 0,77 \text { a } 0,89 \text {. }\end{array}$ \\
\hline $\begin{array}{l}\text { Neiva e } \\
\text { Pantoja } \\
(2011)\end{array}$ & $\begin{array}{l}299 \text { respondentes das três } \\
\text { organizações: duas públicas } \\
\text { e uma privada. }\end{array}$ & $\begin{array}{l}\text { Análise fatorial exploratória: } \\
\text { Estrutura fatorial composta de } 4 \text { fatores:Reprodução, Procura } \\
\text { de Ajuda Interpessoal, Busca de Ajuda em Material Escrito e } \\
\text { Reflexão e Aplicação Prática. Índices de confiabilidade } \\
\text { variando de } 0,76 \text { a } 0,92 \text {. }\end{array}$ \\
\hline $\begin{array}{l}\text { Fernandez } \\
(2012)\end{array}$ & $\begin{array}{l}1.885 \text { integrantes de grupos } \\
\text { de pesquisa, cadastrados na } \\
\text { plataforma Lattes do CNPq. }\end{array}$ & $\begin{array}{l}\text { Análise fatorial exploratória: Estrutura fatorial composta de } \\
2 \text { fatores: Reflexão Ativa, referência externa, Aplicação } \\
\text { Prática e Busca de Ajuda Interpessoal e Reprodução. İ́ndices } \\
\text { de confiabilidade } 0,93 \text { para o primeiro fator e } 0,76 \text { para o } \\
\text { segundo fator. }\end{array}$ \\
\hline $\begin{array}{l}\text { Brandão, } \\
\text { Borges- } \\
\text { Andrade, } \\
\text { Puente- } \\
\text { Palacios e } \\
\text { Laros (2012) } \\
\end{array}$ & $\begin{array}{l}775 \text { participantes de } \\
\text { agências de um banco } \\
\text { público brasileiro, atuante } \\
\text { em todas as regióes do } \\
\text { Brasil e no exterior. }\end{array}$ & $\begin{array}{l}\text { Análise fatorial exploratória: Estrutura fatorial composta de } \\
5 \text { fatores: Reflexão Intrínseca e Extrínseca, Busca de Ajuda } \\
\text { Interpessoal, Busca de Ajuda em Material Escrito, } \\
\text { Reprodução e, Aplicação Prática. Índices de confiabilidade } \\
\text { acima de } 0,78 \text {. }\end{array}$ \\
\hline $\begin{array}{l}\text { Isidro Filho, } \\
\text { Guimarães, } \\
\text { Perin e Leung } \\
\text { (2013) } \\
\end{array}$ & $\begin{array}{l}425 \text { empregados de } \\
\text { diferentes setores de } 3 \\
\text { hospitais privados. }\end{array}$ & $\begin{array}{l}\text { Análise fatorial exploratória: Estrutura fatorial composta de } \\
4 \text { fatores: Reflexão Intrínseca e Extrínseca, Reprodução, } \\
\text { Busca de Ajuda Interpessoal e Aplicação Prática e Busca de } \\
\text { Ajuda em Material Escrito. }\end{array}$ \\
\hline
\end{tabular}

Fonte: Pantoja (2004, p.39); Morais e Borges-Andrade (2010b, p.333); e Fernandez (2012, p.39). Adaptado e expandido até 2014 pelo Autor.

Ao todo, 23 trabalhos foram identificados no período de 2000 a 2013. Apesar do artigo seminal datar de 1998, o primeiro relato de pesquisa empírica envolvendo o uso de escalas de medida de estratégias de aprendizagem no contexto de trabalho corresponde à Warr e Downing (2000). O Gráfico 1 apresenta a progressão quantitativa dessas publicações ao longo do tempo. 
Gráfico 1 - Ano de Publicação dos trabalhos identificados

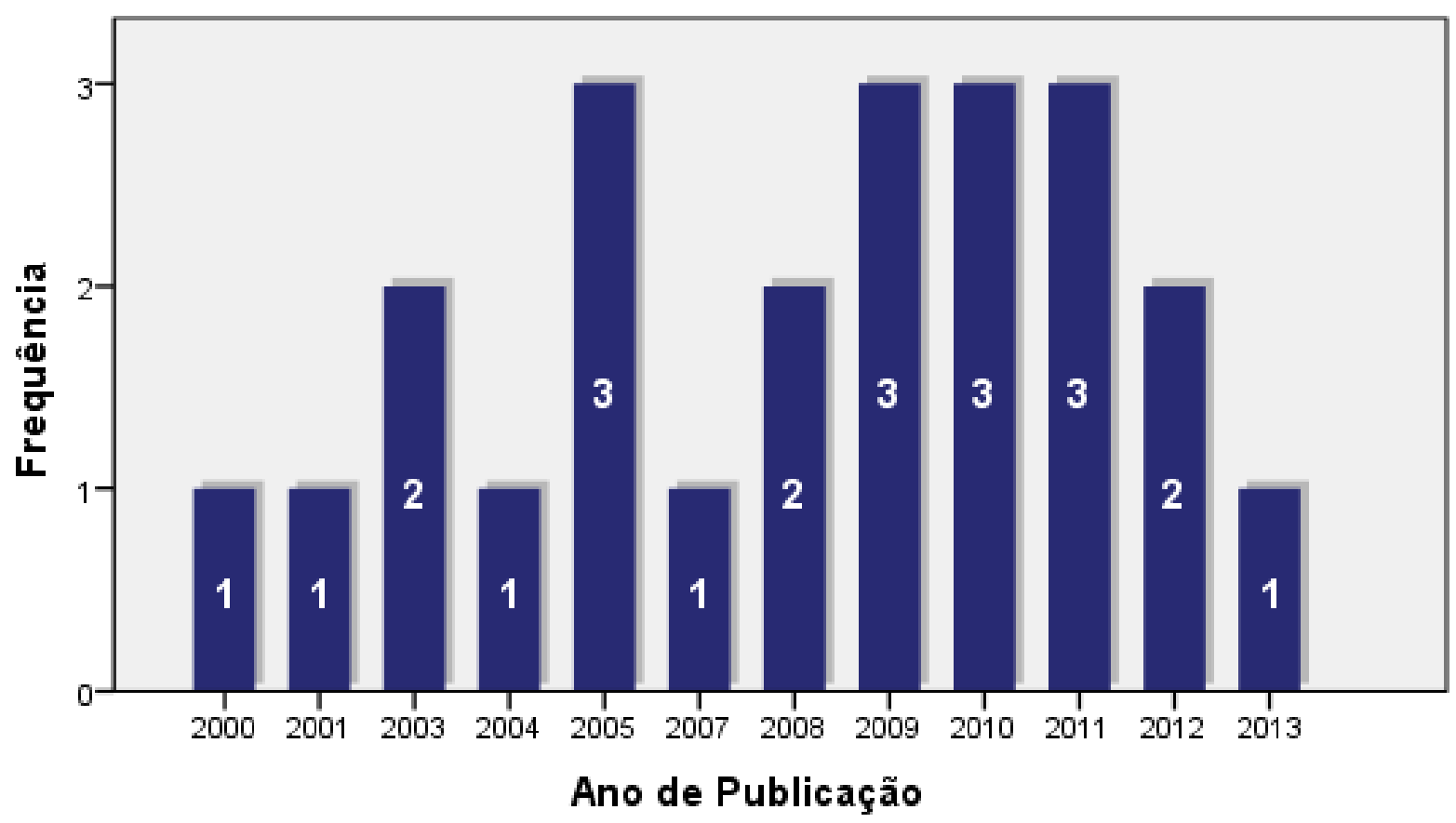

Fonte: Elaborado pelo Autor

Excetuando os dois primeiros trabalhos considerados seminais na área que foram realizados no Reino Unido, todos os demais foram desenvolvidos no Brasil sendo dois deles publicações na língua inglesa para periódicos internacionais.

Do total de estudos relacionados, foram analisados 10 artigos publicados em periódicos, dois trabalhos publicados nos anais de eventos na área ${ }^{1}$ e 11 trabalhos acadêmicos sendo, sete dissertações de mestrado e três teses de doutorado, nas áreas de Psicologia Organizacional e Administração, e um trabalho de pós-graduação na área de Gestão da Educação Corporativa. Seguindo o mesmo critério adotado nas revisões anteriores, optou-se por considerar os trabalhos acadêmicos na relação de achados, o que contribui para a análise da relação entre autores e publicações na área.

Nessa relação de trabalhos apresentados no Quadro 3 ainda não estão elencadas as diferentes medidas de estratégias de aprendizagem no trabalho que foram encontradas. Estão relacionados no quadro os trabalhos identificados que fazem uso dessas medidas ou que se preocupam com o desenvolvimento ou validação destas. Para que se possa identificar as

\footnotetext{
${ }^{1}$ Um artigo publicado no XXIX Encontro Nacional dos Programas de Pós-Graduação em Administração (EnANPAD) realizado em 2005 e outro no Congresso Interamericano de Psicologia realizado em 2003.
} 
diferentes escalas originadas a partir desses trabalhos, faz-se necessário uma análise mais detalhada sobre esse conjunto de publicações.

Inicialmente, para atualizar a revisão dos estudos já identificados na área (PANTOJA, 2004; MORAES; BORGES-ANDRADE, 2010b; FERNANDEZ, 2012), foram adotados dois critérios principais de busca.

O primeiro critério contou com a pesquisa, identificação e análise de publicações estrangeiras e nacionais presentes, no período de 1998 até 2014, nas bases de dados SciELO, Spell e nos bancos de periódicos nacionais e internacionais da Coordenação de Aperfeiçoamento de Pessoal de Nível Superior (CAPES). As palavras-chave utilizadas nos mecanismos de busca foram "Estratégias de Aprendizagem no Trabalho", "Workplace Learning Strategies" e "Learning Strategies at Work". Dos trabalhos identificados, foram selecionados apenas aqueles que envolviam em seu escopo de pesquisa o desenvolvimento, validação ou utilização de escalas de medida de estratégias de aprendizagem no trabalho, foco para este trabalho.

Dado o excesso de ocorrências destoantes da proposta inicial de pesquisa, não foi utilizada a palavra chave "Estratégia de Aprendizagem" desvinculada do contexto de trabalho. O estudo de estratégias de aprendizagem é mais expressivo nas áreas de ensino e educação, especificamente aplicados para o ensino fundamental, nível superior e língua estrangeira. Como estas áreas não são, por si só, foco específico deste trabalho, foram desconsideradas, apesar de, possivelmente, ser uma fonte de grande valia dado o grande volume de publicações sobre o tema nessas áreas de conhecimento. Para Beviláqua-Chaves (2007), é observado que o foco dos estudos sobre estratégias de aprendizagem concentra-se, ainda, na área educacional, contudo percebe-se uma movimentação no sentido de estudar esta variável em outros contextos como o de trabalho. Carvalho-Silva (2008) conclui que, analisando um quadro geral de estratégias de aprendizagem no trabalho, o tema vem despertando crescente, mais ainda pequeno, interesse de teóricos e pesquisadores da Psicologia Organizacional e do Trabalho.

Assim, realizando o levantamento bibliográfico sobre o tema de acordo com os critérios mencionados, ao todo, 17 trabalhos publicados foram identificados. Destes, oito trabalhos foram adicionados aos 14 já levantados pelas revisões feitas até Fernandez (2012), que compreendem o período de 1998 a 2011. Dos oito trabalhos, cinco foram publicados durante o período de análise das revisões anteriores e três foram publicados nos anos 2012 e 2013. Tais trabalhos compreendem as dissertações e teses de Isidro-Filho (2010), Lins (2011) e Fernandez (2012), todas publicadas pela Universidade de Brasília (UnB), e os artigos 
publicados de Zerbini e Abbad (2005), Abbad, Corrêa e Meneses (2010), Neiva e Pantoja (2011), Brandão et al. (2012) e Isidro Filho et al. (2013).

Os trabalhos provenientes de periódicos do portal da CAPES foram os classificados como superiores ou iguais a B1 pelo sistema de avaliação de periódicos Qualis, como apresentado no Quadro 4. Convém ressaltar o interesse em obter uma fotografia a respeito do tema no âmbito da comunidade científica nacional. Consequentemente, a identificação dos periódicos escolhidos atendeu a critérios de boa indexação e avaliação de conceito bastante satisfatório, de acordo com os critérios adotados pela CAPES, semelhante aos usados por Borges-Andrade e Meira (2003).

Quadro 4 - Relação de Periódicos e Classificações

\begin{tabular}{|l|l|c|}
\hline \multicolumn{1}{|c|}{ Trabalho (autor, ano) } & \multicolumn{1}{|c|}{ Periódico } & $\begin{array}{c}\text { Classificação } \\
\text { Qualis/CAPES }\end{array}$ \\
\hline Warr e Downing (2000) & British Journal of Psychology & - \\
\hline Holman, Epitropaki e Fernie (2001) & $\begin{array}{l}\text { Journal of Occupational and Organizational } \\
\text { Psychology }\end{array}$ & A2 \\
\hline Zerbini e Abbad (2005) & RAE Eletrônica & B1 \\
\hline Zerbini e Abbad (2008) & Psico-USF (Impresso) & B1 \\
\hline Abbad, Corrêa e Meneses (2010) & RAM. Revista de Administração Mackenzie & A2 \\
\hline Moraes e Borges-Andrade (2010b) & Estudos de Psicologia (UFRN) & B1 \\
\hline Brandão e Borges-Andrade (2011) & Psicologia: Reflexão e Crítica & A2 \\
\hline Neiva e Pantoja (2011) & Interamerican Journal of Psychology & A2 \\
\hline Brandão et al. (2012) & BAR. Brazilian Administration Review & \multicolumn{1}{|c|}{} \\
\hline Isidro Filho et al. (2013) & BAR. Brazilian Administration Review & \multicolumn{1}{|c|}{} \\
\hline
\end{tabular}

Fonte: Elaborado pelo Autor.

Analisando a ocorrência do termo "Estratégias de Aprendizagem no Trabalho", houve oito trabalhos não filtrados que puderam ser identificados posteriormente devido à utilização do segundo critério de seleção. Essa ocorrência se deu por haver estudos que não utilizaram o termo "no trabalho" tanto no título como no resumo e palavras-chave, apesar de serem estudos relacionados ao contexto de trabalho. Foi o caso dos estudos sobre Educação Corporativa, nos quais a escala era utilizada em cursos e treinamentos voltados ao ambiente profissional ou aplicados pela própria Organização.

O segundo critério de busca utilizado na revisão da literatura sobre o tema teve como base, a partir dos estudos encontrados, procurar textos diferentes dos identificados 
anteriormente analisando as referências explicitadas nos trabalhos da primeira triagem. Esse critério se mostrou oportuno devido ao fato de todos os trabalhos inicialmente encontrados fazerem referências a outros relatos que tratam de escalas de medida de estratégias de aprendizagem no trabalho.

Dos 14 trabalhos levantados em revisões anteriores até Fernandez (2012), nove puderam ser identificados a partir das bases e periódicos definidos neste trabalho. Os cinco trabalhos restantes são dois publicados em eventos da área ${ }^{2}$ - Pantoja Borges-Andrade e Lopes-Ribeiro (2003) e Zerbini, Carvalho e Abbad (2005) - e três dissertações não publicadas, disponíveis em meio físico no repositório de dissertações e teses da Universidade de Brasília. São eles os trabalhos de Zerbini (2003), Pantoja (2004) e Lopes-Ribeiro (2005). Todos esses trabalhos foram encontrados e adicionados a esta pesquisa com base no segundo critério de busca por trabalhos referendados pelas publicações identificadas no primeiro filtro de pesquisa. Além destes, a contribuição de Lins (2009) foi identificada e adicionada segundo o mesmo critério. Esta pesquisa compreende um trabalho de conclusão de curso de pósgraduação em Gestão da Educação Corporativa que se dedicou a adaptar e validar uma escala de estratégias de aprendizagem em um contexto específico de uma organização pública e o instrumento validado foi utilizado posteriormente na pesquisa de Lins (2011), relacionada anteriormente.

A maioria dos trabalhos localizados com base no primeiro critério de busca em bases de dados selecionadas foi evidenciado também nas referências de cada trabalho. Considerando apenas os trabalhos encontrados com base no segundo critério de pesquisa adotado, ao todo, seis trabalhos foram selecionados.

Analisando rapidamente a relação de autores e colaboradores que publicaram trabalhos relacionados a estratégias de aprendizagem no contexto das organizações, percebese que há na literatura nacional uma concentração do tema em um grupo de autores interrelacionados. A Figura 1 apresenta a inter-relação criada entre os autores utilizando os diferentes tipos de publicações selecionadas neste estudo.

\footnotetext{
${ }^{2}$ Um artigo publicado no XXIX Encontro Nacional dos Programas de Pós-Graduação em Administração (EnANPAD) realizado em 2005 e outro no Congresso Interamericano de Psicologia realizado em 2003.
} 
Figura 1 - Inter-relação entre Autores por Publicações

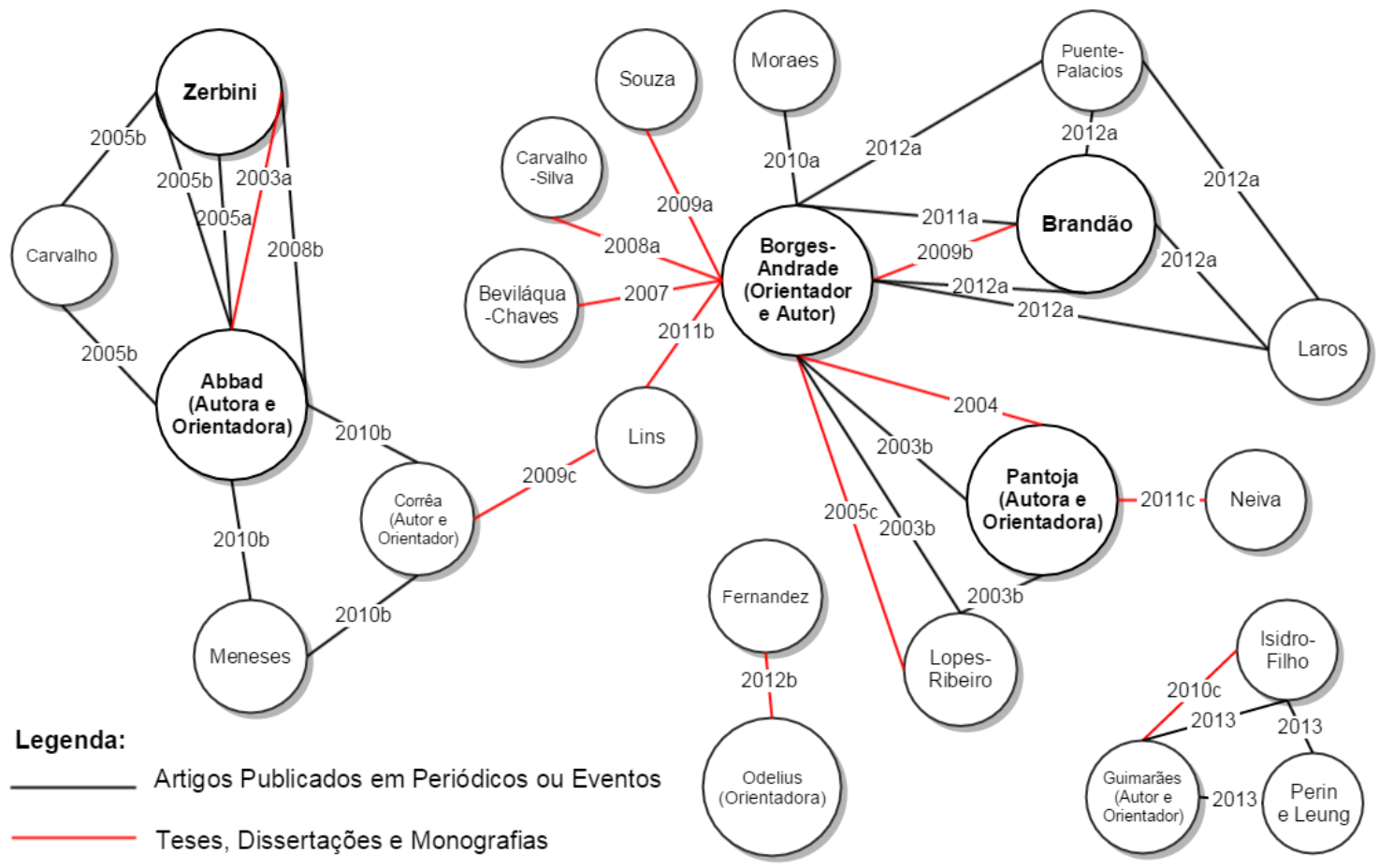

\begin{tabular}{|c|c|c|c|c|c|}
\hline 2003a & (ZERBINI, 2003) & $2008 \mathrm{a}$ & (CARVALHO-SILVA, 2008) & $2010 c$ & (ISIDRO FILHO, 2010) \\
\hline $2003 b$ & $\begin{array}{l}\text { (PANTOJA; BORGES-ANDRADE; } \\
\text { LOPES-RIBEIRO, 2003) }\end{array}$ & $2008 b$ & (ZERBINI; ABBAD, 2008) & $2011 a$ & $\begin{array}{l}\text { (BRANDÃO; BORGES- } \\
\text { ANDRADE, 2011) }\end{array}$ \\
\hline 2004 & (PANTOJA, 2004) & $2009 a$ & (SOUZA, 2009) & $2011 b$ & (LINS, 2011) \\
\hline $2005 a$ & (ZERBINI; ABBAD, 2005) & $2009 b$ & (BRANDÄO, 2009) & 2011c & (NEIVA; PANTOJA, 2011) \\
\hline $2005 b$ & $\begin{array}{l}\text { (ZERBINI; CARVALHO; ABBAD, } \\
\text { 2005) }\end{array}$ & $2009 c$ & (LINS, 2009) & $2012 a$ & (BRANDÃO et al., 2012) \\
\hline $2005 c$ & (LOPES-RIBEIRO, 2005) & $2010 a$ & $\begin{array}{l}\text { (MORAES; BORGES- } \\
\text { ANDRADE, 2010) }\end{array}$ & $2012 b$ & (FERNANDEZ, 2012) \\
\hline 2007 & (BEVILÁQUA-CHAVES, 2007) & $2010 b$ & $\begin{array}{l}\text { (ABBAD; CORREA; } \\
\text { MENESES, 2010) }\end{array}$ & 2013 & (ISIDRO FILHO et al., 2013) \\
\hline
\end{tabular}

Fonte: Elaborado pelo Autor

Por meio da Figura 1 é possível identificar concentrações de publicações relacionadas a medidas de estratégias de aprendizagem no trabalho em alguns autores. Estes são as autoras Zerbini e Abbad (nas medidas voltadas à educação corporativa) e Pantoja, Borges-Andrade e Brandão (mais voltados para o cotidiano de trabalho). Destaque para Borges-Andrade, representado nas interações como um centro tanto no papel de autor, como no de orientador de mestrandos e doutorandos. Esse mapa demonstra como a área está concentrada em poucos autores e analisando a filiação destes é possível verificar um predomínio quase absoluto do estudo na Universidade de Brasília (UnB).

Somando os 17 trabalhos identificados utilizando-se o primeiro critério de busca, com os seis trabalhos encontrados com base no segundo critério, foram selecionados e 
analisados, ao todo, 23 trabalhos que tratam de escalas de medida de estratégias de aprendizagem no trabalho. Estes trabalhos, no entanto, não correspondem necessariamente a diferentes instrumentos de medida. Foram identificados dois objetivos básicos nos estudos envolvendo medidas de estratégias de aprendizagem no trabalho. Um voltado para a instrumentalização de pesquisas sobre as estratégias no contexto estudado, e outro para a utilização de instrumentos já validados na explicação da relação dessas estratégias com outros constructos estudados. Neste último caso, a instrumentalização pode ser uma das etapas para o alcance dos objetivos principais de pesquisa ou pode ser feito o uso de instrumentos já validados em outros estudos com ou sem adaptação.

De 1998 a 2004, Pantoja (2004) já havia constatado um acréscimo de estudos conduzidos em ambientes organizacionais, cujos objetivos são, em geral, instrumentais e explicativos ou ambos. Ou seja, focalizam na construção e o desenvolvimento de medidas para investigação do fenômeno das estratégias de aprendizagem e buscam investigar as relações existentes entre estas e outras variáveis como ganhos de aprendizagem e transferência de aprendizagem no trabalho. Fernandez (2012) argumenta que tem sido explorada a relação de escalas de estratégias de aprendizagem com: Percepções de suporte à aprendizagem contínua (PANTOJA, 2004); treinamento a distância via internet (ZERBINI, 2003; ZERBINI; ABBAD, 2008; ZERBINI; CARVALHO; ABBAD, 2005); clima social da organização e motivação para a aprendizagem (CARVALHO-SILVA, 2008; LOPESRIBEIRO, 2005); mudança organizacional (BEVILÁQUA-CHAVES, 2007); gestão por competências (BRANDÃO, 2009), dentre outras variáveis.

O Quadro 5 apresenta a relação de trabalhos que tratam de escalas de estratégias de aprendizagem no trabalho de acordo com sua abordagem sobre essa variável.

Quadro 5 - Objetivos com o estudo de Estratégias de Aprendizagem

\begin{tabular}{|l|l|l|l|}
\hline \multicolumn{1}{|c|}{ Autor } & $\begin{array}{c}\text { Objetivo com } \\
\text { relação a } \\
\text { escala de } \\
\text { medida }\end{array}$ & $\begin{array}{c}\text { Escalas de medida } \\
\text { usadas como } \\
\text { referência para } \\
\text { construção ou } \\
\text { utilização }\end{array}$ & $\begin{array}{c}\text { Objetivo(s) do estudo com a variável } \\
\text { "Estratégias de aprendizagem no trabalho" }\end{array}$ \\
\hline $\begin{array}{l}\text { Warr e } \\
\text { Downing } \\
(\mathbf{2 0 0 0 )}\end{array}$ & $\begin{array}{l}\text { Instrumental e } \\
\text { explicativo }\end{array}$ & (WARR; ALLAN, 1998) & $\begin{array}{l}\text { Construir uma escala, identificar associação de } \\
\text { estratégia com aprendizagem e correlacionar } \\
\text { estratégias de aprendizagem entre si. }\end{array}$ \\
\hline $\begin{array}{l}\text { Holman, } \\
\text { Epitropaki } \\
\text { e Fernie } \\
\text { (2001) }\end{array}$ & Instrumental & (WARR; DOWNING, & Construir uma escala para o contexto de trabalho. \\
\hline
\end{tabular}




\begin{tabular}{|c|c|c|c|}
\hline Autor & $\begin{array}{l}\text { Objetivo com } \\
\text { relação a } \\
\text { escala de } \\
\text { medida }\end{array}$ & $\begin{array}{l}\text { Escalas de medida } \\
\text { usadas como } \\
\text { referência para } \\
\text { construção ou } \\
\text { utilização }\end{array}$ & $\begin{array}{l}\text { Objetivo(s) do estudo com a variável } \\
\text { "Estratégias de aprendizagem no trabalho" }\end{array}$ \\
\hline $\begin{array}{l}\text { Pantoja, } \\
\text { Borges- } \\
\text { Andrade e } \\
\text { Lopes- } \\
\text { Ribeiro } \\
\text { (2003) }\end{array}$ & Instrumental & $\begin{array}{l}\text { (WARR; DOWNING, } \\
\text { 2000) e (HOLMAN; } \\
\text { EPITROPAKI; FERNIE, } \\
\text { 2001) }\end{array}$ & Construir uma escala para o contexto de trabalho. \\
\hline $\begin{array}{l}\text { Zerbini } \\
(2003)\end{array}$ & $\begin{array}{l}\text { Instrumental e } \\
\text { explicativo }\end{array}$ & $\begin{array}{l}\text { (WARR; ALLAN, 1998) } \\
\text { e (WARR; DOWNING, } \\
\text { 2000) }\end{array}$ & $\begin{array}{l}\text { Relacionar estratégias de aprendizagem como um } \\
\text { aspecto de características da clientela, reações ao } \\
\text { tutor e de procedimentos de um curso via internet } \\
\text { com o impacto do treinamento no trabalho. }\end{array}$ \\
\hline $\begin{array}{l}\text { Pantoja } \\
\text { (2004) }\end{array}$ & $\begin{array}{l}\text { Instrumental e } \\
\text { explicativo }\end{array}$ & $\begin{array}{l}\text { (WARR; DOWNING, } \\
\text { 2000) e (HOLMAN; } \\
\text { EPITROPAKI; FERNIE, } \\
\text { 2001) }\end{array}$ & $\begin{array}{l}\text { Relacionar estratégias de aprendizagem com } \\
\text { características da organização e percepções de } \\
\text { suporte à aprendizagem contínua. }\end{array}$ \\
\hline $\begin{array}{l}\text { Lopes- } \\
\text { Ribeiro } \\
(2005)\end{array}$ & $\begin{array}{l}\text { Explicativo com } \\
\text { revalidação } \\
\text { prévia }\end{array}$ & (PANTOJA, 2004) & $\begin{array}{l}\text { Relacionar estratégias de aprendizagem com } \\
\text { outros aspectos de motivação no trabalho. }\end{array}$ \\
\hline $\begin{array}{l}\text { Zerbini, } \\
\text { Carvalho e } \\
\text { Abbad } \\
(2005)\end{array}$ & Instrumental & $\begin{array}{l}\text { (WARR; ALLAN, 1998) } \\
\text { e (WARR; DOWNING, } \\
\text { 2000) }\end{array}$ & $\begin{array}{l}\text { Construir uma escala de estratégias de } \\
\text { aprendizagem em treinamento a distância via } \\
\text { internet }\end{array}$ \\
\hline $\begin{array}{l}\text { Zerbini, e } \\
\text { Abbad } \\
\text { (2005) }\end{array}$ & $\begin{array}{l}\text { Instrumental e } \\
\text { explicativo }\end{array}$ & $\begin{array}{l}\text { (WARR; ALLAN, 1998) } \\
\text { e (WARR; DOWNING, } \\
\text { 2000) }\end{array}$ & $\begin{array}{l}\text { Relacionar estratégias de aprendizagem como um } \\
\text { aspecto de características da clientela, reações ao } \\
\text { tutor e de procedimentos de um curso via internet } \\
\text { com o impacto do treinamento no trabalho. }\end{array}$ \\
\hline $\begin{array}{l}\text { Beviláqua- } \\
\text { Chaves } \\
(2007)\end{array}$ & $\begin{array}{l}\text { Explicativo com } \\
\text { revalidação } \\
\text { prévia }\end{array}$ & (PANTOJA, 2004) & $\begin{array}{l}\text { Relacionar o uso das estratégias de aprendizagem } \\
\text { no trabalho e percepções de suporte à } \\
\text { aprendizagem contínua num contexto de } \\
\text { mudança. }\end{array}$ \\
\hline $\begin{array}{l}\text { Zerbini e } \\
\text { Abbad } \\
(2008)\end{array}$ & Instrumental & $\begin{array}{l}\text { (WARR; DOWNING, } \\
\text { 2000) e (ZERBINI; } \\
\text { CARVALHO; ABBAD, } \\
\text { 2005) }\end{array}$ & $\begin{array}{l}\text { Construir uma escala de estratégias de } \\
\text { aprendizagem em treinamento a distância. }\end{array}$ \\
\hline $\begin{array}{l}\text { Carvalho- } \\
\text { Silva } \\
(2008) \\
\end{array}$ & $\begin{array}{l}\text { Explicativo com } \\
\text { revalidação } \\
\text { prévia }\end{array}$ & $\begin{array}{l}\text { (PANTOJA, 2004) e } \\
\text { (BEVILÁQUA- } \\
\text { CHAVES, 2007) }\end{array}$ & $\begin{array}{l}\text { Relacionar o uso de estratégias de aprendizagem } \\
\text { no trabalho com clima social da organização e a } \\
\text { motivação dos indivíduos para aprender. }\end{array}$ \\
\hline $\begin{array}{l}\text { Brandão } \\
(2009)\end{array}$ & $\begin{array}{l}\text { Instrumental e } \\
\text { explicativo }\end{array}$ & $\begin{array}{l}\text { (HOLMAN; } \\
\text { EPITROPAKI; FERNIE } \\
\text { 2001); (PANTOJA, } \\
\text { 2004); (WARR; } \\
\text { ALLAN, 1998); } \\
\text { (WARR; DOWNING, } \\
\text { 2000); e (ZERBINI; } \\
\text { CARVALHO; ABBAD, } \\
\text { 2005) }\end{array}$ & $\begin{array}{l}\text { Relacionar o uso de estratégias de aprendizagem } \\
\text { no trabalho com outros aspectos relacionados } \\
\text { com aprendizagem, competência e desempenho } \\
\text { sob uma perspectiva multinível. }\end{array}$ \\
\hline $\begin{array}{l}\text { Souza } \\
(2009)\end{array}$ & $\begin{array}{l}\text { Explicativo com } \\
\text { adaptação }\end{array}$ & (BRANDÃO, 2009) & $\begin{array}{l}\text { Relacionar o uso de estratégias de aprendizagem } \\
\text { no trabalho com a expressão de competências. }\end{array}$ \\
\hline $\begin{array}{l}\text { Lins } \\
(2009)\end{array}$ & Instrumental & $\begin{array}{l}\text { (PANTOJA, 2004); } \\
\text { (BRANDÃO, 2009); } \\
\text { (HOLMAN; } \\
\text { EPITROPAKI; FERNIE, } \\
\text { 2001) }\end{array}$ & $\begin{array}{l}\text { Adaptar uma escala e identificar ações para } \\
\text { apoiar no uso de estratégia com aprendizagem no } \\
\text { trabalho. }\end{array}$ \\
\hline
\end{tabular}




\begin{tabular}{|c|c|c|c|}
\hline Autor & $\begin{array}{l}\text { Objetivo com } \\
\text { relação a } \\
\text { escala de } \\
\text { medida }\end{array}$ & $\begin{array}{c}\text { Escalas de medida } \\
\text { usadas como } \\
\text { referência para } \\
\text { construção ou } \\
\text { utilização } \\
\end{array}$ & $\begin{array}{l}\text { Objetivo(s) do estudo com a variável } \\
\text { "Estratégias de aprendizagem no trabalho" }\end{array}$ \\
\hline $\begin{array}{l}\text { Moraes e } \\
\text { Borges- } \\
\text { Andrade } \\
(2010 b)\end{array}$ & Instrumental & (BRANDÃO, 2009) & Adaptar uma escala para o contexto de trabalho. \\
\hline $\begin{array}{l}\text { Abbad, } \\
\text { Corrêa e } \\
\text { Meneses } \\
(2010) \\
\end{array}$ & $\begin{array}{l}\text { Explicativo com } \\
\text { revalidação } \\
\text { prévia }\end{array}$ & (ZERBINI, 2003) & $\begin{array}{l}\text { Relacionar o uso de estratégias de aprendizagem } \\
\text { com satisfação com treinamentos. }\end{array}$ \\
\hline $\begin{array}{l}\text { Isidro } \\
\text { Filho } \\
(2010)\end{array}$ & $\begin{array}{l}\text { Explicativo com } \\
\text { revalidação } \\
\text { prévia }\end{array}$ & $\begin{array}{l}\text { (PANTOJA, 2004) e } \\
\text { (BRANDÃO, 2009) }\end{array}$ & $\begin{array}{l}\text { Relacionar o uso de estratégias de aprendizagem } \\
\text { com competências profissionais após adoção de } \\
\text { inovações de tecnologia da informação e } \\
\text { comunicação (TIC). }\end{array}$ \\
\hline $\begin{array}{l}\text { Brandão e } \\
\text { Borges- } \\
\text { Andrade } \\
(2011)\end{array}$ & Instrumental & $\begin{array}{l}\text { (HOLMAN; } \\
\text { EPITROPAKI; FERNIE } \\
\text { 2001); (PANTOJA, } \\
\text { 2004); (WARR; } \\
\text { ALLAN, 1998); } \\
\text { (WARR; DOWNING, } \\
\text { 2000); (ZERBINI; } \\
\text { CARVALHO; ABBAD, } \\
\text { 2005) } \\
\end{array}$ & $\begin{array}{l}\text { Construir uma escala para o contexto de trabalho } \\
\text { e verificar a frequência com que ocorrem. }\end{array}$ \\
\hline $\begin{array}{l}\text { Lins } \\
(2011)\end{array}$ & $\begin{array}{l}\text { Explicativo com } \\
\text { revalidação } \\
\text { prévia }\end{array}$ & (LINS, 2009) & $\begin{array}{l}\text { Relacionar o uso de estratégias de aprendizagem } \\
\text { no trabalho com outros aspectos relacionados } \\
\text { com competência e motivação. }\end{array}$ \\
\hline $\begin{array}{l}\text { Neiva e } \\
\text { Pantoja } \\
(2011) \\
\end{array}$ & $\begin{array}{l}\text { Explicativo com } \\
\text { revalidação } \\
\text { prévia }\end{array}$ & (PANTOJA, 2004) & $\begin{array}{l}\text { Relacionar o uso de estratégias de aprendizagem } \\
\text { no trabalho com atitudes frente a mudança } \\
\text { organizacional. }\end{array}$ \\
\hline $\begin{array}{l}\text { Fernandez } \\
(2012)\end{array}$ & $\begin{array}{l}\text { Explicativo com } \\
\text { adaptação }\end{array}$ & $\begin{array}{l}\text { (BRANDÃO; BORGES- } \\
\text { ANDRADE, 2011) } \\
\end{array}$ & $\begin{array}{l}\text { Relacionar o uso de estratégias de aprendizagem } \\
\text { no trabalho com competências desenvolvidas. }\end{array}$ \\
\hline $\begin{array}{l}\text { Brandão et } \\
\text { al. (2012) }\end{array}$ & Explicativo & $\begin{array}{l}\text { (BRANDÃO; BORGES- } \\
\text { ANDRADE, 2011) }\end{array}$ & $\begin{array}{l}\text { Relacionar o uso de estratégias de aprendizagem } \\
\text { no trabalho com outros aspectos relacionados } \\
\text { com aprendizagem, competência e contexto sob } \\
\text { uma perspectiva multinível. }\end{array}$ \\
\hline $\begin{array}{l}\text { Isidro } \\
\text { Filho et al. } \\
\text { (2013) }\end{array}$ & $\begin{array}{l}\text { Explicativo com } \\
\text { revalidação } \\
\text { prévia }\end{array}$ & $\begin{array}{l}\text { (PANTOJA, 2004) e } \\
\text { (BRANDÃO, 2009) }\end{array}$ & $\begin{array}{l}\text { Relacionar o uso de estratégias de aprendizagem } \\
\text { com competências profissionais após adoção de } \\
\text { inovações de tecnologia da informação e } \\
\text { comunicação (TIC). }\end{array}$ \\
\hline
\end{tabular}

Fonte: Elaborado pelo Autor

Analisando o Quadro 5, é possível identificar a rede envolvendo as escalas de medida utilizadas como referência para o desenvolvimento de novas escalas ou para a utilização dessas escalas com adaptações, necessitando de nova validação. Percebe-se com isso que todas as escalas desenvolvidas ou adaptadas estão, de certo modo, relacionadas entre si por escalas consideradas de referência na área que servem de modelo para estudos futuros da área. Além disso, nota-se a origem comum de todas as escalas de medida nos trabalhos 
empíricos seminais de Warr e Downing (2000) e Holman, Epitropaki e Fernie (2001) e no ensaio teórico de Warr e Alan (1998), como melhor ilustra a Figura 2.

Figura 2 - Rede de Construção de Escalas de Estratégias de Aprendizagem

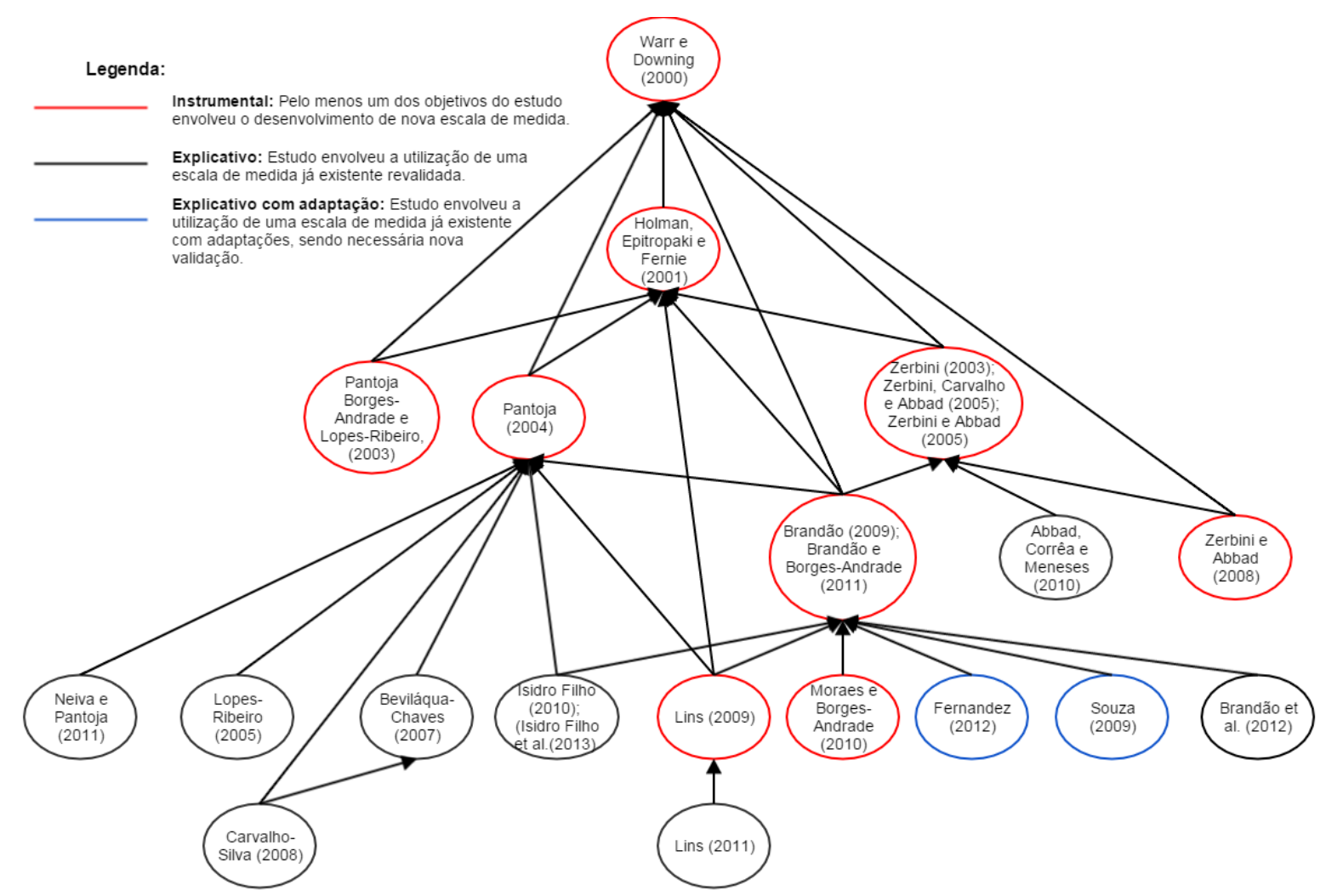

Fonte: Elaborado pelo Autor

Para melhor compreensão da relação entre as escalas desenvolvidas, trabalhos de uma mesma origem que compartilham os mesmos instrumentos de coleta e dados de pesquisa foram agrupados na Figura 2. Esses estudos com múltiplas publicações podem ser compreendidos dado que muitos dos trabalhos identificados são produções acadêmicas como dissertações e teses que, possivelmente, deram origem a artigos ou trabalhos publicados em eventos. Exemplo desse agrupamento pode ser a tese de doutorado de Brandão (2009) que gerou a publicação do relato de pesquisa de Brandão e Borges-Andrade (2011).

Como consequência dessa rede de relacionamento entre as escalas de estratégias de aprendizagem no trabalho desenvolvidas, é possível identificar a similaridade dos resultados quanto a estrutura fatorial como apresentados no Quadro 3. Morais e Borges-Andrade (2010) destacam que poucas variações têm sido evidenciadas na estrutura de estudos mais recentes sobre estratégias de aprendizagem no trabalho após os trabalhos desenvolvidos por Holman, Epitropaki e Fernie (2001). Entretanto, apesar de pouco, a diversidade é evidente e suas 
causas podem estar relacionadas a diferentes fatores como a metodologia empregada na pesquisa e o contexto estudo. Warr e Downing (2000) afirmam que algumas estratégias de aprendizagem não podem ser utilizadas por todas as pessoas, profissões e organizações.

Uma grande preocupação relacionada ao desenvolvimento de novas escalas de medida está na sua aplicabilidade independente das condições iniciais onde foram concebidas. Não é por menos que grande parte dos principais trabalhos dedicados ao desenvolvimento e validação de escalas de estratégias de aprendizagem propõe em sua agenda de pesquisa a utilização dos instrumentos em contextos diferentes (HOLMAN; EPITROPAKI; FERNIE, 2001; ZERBINI; CARVALHO; ABBAD, 2005; BRANDÃO; BORGES-ANDRADE, 2011). As características do contexto onde a pesquisa foi realizada podem responder muito sobre os resultados alcançados com a utilização de cada escala ou até mesmo com o uso da mesma escala em populações diferentes. Portanto, se faz necessária uma análise comparada mostrando as divergências entre os contextos no qual os trabalhos selecionados foram aplicados. O Quadro 6 apresenta uma análise quanto ao contexto trabalhado em cada relato.

Quadro 6 - Características de Contextos Utilizados no Estudo com Escalas de Estratégias de Aprendizagem

\begin{tabular}{|c|c|c|c|c|}
\hline Critérios: & 1 Organização & $\begin{array}{c}2 \text { a } 4 \\
\text { Organizações }\end{array}$ & $\begin{array}{c}\text { Mais de } 4 \\
\text { Organizações }\end{array}$ & $\begin{array}{c}\text { Sem } \\
\text { delimitação de } \\
\text { Organização }^{3}\end{array}$ \\
\hline $\mathrm{N}^{0}$ de organizações estudadas & 7 & 6 & 5 & 5 \\
\hline Critérios: & Público & Privado & $\begin{array}{l}\text { Ambos ou } \\
3^{\circ} \text { Setor }\end{array}$ & $\begin{array}{c}\text { Não aplicável }^{4} \\
\text { ou não } \\
\text { informado }\end{array}$ \\
\hline Setor estudado & 10 & 2 & 5 & 6 \\
\hline Critérios: & $\begin{array}{c}\text { Contexto } \\
\text { cotidiano de } \\
\text { trabalho } \\
\end{array}$ & $\begin{array}{c}\text { Contexto } \\
\text { formalizado de } \\
\text { ensino (TD\&E) }\end{array}$ & $\begin{array}{c}\text { Segmento } \\
\text { profissional }\end{array}$ & \\
\hline $\begin{array}{l}\text { Contexto de aprendizagem } \\
\text { estudado }\end{array}$ & 12 & 6 & 5 & \\
\hline
\end{tabular}

Fonte: Elaborado pelo Autor

Sobre os dados apresentados no Quadro 6, especificamente quanto ao setor estudado, grande parte dos trabalhos foi aplicado em organizações do setor público. Esta ocorrência pode ser decorrente do fato de que há um concentrado número de publicações oriundas do Distrito Federal (DF) em que há uma predominância de organizações desse setor. Outra

\footnotetext{
${ }^{3}$ No caso de estudos realizados em cursos profissionalizantes ou com segmentos profissionais sem delimitação quanto a Organização.

${ }^{4}$ Idem.
} 
característica a ser destacada analisando o contexto em que as escalas foram aplicadas está no ambiente de aprendizagem estudado. Por um lado, há estudos aplicados para o contexto de aprendizagem formal promovidos pela organização como cursos e treinamentos presenciais e a distância. Por outro lado, outros estudos foram aplicados em contextos informais de aprendizagem como o próprio local de trabalho. Segundo Coelho Junior e Borges Andrade (2008), os conceitos de aprendizagem permitem sua aplicação tanto em contextos formalizados de ensino (aprendizagem formal) quanto no contexto cotidiano de trabalho (aprendizagem informal ou natural).

Por fim, analisando as estruturas metodológicas adotadas nos trabalhos levantados sobre escalas de medidas, todos podem ser enquadrados como estudos de natureza teórico e empírico e de abordagem quantitativa com etapas qualitativas considerando o desenvolvimento inicial de questionários e itens. Com exceção do trabalho de Brandão et al. (2012) cujos dados utilizados foram providos do levantamento realizado em Brandão (2009), os demais estudos foram constituídos a partir de dados primários coletados presencialmente, a distância por meio eletrônico ou ambos, dependendo das condições do contexto pesquisado.

Finalmente, após análise das publicações selecionadas foi possível identificar as medidas de estratégias de aprendizagem no trabalho originadas a partir desses estudos. Os procedimentos e critérios adotados para essa constatação, em ordem de prioridade, foram:

- A escala foi desenvolvida e validada no estudo, possuindo bons índices de confiabilidade;

- A escala apresenta estrutura fatorial diferente das demais identificadas;

- A escala adaptada para um contexto específico envolveu etapas de validação por juízes, semântica e empíricas em sua adaptação;

- Em diferentes publicações de um mesmo trabalho, a escala considerada foi aquela publicada em periódico analisado por pares. Não havendo publicações desse tipo, a escala considerada foi aquela publicada em trabalhos acadêmicos (teses e dissertações) ou publicações em eventos;

Dos 23 trabalhos analisados, foram identificadas oito diferentes escalas de estratégias de aprendizagem no trabalho apresentadas no Quadro 7. 
Quadro 7 - Escalas de Estratégias de Aprendizagem no Trabalho

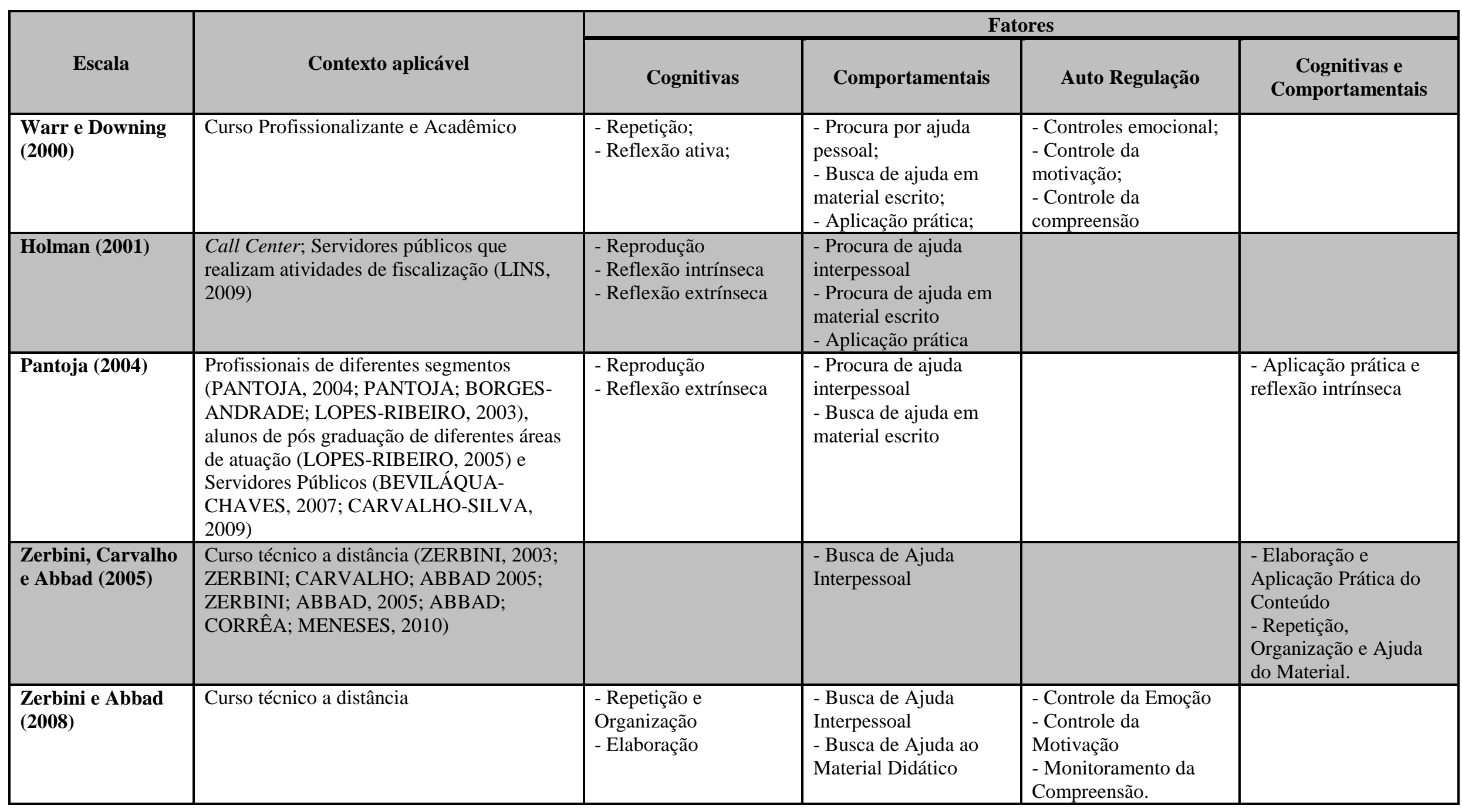




\begin{tabular}{|c|c|c|c|c|c|}
\hline Escala & Contexto aplicável & Cognitivas & Comportamentais & Auto Regulação & $\begin{array}{c}\text { Cognitivas e } \\
\text { Comportamentais }\end{array}$ \\
\hline Souza (2009) & $\begin{array}{l}\text { Trabalhadores de organização de } \mathrm{P} \& \mathrm{D} \text { para } \\
\text { o agronegócio }\end{array}$ & $\begin{array}{l}\text { - Reflexão intrínseca e } \\
\text { extrínseca } \\
\text { - Reprodução }\end{array}$ & $\begin{array}{l}\text { - Busca de ajuda } \\
\text { interpessoal } \\
\text { - Busca de ajuda em } \\
\text { material escrito }\end{array}$ & & \\
\hline $\begin{array}{l}\text { Brandão e Borges- } \\
\text { Andrade (2011) }\end{array}$ & $\begin{array}{l}\text { Gestores de agências de banco público } \\
\text { (BRANDÃO, 2009; BRANDÃO; BORGES- } \\
\text { ANDRADE, 2011); BRANDÃO et al., } \\
\text { 2012), Prefeitos e Secretários municipais } \\
\text { (MORAES; BORGES-ANDRADE, 2010b) } \\
\text { e Gestores de Órgãos públicos (LINS, 2011) }\end{array}$ & $\begin{array}{l}\text { - Reflexão ativa } \\
\text { (intrínseca + } \\
\text { extrínseca) } \\
\text { - Reprodução }\end{array}$ & $\begin{array}{l}\text { - Busca de ajuda } \\
\text { interpessoal } \\
\text { - Busca de ajuda em } \\
\text { material escrito } \\
\text { - Aplicação prática }\end{array}$ & & \\
\hline Fernandez (2012) & Integrantes de grupos de pesquisa & - Reprodução & & & $\begin{array}{l}\text { - Reflexão ativa, } \\
\text { referência externa, } \\
\text { aplicação prática, busca } \\
\text { de ajuda interpessoal }\end{array}$ \\
\hline
\end{tabular}

Fonte: Elaborado pelo Autor 
Para este estudo serão adotadas como estratégias de aprendizagem no trabalho, a relação indicada na escala desenvolvida por Brandão e Borges-Andrade (2011). A escolha foi feita com base na análise de frequência com que tais estratégias puderam ser evidenciadas considerando todos os 23 trabalhos encontrados, os oito trabalhos com as diferentes escalas encontradas e os 12 trabalhos aplicados em contextos informais de aprendizagem (cotidiano de trabalho). Em todos esses agrupamentos de análise, as estratégias relacionadas na escala de Brandão e Borges-Andrade (2011) foram as mais frequentes. São, ao todo, cinco estratégias assim descritas pelos autores, sendo as duas primeiras cognitivas e as três últimas comportamentais (BRANDÃO; BORGES-ANDRADE, 2011, p.452):

1. Reflexão ativa: diz respeito à reflexão do indivíduo sobre partes componentes do seu trabalho, bem como à organização de estruturas mentais que relacionam o trabalho da pessoa a diferentes aspectos da organização;

2. Reprodução: relativo à memorização e à repetição mental de informações, sem reflexão sobre seu significado;

3. Busca de Ajuda Interpessoal: versa sobre a procura ativa do indivíduo pelo auxílio de outras pessoas;

4. Busca de ajuda em material escrito: remete a pesquisa e a localização de informações em documentos, manuais, normativos, livros e outras fontes nãosociais; e

5. Aplicação prática: designa a tentativa do indivíduo de aprender por meio da experimentação, de colocar em prática os seus conhecimentos enquanto aprende.

Abordada a primeira temática deste trabalho referente à aprendizagem no trabalho e suas formas de investigação disponíveis na literatura, nas seções seguintes deste Capítulo será trabalhado o segundo construto investigado referente à criatividade no ambiente de trabalho das organizações.

\subsection{Criatividade e o Ambiente de Trabalho}

A segunda parte deste referencial destina-se à revisão da literatura sobre criatividade no contexto das organizações. Para tanto, foram realizados levantamentos bibliográficos com base em três principais formas de pesquisa. Primeiro foram levantados trabalhos de revisão, nacionais e internacionais, da literatura sobre criatividade nas organizações. Em seguida foi feito um levantamento próprio de artigos nacionais em bases selecionadas para complementar a revisão nacional. Por fim, foram levantados handbooks internacionais recentemente publicados em adição à revisão internacional.

Inicialmente buscou-se entender de forma macro como os estudos sobre criatividade no trabalho estão se configurando nos contextos nacional e internacional. O objetivo é ter um 
panorama dos conhecimentos gerados na área que possa direcionar o referencial desta pesquisa. Para tanto, foram pesquisados trabalhos dedicados à revisão da literatura sobre criatividade nas organizações que pudessem fornecer uma visão geral sobre as pesquisas realizadas na área.

Para compreensão da produção nacional foi considerada a revisão de Bruno-Faria, Veiga e Macêdo (2008) que teve como objetivo apresentar um panorama da produção cientifica sobre o tema no contexto organizacional brasileiro entre 1997 e 2006. Neste trabalho, 40 publicações entre artigos em periódicos, eventos, livros e (ou) capítulos foram identificadas e analisados individualmente. Para as autoras, o estudo aponta a necessidade de uma atenção especial para a produção cientifica sobre criatividade no país que ainda se encontra dispersa, sem sistematização do que foi produzido e do que necessita ser investigado (BRUNO-FARIA; VEIGA; MACÊDO, 2008).

Quanto a produção internacional sobre criatividade nas organizações, foram identificados três trabalhos que pudessem oferecer um panorama geral sobre o tema por meio de revisões da literatura na área. O primeiro trabalho, publicado por Zhou e Hoever (2014), teve como foco a revisão de trabalhos empíricos publicados desde 2000 nas áreas de psicologia organizacional e administração. Neste estudo, a compreensão da relação indivíduo e contexto é entendida como uma das perspectivas mais promissoras para se compreender o fenômeno da criatividade no ambiente de trabalho.

Outra revisão, que compreende o período seguinte de 2005 à 2015, foi realizada por Freitas, Santana e Ruas (2015) e consiste em uma análise bibliométrica das publicações científicas internacionais que tangenciam o tema da criatividade nas organizações. O estudo resultou em uma amostra de 1744 artigos classificados segundo sua frequência nos principais periódicos, expressões mais empregadas nos títulos e palavras-chave, artigos e autores mais citados, dentre outras. Segundo as autoras, a maior contribuição deste estudo está na possibilidade de oferecer uma visão atualizada, sistêmica e mais integrada da produção sobre o tema (FREITAS; SANTANA; RUAS, 2015).

A terceira revisão considerada trata especificamente de um levantamento dos instrumentos de avaliação de ambientes criativos e de inovação nas organizações feito por Marthisen e Einarsen (2004). Como detalhado adiante, esta revisão contribui na identificação e definição dos instrumentos de mensuração disponíveis na literatura sobre criatividade no ambiente de trabalho que poderiam vir a ser utilizados nesta pesquisa. 
$\mathrm{Na}$ tentativa de identificar mais trabalhos relevantes realizados em âmbito nacional que pudessem complementar o entendimento sobre a produção brasileira sobre criatividade no trabalho, foi realizada a segunda forma de pesquisa baseada em um levantamento próprio de estudos na área. Para tanto, foram utilizadas as bases de dados SciELO, Spell e o banco de periódicos nacionais e internacionais da CAPES qualificados entre B2 e A1 pelo sistema de avaliação de periódicos Qualis. Além desses, foi utilizada a base de livre acesso Google Scholar. A escolha das bases foi feita procurando identificar os trabalhos sobre o assunto na área de administração. Foram utilizados nos mecanismos de busca os termos "criatividade no trabalho", "criatividade nas organizações", "condições para criar no trabalho", "condições para criar na organização", "criatividade no ambiente de trabalho", "criatividade no ambiente das organizações", "criatividade no contexto de trabalho" e "criatividade no contexto das organizações". A ocorrência dos termos foi investigada tanto no título como em palavras chaves e assunto do trabalho.

Após análise inicial dos trabalhos, com base nos critérios previamente estabelecidos de adequação e relevância temática em relação ao estudo proposto, as 20 publicações nacionais apresentadas no Quadro 8 foram utilizadas como parte das referências para esta seção. 
Quadro 8 - Trabalhos Nacionais Levantados sobre Criatividade nas Organizações

\begin{tabular}{|c|c|}
\hline Trabalho & Periódico/Fonte \\
\hline (ALENCAR, 1995) & RAE Executiva \\
\hline (ALENCAR, 1996) & Livro: Ed. Makron Books \\
\hline (BRUNO-FARIA; ALENCAR, 1996) & RAUSP - Revista de Administração \\
\hline (BRUNO-FARIA, 1996) & Repositório Institucional UnB \\
\hline (ALENCAR, 1998) & RAE - Revista de Administração de Empresas \\
\hline (BRUNO-FARIA; ALENCAR, 1998) & RAUSP - Revista de Administração \\
\hline (RODRIGUES; SILVA, 1998) & REGE - Revista de Gestão \\
\hline (TERRA, 2000) & RAUSP - Revista de Administração \\
\hline (BRUNO-FARIA, 2003) & Capítulo de Livro: Ed. FGV \\
\hline (PAROLIN, 2003) & REGE - Revista de Gestão \\
\hline (CRESPO, 2004) & Estudos de Psicologia (Campinas) \\
\hline (HORTA, 2006) & Repositório Institucional PUC-RC \\
\hline (SILVA; RODRIGUES, 2007) & $\begin{array}{l}\text { SINERGIA - Revista do Instituto de Ciências Econômicas, } \\
\text { Administrativas e Contábeis }\end{array}$ \\
\hline (VALENTIM, 2008) & CRB-8 Digital \\
\hline (MORAES; LIMA, 2009) & Paideia (Ribeirão Preto) \\
\hline (BRUNO-FARIA, 2010) & Capítulo de Livro: Ed. Artmed \\
\hline (TUDDA; SANTOS, 2011) & RAD - Revista Administração em Diálogo \\
\hline (BEDANI, 2012) & RAM - Revista de Administração Mackenzie \\
\hline (BRUNO-FARIA; VEIGA, 2015) & Revista de Administração (FEA-USP) \\
\hline $\begin{array}{l}\text { (PORCARO-SOUSA; FUKUDA; LAROS, } \\
\text { 2015) }\end{array}$ & Avaliação Psicológica \\
\hline
\end{tabular}

Fonte: Elaborado pelo Autor

Metade dos trabalhos identificados no levantamento realizado neste estudo também foram considerados na revisão de Bruno-Faria, Veiga e Macêdo (2008). As publicações adicionais identificadas se referem a trabalhos produzidos após o ano de publicação dessa revisão ou devido a inclusão de trabalhos de bases diferentes das utilizadas pelas autoras.

A terceira forma de pesquisa empregada teve como foco de análise os principais aglomerados de conhecimento sobre criatividade no contexto organizacional publicados no formato de Handbook, que reúnem importantes consolidações sobre a temática e podem esclarecer os direcionamentos de pesquisas na área. Mumford, Kimberly e Robledo (2012) explicam que o Handbook desenvolvido por eles é um exame das variáveis que influenciam a criatividade e a inovação nas organizações e esperam que sirva não somente para demonstrar um background necessário para futuras pesquisas, mas também para prover ideias à gestores que queiram encorajar a criatividade e inovação em suas organizações. Outro trabalho do mesmo tipo utilizado foi o Handbook sobre criatividade de Cambridge, editado por Kaufman e Sternberg (2007).

Assim, com base nas formas de pesquisa apresentadas foi possível levantar o arcabouço teórico deste trabalho que se encontra dividido em duas partes. A primeira trata da 
criatividade nas organizações, onde serão apresentadas algumas linhas conceituais sobre o objeto de forma geral e no contexto das organizações. A segunda parte diz respeito a criatividade e o ambiente organizacional e do trabalho, no qual suas características e influências podem se tornar aspectos favoráveis ou desfavoráveis à criatividade.

\subsubsection{Criatividade nas Organizações}

A criatividade não é um tema exclusivo de uma única área de conhecimento. Este constructo foi abordado ao longo do tempo em diversos campos como da Filosofia, Educação, Sociologia e Administração, em razão de sua importância e aplicação ao contexto de desenvolvimento humano e organizacional (TUDDA; SANTOS, 2011).

A definição de criatividade ainda não é consenso entre os autores que tratam do assunto. Sua aplicação multidisciplinar, com objetivos e aplicações variadas, torna a conceituação sobre o tema diversificada, complexa e fruto de visões adaptadas a contextos particulares de análise. Horta (2006) explica que embora haja um consenso de que é algo abstrato, de difícil definição, muitos pesquisadores buscam conceituá-la, cada qual com suas aplicações e objetivos, o que gera definições diversas, mas, geralmente convergentes em pelo menos três aspectos destacados pela autora: (a) relativo a natureza do pensamento e das atividades intelectuais utilizadas na resolução de problemas, (b) características pessoais aliadas às habilidades intelectuais dos indivíduos e (c) resultado gerado de tentativas criativas.

Assim, Horta (2006) define criatividade como uma competência humana para gerar variedades de informações a partir de uma dada informação, denominada produção divergente ou pensamento divergente, como resultante da interação de todas as habilidades pertencentes à estrutura do intelecto. Nesse contexto, a criatividade é identificada como um conjunto de habilidades intelectuais e cognitivas que dizem respeito a processos psicológicos envolvidos em conhecer, compreender, perceber, aprender e estariam relacionados à forma como o indivíduo lida com os estímulos externos (ALENCAR, 1993).

Um conceito sobre criatividade amplamente difundido e analisado por James e Drown (2012) consiste no sugerido por Amabile (1996) em que a criatividade seria a geração de algo singular e útil para a realização dos objetivos desejados. Segundo os autores, "algo" não significaria necessariamente um objeto concreto sendo, por exemplo, uma ideia ou a resolução de um problema. Da mesma forma, "singular" (termo original "novel") não 
representaria algo completamente novo podendo ter um grau de novidade moderado ou radical. Por fim, James e Drown (2012) destacam o termo "objetivo" como algo fruto da decisão humana que pode depender quanto à sua utilidade de acordo com diferentes pessoas ou grupos.

Mumford, Kimberly e Robledo (2012), analisando a definição de criatividade como sendo a produção de soluções de problemas de alta qualidade, originais e alinhadas, implicam que a criatividade é uma forma de performance, produto da cognição humana de alto nível, que parte de uma decisão consciente e que não se refere a um nível específico em que o problema pode ocorrer.

Com o direcionamento da criatividade para o enfoque na organização, tem-se que os conceitos passam a convergir para uma linha mais clara sobre o objeto de estudo e suas interações com outros conceitos. Para Alencar (1995), a criatividade nas organizações é um processo que ocorre a partir da interação entre os fatores organizacionais e os individuais. $\mathrm{O}$ conceito definido por Bruno-Faria (2003, p.117) e adotado neste trabalho para criatividade no contexto de trabalho envolve três importantes aspectos.

\begin{abstract}
(a) A geração de ideias, processos, produtos e/ou serviços novos para aquele indivíduo, grupo ou naquele contexto; (b) que possam gerar contribuições valiosas para a organização e/ou para o bem-estar das pessoas que trabalham naquele contexto; e (c) que possuam elementos essenciais à sua implementação.
\end{abstract}

Tudda e Santos (2011) citam que os estudos relacionados à criatividade no ambiente das organizações, devem considerar: indivíduo, ambiente, cultura organizacional, estilos gerenciais e processos de trabalho. Sendo assim, a criatividade mesmo sendo abordada sob o foco específico do contexto de trabalho das organizações, não perde seu caráter complexo e multidisciplinar.

O crescente interesse em estudos sobre a criatividade nas organizações é explicado por duas principais tendências apontadas por Puccio e Cabra (2010). A primeira tendência corresponde a necessidade das organizações de se adaptarem rapidamente às mudanças enquanto a segunda tendência, interligada à primeira, está relacionada a busca da inovação. Alencar (1998) expõe que as organizações sofrem uma enorme pressão para se manterem em um processo permanente de inovação, o qual se origina das ideias criativas dos indivíduos. Bruno-Faria e Veiga (2015) explicam que dada a importância da criatividade na geração da inovação, muitas organizações buscam estratégias diferenciadas para facilitar sua emergência nesses espaços de trabalho. 
Neste sentido, a criatividade se contrasta com outro conceito amplamente discutido nas organizações e no contexto empresarial chamado inovação. Existe um consenso de que a criatividade e a inovação são processos relacionados, porém, diferentes (SILVA; RODRIGUES, 2007). A primeira consiste num processo de surgimento da ideia nova ou, segundo Alencar (1995), em um componente ideacional da inovação. Já este representa o processo de aplicação, introdução, operacionalização e concretização da ideia nova na organização (ALENCAR, 1995; SILVA; RODRIGUES, 2007).

Outros autores corroboram o entendimento de que a inovação seria o resultado da criatividade. Valentim (2008) acredita que a inovação representa a aplicação da criatividade, ou seja, primeiro tem-se a criatividade, depois a inovação. Logo, acredita-se que a criatividade é pensar algo original e a inovação é a execução, ou seja, a inovação é a implantação da ideia criativa. Alencar (1996) explica que inovar significa, como o próprio nome sugere, introduzir novidade. A inovação organizacional é concebida como processo de introduzir, adotar e implementar uma nova ideia, seja ela um processo, bem ou serviço, em uma organização em resposta a um problema percebido, transformando uma nova ideia em algo concreto.

É importante ressaltar o fator viabilidade na interação criatividade-inovação. Apesar de afirmar que a criatividade é o primeiro passo para a inovação, Valentim (2008) lembra que apesar da forte relação, nem sempre uma ideia criativa resulta em uma inovação. Isso ocorre devido às condições, nem sempre viáveis de implantação da ideia. Dessa forma, a inovação depende essencialmente do fator viabilidade como condicionante. Zhou e Hoever (2014) apontam ainda que a criatividade, além de servir como ideia central para uma possível inovação, pode ajudar na superação de desafios que surgem durante a implementação.

Segundo Mumford, Kimberly e Robledo (2012), em última análise, inovação, como a produção de um novo produto, serviço ou processo só é possível com a geração de uma solução criativa para um problema. A criatividade representa uma necessidade mas não uma condição suficiente para a inovação (MUMFORD; KIMBERLY; ROBLEDO, 2012).

Freitas, Santana e Ruas (2015) apontam que na literatura sobre criatividade nas organizações, o debate sobre a relação criatividade e inovação está presente em grande parte dos estudos da área. Entretanto, apesar dessa constatação, segundo Puccio e Cabra (2010), um número reduzido de estudos tem se esforçado para demonstrar a relação de forma empírica entre criatividade e inovação nas organizações, o que pode demonstrar a importância da criatividade e os benefícios tangíveis da inovação na organização. De qualquer forma, a 
relação estreita da criatividade com a inovação é conceitualmente clara e de certo modo fundamental para as organizações no contexto em que estão inseridas.

Alencar (1995) observa que o termo "inovação" tem sido mais utilizado no contexto das organizações enquanto o termo "criatividade" tem sido usado para falar de indivíduos e grupos de indivíduos. Mathisen e Einarsen (2004) também destacam a diferença entre estudos sobre criatividade e inovação segundo o nível de análise acrescentando grupos em inovação e reforçando a criatividade no nível dos indivíduos. De qualquer forma, a relação estreita da criatividade com a inovação é clara e de certo modo fundamental para as organizações no contexto em que estão inseridas. Em linhas gerais, Bruno-Faria e Veiga (2015) explicam que embora não haja unanimidade nas definições de criatividade e inovação, ambos apresentam mais acordos do que divergências.

Tudda e Santos (2011) explicam que no ambiente organizacional contemporâneo, competitivo e caracterizado por constantes e rápidas mudanças, percebe-se que as organizações dependem da inovação e não somente de sua capacidade de adaptação e padronização. Portanto, o desenvolvimento da criatividade dos indivíduos da organização, aliado a um ambiente de implementação e transformação das ideias criativas em produtos, serviços ou práticas inovadoras, representa a manutenção de sua competitividade no mercado.

Silva e Rodrigues (2007) também afirmam que a criatividade, em razão de sua importância para as organizações, vem sendo um tema muito discutido no campo organizacional. Segundo as autoras, sua importância resulta das constantes e rápidas mudanças e competitividade que exigem que as empresas criem novas e melhores maneiras de enfrentar esses desafios.

Pesquisadores e profissionais interessados em aplicar os conhecimentos gerados sobre criatividade e inovação em suas organizações procuram formas cada vez mais adequadas para compreender o complexo fenômeno da criatividade nas organizações. Entretanto, segundo Mumford, Kimberly e Robledo (2012) nenhum método é uma descrição completa, adequada do desempenho criativo. Cada método tem pontos fortes e fracos que precisam ser considerados. Bruno-Faria (2010) explica que tal complexidade demanda estratégias metodológicas diversas para a sua compreensão, as quais devem contemplar aspectos relacionados àqueles que criam (indivíduos e grupos), ao ambiente de trabalho, assim como o ambiente externo que impacta no modo de atuação da organização.

Para Mumford, Kimberly e Robledo (2012), a natureza complexa dos fenômenos relacionados à criatividade e à inovação são acentuados por outros aspectos do fenômeno que 
operam em diferentes níveis de análise dentro da configuração organizacional. Portanto, a criatividade seria um fenômeno que deveria ser analisado de acordo com diferentes perspectivas para que se possa chegar perto de identificar e mensurar o fenômeno e as variáveis que a influenciam.

Realizando uma análise da produção acadêmica sobre criatividade de 1995 a 2009, James e Drown (2012) resumem o conteúdo empírico e conceitual analisado em um modelo multinível sobre a criatividade apresentado na Figura 3.

Figura 3 - Modelo Multinível de Criatividade Organizacional

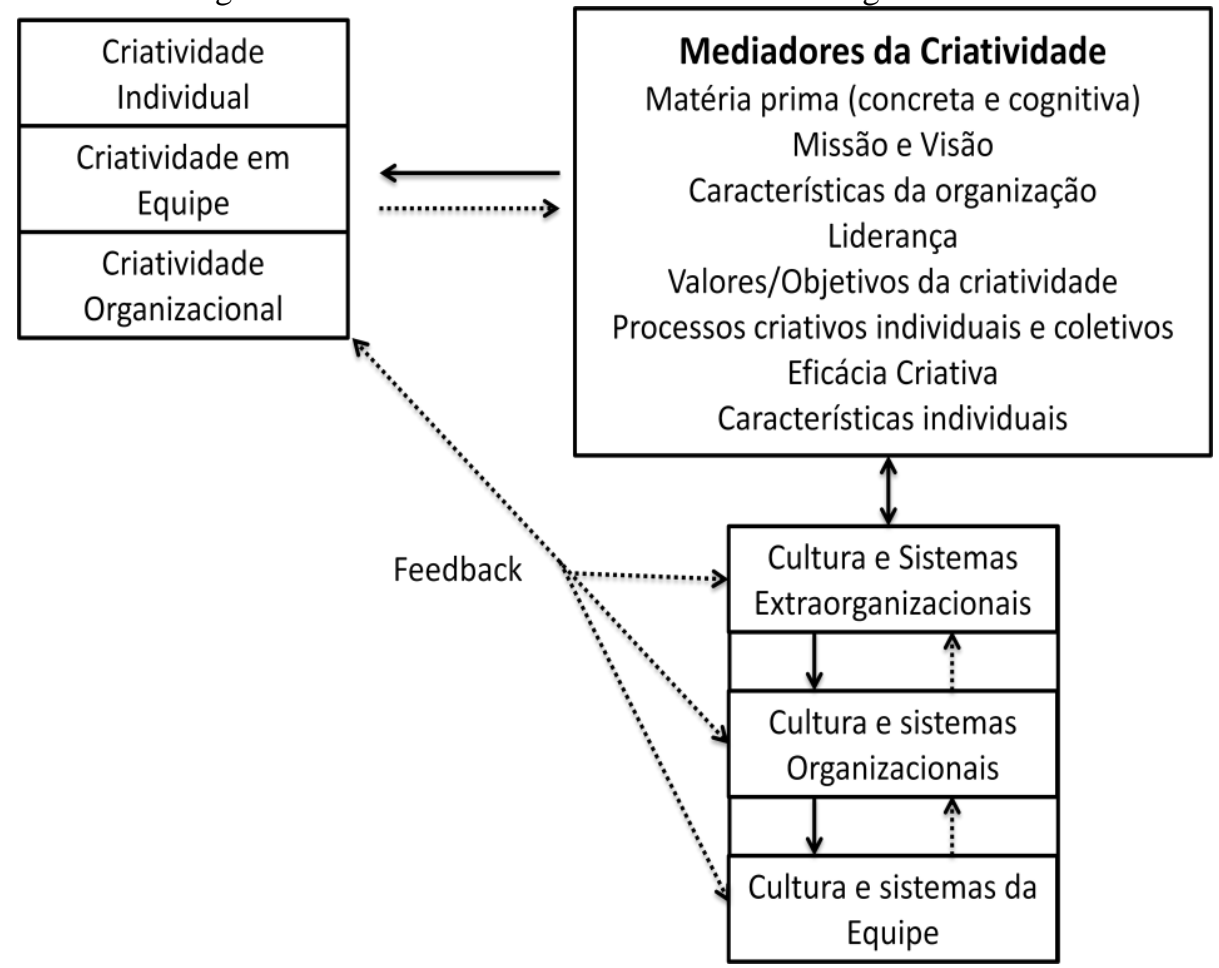

Fonte: James e Drown (2012, p. 19)

Analisando o modelo de James e Drown (2012), as diversas condicionantes da criatividade nas organizações podem ser agrupadas em três níveis de análise: individual, de grupo/equipe e organizacional. Como destacam os próprios autores, a criatividade não se desenvolve no vácuo, havendo uma interação com elementos externos da organização como sistemas e culturas que retroalimentam essa interação (JAMES; DROWN, 2012).

Segundo Robledo et al. (2012), historicamente a literatura em criatividade é tida como uma perspectiva do indivíduo. A partir da década de 80, com os estudos sobre a psicologia social da criatividade de Amabile, expandiram-se as pesquisas que contemplavam os aspectos do ambiente surgindo, assim, propostas que pudessem integrar os níveis do 
indivíduo, grupo e organização (BRUNO-FARIA; VEIGA; MACÊDO, 2008). Hennessey e Amabile (2010) enfatizam que mais progresso será feito na área quando mais pesquisadores reconhecerem que a criatividade surge por meio de um sistema de forças inter-relacionadas que operam em múltiplos níveis.

Zhou e Hoever (2014), em outra revisão sobre o tema, reconhecem essa evolução no sentido de tratar do fenômeno da criatividade em diferentes níveis de análise de forma interacionista, com foco principalmente na relação entre os atores com o ambiente de trabalho no qual atuam. Segundo esse enfoque, a criatividade seria o resultado de uma complexa interação de características estáveis ou transitórias de um ator, individual ou em equipe, com fatores contextuais (ZHOU; HOUVER, 2014).

Em ressonância com esse enfoque interacionista, Bruno-Faria (1996) ressalta que a criatividade nas organizações é um fenômeno multifacetado que envolve aspectos tanto do ambiente quanto do indivíduo, que desperta o interesse de diversos estudiosos, dada a sua importância no mundo atual, marcada pela mudança, pela incerteza e pela competição empresarial sem precedentes. Assim, as organizações se voltam para seus recursos e as condições em que atuam e buscam internamente transferir essa importância para o seu contexto. Destacam-se neste momento, as pessoas como promotoras desse potencial criativo.

Bruno-Faria e Alencar (1998) destacam que para enfrentar os novos desafios, as empresas necessitam contar com pessoas que façam uso de seu potencial criador no trabalho, apresentando novas ideias. Pessoas que se caracterizam pela iniciativa, independência de pensamento e ação, flexibilidade, persistência e autoconfiança têm maiores chances de aproveitar e desenvolver ideias criativas (ALENCAR, 1998). Entretanto, o foco deveria ser ampliado das características de personalidade dos indivíduos criativos para a análise do ambiente de trabalho. Bruno-Faria e Alencar (1996) apontam que dentre as condições necessárias para a manifestação da criatividade, destacam-se tanto fatores de natureza social e cultural quanto outros do próprio indivíduo. Tais fatores não constituem aspectos isolados, mas atuam de forma integrada e interativa.

Tudda e Santos (2011) explicam que a relação do indivíduo com as organizações acompanha mudanças observadas na humanidade que, cada vez mais, valoriza a interação sistêmica, complexa e holística. Mente e cérebro, interagindo de maneira complexa com o ambiente, traz à ciência uma demanda por multidisciplinaridade que destaca o papel da criatividade. Alencar (1996) observa que há uma influência recíproca entre esses dois grupos de fatores - organização e indivíduo - esquematizada na Figura 4. 
Figura 4 - Relações Organização-Indivíduo

\title{
Organização
}

\author{
Atitudes e comportamentos do indivíduo \\ influenciam e são influenciados pelo sistema \\ organizacional
}

Fonte: Alencar (1996, p.22).

Apesar de haver discursos sobre as condições inatas das pessoas criativas, segundo Horta (2006), a criatividade pode ser fomentada pelas organizações, sendo que, os resultados específicos do aumento dessa criatividade no trabalho podem ser identificados nos produtos novos e nos novos métodos que aumentam a eficiência. Motta (1995 apud SILVA; RODRIGUES, 2007) explica que o fato de alguns indivíduos estarem mais avançados do que outros no desenvolvimento de novas habilidades, não significa que os primeiros possuem qualidades criativas inatas. Em seus estudos na área, Terra (2000) conclui que é possível treinar as pessoas para que elas possam se tornar mais criativas e produtivas.

Bruno-Faria e Alencar (1996) apontam que desmitificando a criatividade como um atributo presente nos gênios ou iluminados, prevalece a concepção de que a criatividade seja um fenômeno universal, passível de desenvolvimento e que necessita de determinadas condições para se manifestar. Com isso, tornou-se primordial que as organizações criem condições para que os indivíduos possam expressar a criatividade no ambiente de trabalho. A seção a seguir trata dessa abordagem.

\subsubsection{Condições para Criar no Ambiente de Trabalho}

Rodrigues e Silva (1998) afirmam que é necessário que as organizações criem condições favoráveis a um ambiente de trabalho criativo para que a criatividade possa ser expressa e desenvolvida. Terra (2000) reafirma que as organizações deveriam se preocupar em oferecer tais condições que permitam aos indivíduos desenvolver seu potencial criativo. $\mathrm{O}$ conhecimento por parte da organização dos fatores influenciadores à criatividade proporciona 
oportunidades para que possa despertar a criatividade de seus membros e aproveitá-la da melhor maneira possível (RODRIGUES; SILVA, 1998).

Entretanto, o potencial criativo do indivíduo é muito pouco utilizado pela empresa por falta de mecanismos e estímulos adequados. Bruno-Faria (1996) explica que embora haja reconhecimento da necessidade de pessoas criativas nas organizações, é muito reduzido o número de pesquisas relativas a como tornar o ambiente de trabalho mais fecundo à expressão da criatividade. Para Terra (2000), a complexidade do tema talvez explique, mas não justifica, o fato do gerenciamento pró ativo da criatividade raramente ser uma das prioridades no mundo empresarial e acadêmico, apesar de sua importância. Mais recente, analisando a produção nacional, Moraes e Lima (2009) reforçam que apesar da relevância do tema, há poucas pesquisas empíricas sobre criatividade no trabalho.

Alencar (1998) expõe que muitas organizações tendem a ignorar o potencial para a competência, responsabilidade e produtividade, estimulando mais a dependência e a passividade do que a iniciativa e a criatividade. A falta de conhecimento, por parte de gestores e da própria organização, dos reais fatores que podem estimular ou inibir a expressão criativa dentro de cada organização está relacionada com a inadequação das ações tomadas para tornar o ambiente de trabalho mais propenso à criatividade. Para Silva e Rodrigues (2007) o conhecimento dos fatores influenciadores por parte da organização proporciona oportunidades para que esta possa estimular a criatividade de seus membros e aproveitá-la da melhor maneira possível.

Diversos são os fatores que levam uma organização a ter um ambiente favorável ou desfavorável à criatividade. $\mathrm{O}$ ambiente é apenas um dos fatores que influenciam a expressão da criatividade. Bruno-Faria e Alencar (1996) destacam o papel tanto fatores de natureza social e cultural quanto outros do próprio indivíduo, como os atributos de personalidade. Estes não constituem aspectos isolados, mas atuantes de forma integrada e interativa (BRUNO-FARIA; ALENCAR, 1996).

Alencar (1996) esclarece que ainda há outros fatores de natureza extraorganizacional que também atuam afetando o indivíduo e a organização tais como a competição entre outras empresas do mesmo setor, o espírito da época (zeitgeist), as oportunidades oferecidas pela sociedade de aprimoramento profissional, o grau de reconhecimento social às produções criativas e os valores comuns compartilhados pelos indivíduos de uma sociedade.

Por meio de estudos bibliográficos, Silva e Rodrigues (2007) realizaram uma síntese dos principais fatores influenciadores da criatividade dentro das organizações, segundo 
diversos autores que realizaram pesquisas sobre o tema, como apresentado de forma sintetizada no Quadro 9.

Quadro 9 - Principais Fatores Influenciadores da Criatividade

\begin{tabular}{|l|l|}
\hline \multicolumn{1}{|c|}{ Autores } & \multicolumn{1}{|c|}{ Principais fatores influenciadores da criatividade } \\
\hline VanGundy (1987) & Autonomia e liberdade; \\
& Justiça e adequação do sistema de recompensa; \\
& Apoio da organização às novas ideias; \\
& Aceitação das diferenças e interesse pela diversidade entre as pessoas; \\
& Reconhecimento das habilidades e esforços das pessoas; \\
& Apoio da alta gerência na criação de um clima criativo. \\
\hline \multirow{2}{*}{ Vasconcellos (1990) } & Flexibilidade da estrutura organizacional; \\
& Adequação do sistema de recompensas; \\
& Apoio da organização às ações criativas; \\
& Utilização de técnicas de incentivo à criatividade; \\
& Reconhecimento do potencial criativo das pessoas; \\
& Enfase no registro de ideias geradas por toda a organização; \\
& Adequação do layout; \\
& Enffase na formação de Círculos de Controle da Qualidade (CCQ); \\
& Envolvimento de pessoas com diferentes formações para realizarem \\
& projetos; \\
& Adequação da carga de trabalho. \\
\hline \multirow{2}{*}{ Amabile et al. (1989 apud } & Liberdade para decidir como realizar a tarefa; \\
BURNSIDE, 1990) & Recompensas e reconhecimento; \\
& Apoio da alta gerência às ideias criativas; \\
& Acesso a recursos apropriados; \\
& Trabalhos realizados em times; \\
& União, cooperação e confiança entre as pessoas e áreas; \\
& Comprometimento no trabalho; \\
& Desafio do trabalho; \\
& Receptividade às mudanças na execução tradicional das tarefas; \\
& Adequação dos sistemas de avaliação e feedback; \\
& Adequação do tempo para fazer o trabalho necessário. \\
\hline \multirow{2}{*}{ Bruno-Faria e Alencar (1996) } & Autonomia e liberdade; \\
& Salário e benefícios adequados; \\
& Apoio da organização (chefia e colegas) e da alta gerência; \\
& Flexibilidade e dinamismo da estrutura organizacional; \\
& Comunicações e relaçães interpessoais; \\
& Participação e treinamento do pessoal; \\
& Cultura organizacional que valorize a criatividade; \\
& Recursos tecnológicos e materiais; \\
& Adequação do ambiente físico; \\
& Adequacão do volume de serviços. \\
\hline & \\
&
\end{tabular}

Fonte: Silva e Rodrigues (2007, p.24).

Bruno-Faria, Veiga e Macedo (2008) chamam atenção para um aspecto relevante quando se tratam das condições propícias à criatividade. Segundo as autoras, nota-se que quase sempre o ambiente é tido como universal e, portanto, os estímulos e inibidores da criatividade são os mesmos para quaisquer tipos de indivíduos e organizações. Dessa forma, a 
interação entre elementos do indivíduo e do ambiente é negligenciada (BRUNO-FARIA; VEIGA; MACÊDO, 2008).

De acordo com Valentim (2008), a criatividade humana está relacionada com a necessidade de transcender os limites pré-estabelecidos. Neste caso, o ambiente poderia atuar como um estimulante ou um inibidor do processo criativo do indivíduo. Dessa forma, surge a ideia das barreiras e estímulos que são percebidos pelos funcionários dentro do ambiente de trabalho que podem inibir ou incentivar, respectivamente, a criatividade dos mesmos. Em suas pesquisas, Bruno-Faria e Alencar (1996), observaram que embora os indivíduos reconheçam a necessidade de estímulos à criatividade nos ambientes de trabalho, nem sempre se encontram tais estímulos nas organizações em que atuam. A pesquisa realizada pelas autoras evidenciou um conjunto de fatores facilitadores e bloqueadores da criatividade, presentes em diversas organizações. Dentre os facilitadores estão fatores como: suporte organizacional da chefia e dos colegas de trabalho, estrutura organizacional, liberdade e autonomia, salário e benefícios, ambiente físico e comunicação e participação. Já como bloqueadores estão: estrutura organizacional, características da chefia, relações interpessoais, cultura organizacional, comunicação, falta de recursos tecnológicos e materiais, ambiente físico, características da tarefa, influências político-administrativas, volume de serviços, falta de treinamento e salários e benefícios (BRUNO-FARIA; ALENCAR, 1996).

Ao longo das últimas décadas, a busca por instrumentos ou mecanismos que possam identificar, avaliar e fornecer informações consistentes sobre os fatores que influenciam na expressão da criatividade no ambiente de trabalho foi o objetivo de alguns autores especializados no tema. Segundo Bruno-Faria e Alencar (1996), vários foram os pesquisadores que desenvolveram instrumentos com a finalidade de identificar fatores do ambiente de trabalho que influenciam a criatividade. Poucos, porém, dedicaram-se ao estudo de estímulos e obstáculos à expressão criativa a partir de estudos empíricos e teóricos.

Procurando identificar os instrumentos disponíveis na literatura internacional, Mathisen e Einarsen (2004) apresentam uma revisão que considerou os seguintes critérios: (a) o instrumento deve avaliar a qualidade do ambiente social da organização em relação a criatividade ou inovação; (b) as características psicométricas devem ser disponibilizadas; (c) o instrumento deve estar disponível para estudos e uso comercial; e (d) deve ser descrito em um jornal internacional. Assim, os instrumentos encontrados foram os de Siegel e Kaemmerer (1978), Amabile et al. (1996), Ekvall (1996), Anderson e West (1998) e de Isaksen, Lauer e Ekvall (1999). 
O instrumento chamado de Escala de Apoio à Inovação de Siegel ${ }^{5}$ (Siegel Scale of Support for Innovation - SSSI), destaca três fatores característicos do clima das organizações inovadoras: suporte à criatividade, tolerância às diferenças e compromisso individual (SIEGEL; KAEMMERER, 1978).

O instrumento de Ekvall (1996), denominado Questionário de Clima Criativo (Creative Climate Questionnaire- CCO), se baseia em nove dimensões consideradas estímulos à criatividade: Desafio, liberdade, suporte para ideias, confiança/abertura, dinamismo/vivacidade, brincadeira/humor, debate, correr riscos e tempo para criar. Além dessas dimensões, Ekvall (1996) acrescenta uma décima dimensão, conflitos, que supostamente é negativamente relacionada com a criatividade. Em sua versão traduzida para a língua inglesa denominada Questionário de Perspectiva Situacional (Situational Outlook Questionaire - $S O Q$ ), a dimensão dinamismo/vivacidade foi retirada passando o instrumento a ser formado por nove dimensões (ISAKSEN; LAUER; EKVALL, 1999).

O Inventário de Clima de Equipe (Team Climate Inventory - TCI) proposto por Anderson e West (1998), é mais voltado para a avaliação do clima de inovação em trabalhos em grupo. As quatro dimensões avaliadas são relativas à visão, segurança participativa, orientação de tarefas e ao suporte para a inovação.

O instrumento desenvolvido por Amabile et al. (1996), denominado Avaliando o Ambiente de Trabalho para a Criatividade (Assessing the Work Environment for Creativity $K E Y S$ ), tem como foco as percepções individuais do ambiente de trabalho que influenciam a criatividade das organizações. Esse é composto por seis fatores que descrevem estímulos à criatividade - liberdade, trabalho desafiante, recursos suficientes, encorajamento do supervisor, suporte ao grupo de trabalho e encorajamento organizacional - dois fatores que descrevem obstáculos - impedimentos organizacionais e pressão no trabalho, - e duas escalas critério utilizadas para avaliar a criatividade e produtividade da organização.

Nas conclusões da revisão de Mathisen e Einarsen (2004), os autores elegem o instrumento KEYS de Amabile et al. (1996) como uma das medidas sobre criatividade de maior qualidade científica segundo os critérios analisados na revisão, além de ser melhor documentado do que os demais.

\footnotetext{
${ }^{5}$ Apesar da utilização do termo "Inovação", o instrumento envolve fatores relacionados à criatividade tendo esta como o principal fator de apoio à ação de inovar.
} 
Bruno-Faria e Alencar (1998) e Crespo (2004) destacam também um inventário desenvolvido por Rickards e Jones (1991) que visa avaliar especificamente distintas barreiras à criatividade. O instrumento, denominado Inventário Jones de Barreiras (The Jones Inventory of Barriers), objetiva identificar fatores inibidores do processo criativo e, por seus resultados, promover o autoconhecimento do empregado; pode ainda servir como veículo de desenvolvimento da organização. Os quatro fatores que estruturam a medida são relacionados à estratégia, valores, percepção e autoimagem (RICKARDS; JONES, 1991).

Com base nas pesquisas realizadas, Bruno-Faria e Alencar (1998) concluíram pela necessidade das organizações contarem com instrumentos que sirvam de medidor de seus ambientes para a criatividade. Considerando ainda que no Brasil ainda não haviam sido desenvolvidos instrumentos disponíveis com tal finalidade e aqueles existentes eram originários de outros países, com culturas diferentes e características diferenciadas de ambiente de trabalho, as autoras desenvolveram um instrumento de medida da percepção de estímulos e barreiras à criatividade no ambiente de trabalho, denominado Indicadores de Clima para a Criatividade (ICC) (BRUNO-FARIA; ALENCAR, 1998). Segundo Bruno-Faria (2010), acredita-se que, a partir da aplicação desse instrumento, possa ser realizado um diagnóstico das condições do ambiente de trabalho que favoreçam o planejamento de ações, com intuito de facilitar a expressão da criatividade de diferentes profissionais em diversas realidades de trabalho.

Para as etapas de construção do instrumento ICC, as autoras partiram de uma pesquisa preliminar com o objetivo de identificar estímulos e barreiras do ambiente de trabalho à expressão do potencial criador de profissionais de organizações diversas do Distrito Federal (BRUNO-FARIA; ALENCAR, 1996). O trabalho exploratório realizado por BrunoFaria e Alencar (1996) subsidiou a construção da medida publicada em 1998 pelas mesmas autoras. O conjunto de oito fatores de estimulo e quatro fatores de bloqueio à criatividade identificados coincidiu em sua maioria com aqueles ressaltados pelos teóricos da área como relevantes para a expressão da criatividade no ambiente de trabalho (BRUNO-FARIA; ALENCAR, 1998). Entretanto, foi destacado que embora os resultados das análises fatorial e de consistência interna tenham sido satisfatórias, seriam necessárias mais aplicações do instrumento, a fim de confirmar as estruturas fatoriais encontradas a partir das análises realizadas (BRUNO-FARIA; ALENCAR, 1998).

Revisando outros estudos nacionais preocupados com medidas capazes de avaliar o impacto do ambiente na expressão da criatividade no trabalho, dois outros instrumentos foram 
identificados sendo que apenas um deles foi validado estatisticamente. O primeiro deles, desenvolvido por Crespo (2004), foi intitulado Questionário de Indicadores de Clima para a Criatividade e é composto por 13 indicadores que buscam definir as variáveis de clima para a criatividade no trabalho. Os itens do instrumento se referem à: Motivação e Comprometimento, Dinamismo e Energia, Tempo para Ideias, Liberdade para Criar, Ludismo e Humor, Apoio às ideias, Discussão e Debates, Ausência de conflito, Confiança e Franqueza, Correr Risco, Suporte à inovação, Salários e Benefícios e Tolerância às Diferenças. Apesar dessas variáveis terem sido submetidas à avaliação de juízes e demonstrarem semelhanças com outros estudos da área, a escala não foi avaliada estatisticamente.

O segundo instrumento foi apresentado por Parolin et al. (2007) e teve como objetivo pesquisar a percepção das categorias que compõem as condições para que o processo criativo ocorra na organização. As categorias, levantadas a partir de uma abordagem sóciointeracionista, deram origem a cinco fatores que compõem o instrumento: Estímulo à criatividade, Relações interpessoais, Ambiente da tarefa, Pressão e Controle e Bloqueios à criatividade. Segundo os desenvolvedores da medida, os testes realizados e os níveis de confiabilidade alcançados comprovam a legitimidade do instrumento (PAROLIN et al., 2007), porém, sendo parte de um estudo maior, informações como a relação de itens não foram relatadas e a necessidade de revisão para novas aplicações destacada.

Por fim, seguindo os apontamentos destacados por Bruno-Faria (2010) sobre a necessidade de revalidação do instrumento ICC desenvolvido por Bruno-Faria e Alencar (1996; 1998), Bruno-Faria e Veiga (2015) desenvolveram uma nova medida chamada Indicadores de Condições para Criar no Ambiente de Trabalho (ICCAT). Dentre as propostas deste novo instrumento estavam as necessidades de reduzir o número de itens e acrescentar novos achados da literatura sobre o tema a partir da revalidação do ICC (BRUNO-FARIA; VEIGA, 2015).

O ICCAT é composto de duas escalas que avaliam as condições favoráveis e desfavoráveis à expressão da criatividade no ambiente de trabalho. Essa alteração na terminologia difere dos estímulos e barreiras avaliados pelo ICC dada a premissa de que "alguns aspectos do ambiente de trabalho, embora sejam desfavoráveis à expressão da criatividade, podem não se constituir em barreiras para que a criatividade ocorra" (BRUNOFARIA; VEIGA, 2015, p.495). 
Os fatores favoráveis à criatividade do instrumento ICCAT foram definidos operacionalmente e correspondem aos seguintes aspectos avaliados na primeira escala do instrumento (BRUNO-FARIA; VEIGA, 2015, p.496):

1. Suporte do Gerente Imediato: ações do gerente que apoiam e/ou estimulam a expressão da criatividade dos colaboradores no dia a dia de trabalho.

2. Atividades Desafiantes: tarefas que possibilitam a busca por novos conhecimentos, utilização de diversas competências, a possibilidade de oferecer novas soluções, que são valorizadas pelo próprio empregado.

3. Estratégias e Ações Organizacionais em Apoio a Ideias Novas: diferentes estratégias e ações organizacionais que estimulam e/ou facilitam a emergência de ideias novas no trabalho.

4. Clima Entre Colegas de trabalho: relacionamento que se estabelece entre os pares no ambiente de trabalho, caracterizado pelo incentivo e elogio à produção de ideias novas, ao reconhecimento do valor das ideias, à troca de informações e ao apoio mútuo.

5. Liberdade de Ação: sentimento de estar à vontade para opinar sobre o modo de realizar suas tarefas e expressar ideias diferentes no trabalho.

6. Características do Ambiente Físico: são condições essenciais do ambiente físico de trabalho (tais como luminosidade, espaço, equipamentos), necessárias para que o indivíduo possa se concentrar na realização de suas atividades e produzir ideias novas.

Como fatores desfavoráveis à criatividade foram definidos operacionalmente os seguintes aspectos que delimitam o escopo e elaboração dos itens da segunda escala do instrumento ICCAT (BRUNO-FARIA; VEIGA, 2015, p.497):

1. Atuação Inadequada do Gerente: ações do gestor que dificultam ou impedem o aparecimento de novas ideias dos indivíduos que compõem a equipe de trabalho.

2. Excesso de Serviço e Escassez de Tempo: relação entre o tempo e a quantidade de atividades a serem realizadas no trabalho, impedindo ou dificultando o surgimento de ideias novas e de valor.

3. Dificuldade de Comunicação e Rigidez das Normas e Regras na Organização: Obstáculos à troca de informações entre áreas e/ou setores da organização que dificultam a criatividade, grau elevado de padronização no modo de realizar as atividades e o excesso de regras existentes na organização que dificultam a expressão da criatividade dos trabalhadores.

Com base na revisão de literatura apresentada neste Capítulo, o capítulo seguinte tratará do delineamento da pesquisa. 


\section{DELINEAMENTO DE PESQUISA}

O delineamento da pesquisa que norteia o desenvolvimento do estudo proposto encontra-se dividido em objetivos geral e específicos, hipóteses de pesquisa e justificativas.

\subsection{Objetivos Geral e Específicos}

Este trabalho tem por objetivo geral identificar as relações existentes entre as condições para criar e o uso de estratégias de aprendizagem no ambiente de trabalho.

Para tanto, os objetivos específicos da pesquisa são:

1) Identificar evidências de validação da escala de estratégias de aprendizagem no trabalho;

2) Descrever as estratégias de aprendizagem utilizadas na Organização segundo a percepção de seus membros;

3) Identificar evidências de validação das escalas de condições para criar no trabalho;

4) Identificar fatores favoráveis e fatores desfavoráveis à expressão da criatividade na organização segundo a percepção de seus membros;

5) Analisar a correlação entre estratégias de aprendizagem e condições para criar no ambiente de trabalho.

A estrutura básica da pesquisa relacionando os objetivos mencionados pode ser ilustrada no modelo apresentado na Figura 5. 
Figura 5 - Estrutura da Pesquisa

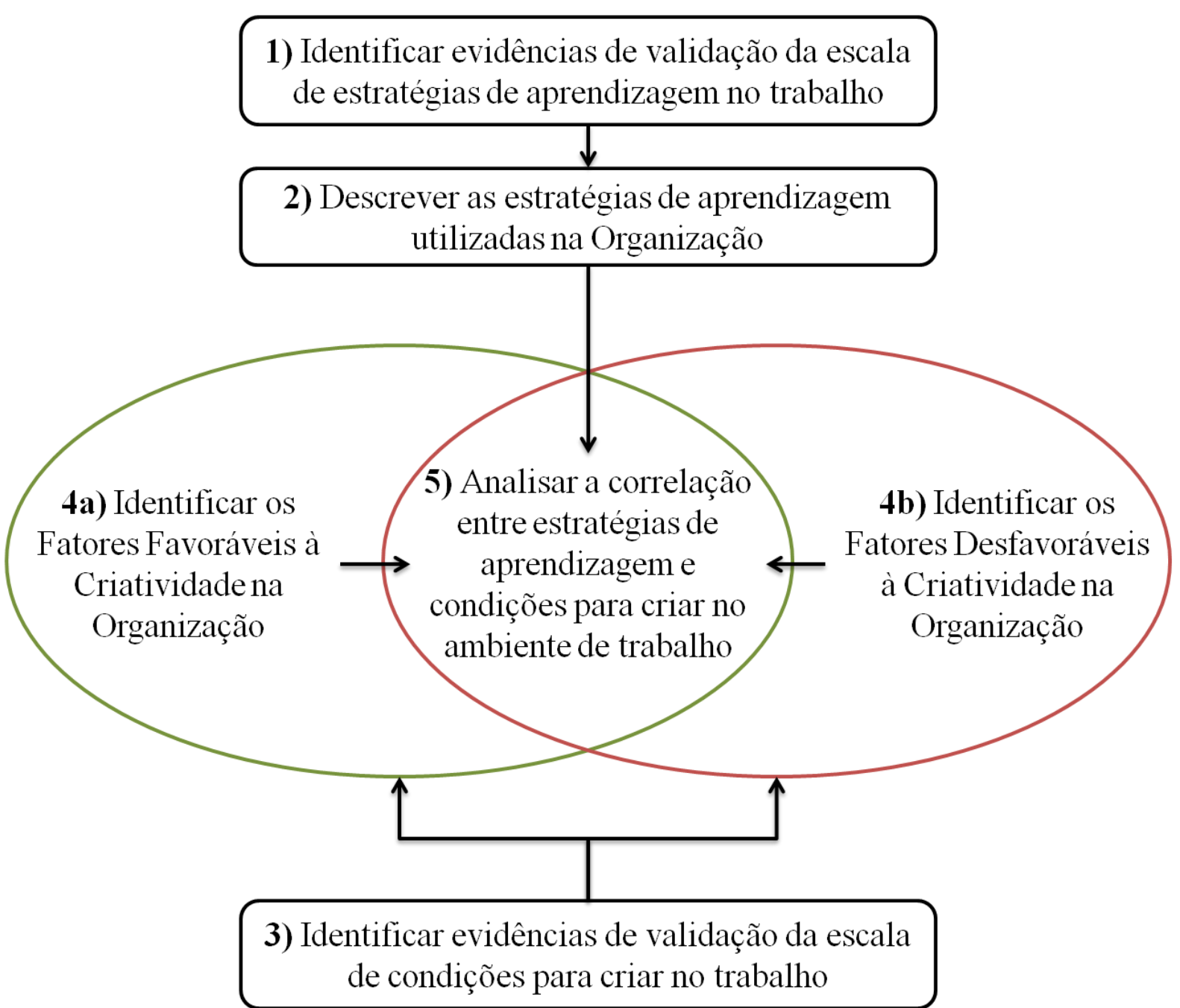

\subsection{Hipóteses da pesquisa}

A partir do referencial apresentado no capítulo anterior e tendo como base as estratégias de aprendizagem do modelo adotado para este projeto, de Brandão e BorgesAndrade (2011) e as condições para criar definidas por Bruno-Faria e Veiga (2015), as seguintes hipóteses de associações são levantadas, como esquematizado na Figura 6. 
Figura 6 - Hipóteses de Pesquisa

Condições Favoráveis

à Criatividade
Estratégias de

Aprendizagem
Fatores Desfavoráveis

à Criatividade

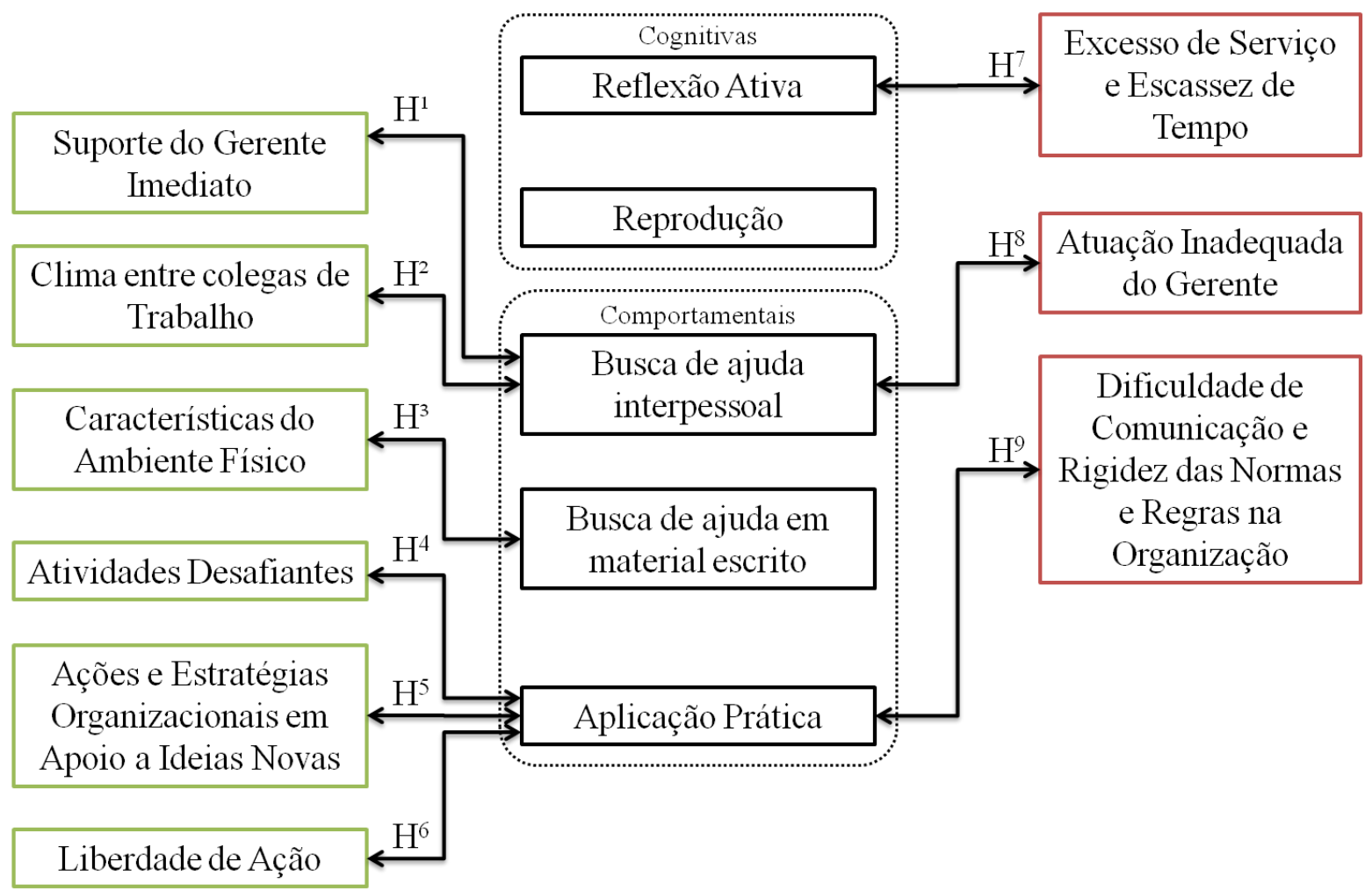

- $H^{1}$ : Condições favoráveis à criatividade referentes ao Suporte do Gerente Imediato estão relacionadas positivamente com a utilização de estratégias de aprendizagem de Busca de Ajuda Interpessoal.

- $H^{2}$ : Condições favoráveis à criatividade referentes ao Clima entre Colegas de Trabalho estão relacionadas positivamente com a utilização de estratégias de aprendizagem de Busca de Ajuda Interpessoal.

- $H^{3}$ : Condições favoráveis à criatividade referentes a Características do Ambiente Físico estão relacionadas positivamente com a utilização de estratégias de aprendizagem de Busca de Ajuda em Material Escrito.

- $H^{4}$ : Condições favoráveis à criatividade referentes a Atividades Desafiantes estão relacionadas positivamente com a utilização de estratégias de aprendizagem de Aplicação Prática.

- $H^{5}$ : Condições favoráveis à criatividade referentes a Ações e Estratégias Organizacionais em Apoio a Ideias Novas estão relacionadas positivamente com a utilização de estratégias de aprendizagem de Aplicação Prática. 
- $\quad H^{6}$ : Condições favoráveis à criatividade referentes a Liberdade de Ação estão relacionadas positivamente com a utilização de estratégias de aprendizagem de Aplicação Prática.

- $H^{7}$ : Condições desfavoráveis à criatividade referentes ao Excesso de Serviço e Escassez de Tempo estão relacionadas negativamente com a utilização de estratégias de aprendizagem de Reflexão Ativa.

- $H^{8}$ : Condições desfavoráveis à criatividade referentes a Atuação Inadequada do Gerente estão relacionadas negativamente com a utilização de estratégias de aprendizagem de Busca de Ajuda Interpessoal.

- $H^{9}$ : Condições desfavoráveis à criatividade referentes a Dificuldade de comunicação e rigidez das normas e regras na organização estão relacionadas negativamente com a utilização de estratégias de aprendizagem de Aplicação Prática.

Buscando evidências claras que justifiquem as hipóteses propostas com base na literatura pesquisada, é possível identificar que estudiosos, tanto de aprendizagem quanto de criatividade nas organizações, enfatizam aspectos influenciadores que oferecem indícios de relação entre as condições para criar no ambiente de trabalho e a utilização de estratégias de aprendizagem.

Propondo um modelo teórico para analisar o suporte à aprendizagem informal no trabalho, Coelho Junior e Mourão (2011) explicam que a literatura na área de aprendizagem nas organizações sustenta a premissa teórica de que o suporte psicossocial de chefias $\left(H^{I}\right)$ e pares $\left(H^{2}\right)$ ao uso de novas habilidades e inovação nas rotinas de trabalho dos indivíduos é importante variável de apoio à aprendizagem natural reforçando, inclusive, o comportamento de inovação dos empregados. Com base na literatura apresentada, entende-se o comportamento de inovação como as ações de expressão da criatividade por parte do indivíduo na busca pela inovação.

Pantoja e Borges-Andrade (2009) supõem em seu estudo que, para a sobrevivência e manutenção da organização, são necessários esforços no provimento do suporte necessário à ocorrência dos processos informais de aprendizagem, nos quais os indivíduos possam aprender trocando informações importantes com colegas mais experientes $\left(H^{2}\right)$, consultando boletins informativos e materiais na internet, entre outros meios $\left(H^{3}\right)$. Bruno-Faria e Alencar (1996), buscando identificar estímulos e barreiras à criatividade junto a diversos profissionais, 
relataram a disponibilidade de recursos matérias e tecnológicos como fatores físicos do ambiente que podem influenciar, também, na criatividade $\left(H^{3}\right)$.

Ainda sobre o suporte à aprendizagem informal, onde se inserem as estratégias de aprendizagem, Coelho Junior e Mourão (2011) afirmam que ambientes de aprendizagem individual, nas organizações, para serem eficazes, provavelmente deveriam incentivar a autonomia $\left(H^{6}\right)$ do empregado na busca por novas formas de executar seu trabalho. Da mesma forma, Alencar (1998), citando Amabile (1995), já destacava dentre as condições que facilitam a criatividade, um ambiente onde os indivíduos se sentem desafiados $\left(H^{4}\right)$, encorajados a correr riscos e apoiados em sua autonomia $\left(H^{6}\right)$.

Como relatado no capítulo introdutório, como citado por Coelho Junior e Mourão (2011), Andersen e Andersen (2007) e Pentland (1995) explicitam que a aprendizagem contínua dos empregados e a posterior aplicação de novas habilidades necessitam do apoio organizacional voltado à inovação, criatividade e experimentação $\left(H^{5}\right)$. Apoio esse percebido, por parte dos colaboradores, de que a organização está aberta a novas ideias e apoia mudanças benéficas (ALENCAR, 1995).

Em sua revisão crítica sobre pesquisas empíricas que abordam conjuntamente competências e aprendizagem no trabalho e nas organizações, Brandão (2008) destaca que talvez o principal espaço de aprendizagem dentro das organizações seja o próprio ambiente de trabalho. De acordo com Le Boterf (1999 apud BRANDÃO; BORGES-ANDRADE, 2011), o momento da reflexão $\left(H^{7}\right)$ como um dos elementos que tornam o ambiente de trabalho uma oportunidade de aprendizagem. Entretanto, esse mesmo ambiente de trabalho, com um excessivo volume de tarefas e pouco tempo para se dedicar a reflexão, pode ser impactante, tanto para a criatividade quanto para as práticas de aprendizagem $\left(H^{7}\right)$.

As similaridades entre as condições para criar e os fatores influenciadores de suporte à aprendizagem informal são evidências ainda mais contundentes sobre a possível relação estudada neste trabalho. Utilizando exemplos de comportamentos de ajuda mútua entre funcionários no ambiente de trabalho, Coelho Junior e Borges-Andrade (2008) argumentam que o suporte efetivo à aprendizagem surgiria dos colegas e pares do trabalho $\left(H^{2}\right)$, bem como da chefia imediata $\left(H^{I}\right)$ e da própria organização como um todo $\left(H^{5}\right)$, podendo impactar sensivelmente seus resultados e desempenho final. Os autores destacam ainda que o gestor de recursos humanos deve ser capaz de propor ações $\left(H^{5}\right)$ que incentivem a aprendizagem informal entre seus membros, favorecendo à aquisição de competências e ao desempenho no trabalho (COELHO JUNIOR; BORGES-ANDRADE, 2008). Entretanto, havendo uma 
atuação inadequada desse gestor, o desenvolvimento e expressão de competências essenciais para a organização, por parte de seus membros, pode ser prejudicada $\left(H^{8}\right)$. Ainda, havendo problemas organizacionais quanto ao volume excessivo e rigidez de regras e aversão a mudanças, mais barreiras podem ser observadas $\left(H^{9}\right)$.

Por fim, buscando exemplificar a maior parte das hipóteses aqui apresentadas, faz-se uso da agenda de pesquisa proposta por Brandão e Borges Andrade (2011) que apontam a necessidade de examinar em que medida características da equipe de trabalho (como o clima organizacional $\left[H^{I}\right]$ e o suporte gerencial $\left[H^{2}\right.$ e $\left.H^{8}\right]$, por exemplo) e da natureza deste trabalho (como autonomia $\left[H^{6}\right]$, significado, liberdade, importância atribuída $\left[H^{4}\right]$, processos e tecnologias utilizados $\left[H^{3}\right]$ ) influenciam a utilização de estratégias de aprendizagem no trabalho e seus resultados.

Outros tipos de combinações entre os fatores também podem representar possíveis relações. Entretanto, não se julgou razoável identificar na literatura todas as possibilidades de interação entre os dois temas antes da realização da pesquisa. As nove hipóteses sugeridas serviram de escopo inicial de análise, sendo relatados ao final do estudo outros resultados encontrados.

\subsection{Justificativas}

Os gestores precisam conhecer quais são os recursos de que suas organizações dispõem e, principalmente, dos fatores que podem provocar ou impulsionar o uso desses recursos de modo a obter um resultado diferenciado. É importante ter o conhecimento sobre as fontes que podem gerar ganhos para a empresa, além dos aspectos que potencializam ou impedem que a organização obtenha sucesso no alcance dos seus objetivos. Além disso, a compreensão da interação e possíveis impactos entre esses recursos parece ser outra preocupação que também deve ser conhecida pela organização. Assim, a compreensão por parte de gestores e estudiosos na área da relação entre a aprendizagem e as condições para criar nesse contexto se mostra de grande valia. Tratando do papel das lideranças organizacionais, Parolin (2003) explica que a relação da aprendizagem na organização com a importância do ambiente para a expansão da criatividade faz com que os gestores se tornem responsáveis pela qualidade do ambiente de trabalho e pela transmissão de uma visão orientadora aos seus funcionários. 
A capacidade de aprender no trabalho, atrelada à expressão da criatividade dos indivíduos em seu contexto profissional, pode contribuir não somente para a organização como para os próprios trabalhadores quando se tratam de elementos como empregabilidade e retenção de mão de obra qualificada. Parrolin et al. (2007) destacam a crescente relevância do clima organizacional favorável tanto para a manifestação da criatividade quanto para a aprendizagem no que diz respeito à retenção de talentos e no alcance de resultados competitivos em inovação.

A iniciativa de produzir conhecimentos científicos sobre estratégias adotadas pelos indivíduos para aprender no trabalho e suas possíveis variáveis influenciadoras, incluídas características da organização do trabalho, pode ser útil e oportuna. Considerando inclusive um contexto de trabalho que demanda ações contínuas de desenvolvimento, por parte dos trabalhadores, para que possam manter sua empregabilidade (PANTOJA; BORGESANDRADE, 2009; CARVALHO-SILVA, 2008).

Souza (2009) explica que o foco da competitividade e da empregabilidade está centrado no indivíduo, cuja aprendizagem pode ser influenciada por variáveis individuais e variáveis organizacionais. Cabe procurar neste estudo, portanto, evidências de como as condições para criar oferecidas no ambiente de trabalho da organização podem influenciar nas estratégias de aprendizagem empregadas pelo funcionário que buscam a manutenção de sua empregabilidade ou permanência em uma área ou organização.

Analisando a produção acadêmica sobre ambos os fenômenos, podem ser evidenciados relatos de que, apesar do reconhecimento da importância, ainda não são satisfatórios os estudos em determinados aspectos de cada construto. Analisando a literatura sobre estratégias de aprendizagem no trabalho, Pantoja e Borges-Andrade (2009) mostram que embora haja estudos científicos do tema na área educacional, poucos esforços de pesquisa vêm sendo desenvolvidos para investigação dessa variável no campo organizacional. Carvalho-Silva (2008) corrobora explicando que há muito a área de educação tem dedicado especial atenção a essa temática e são poucos os estudos que buscam entender, conceituar e operacionaliza-la no campo da organizacional e do trabalho.

Da mesma forma, em um estudo sobre a produção científica nacional em periódicos e livros de administração e psicologia, Bruno-Faria, Veiga e Macêdo (2008) argumentam que: se constatou um aumento substancial na produção científica sobre criatividade nas organizações nos últimos 10 anos onde predominam estudos no campo da Administração, embora com uma carência de abordagens teóricas produzidas no país e a predominância de 
estudos descritivos e exploratórios. As autoras destacam a necessidade de mais estudos em diversos temas na área, como criatividade em grupo e medidas de criatividade no contexto organizacional e sugerem investigações sobre a relação entre criatividade e variáveis individuais (BRUNO-FARIA; VEIGA; MACÊDO, 2008). Portanto, este trabalho procura contribuir para os estudos de ambas as áreas no sentido de buscas abordagens ainda não evidenciadas na literatura, como a relação entre as estratégias informais de aprendizagem e as condicionantes da expressão criativa nas organizações.

Para contribuir com os avanços na área, procurou-se trabalhar de forma embasada e congruente com pesquisas de destaque sobre os temas aqui estudados. Para tanto, buscou-se dar continuidade a agendas de pesquisa que propõem o avanço nos estudos sobre a relação das Estratégias de Aprendizagem e Condições para Criar com outras variáveis do contexto organizacional. No desenvolvimento do instrumento ICCAT, Bruno-Faria e Veiga (2015) destacam a importância da medida para a avaliação das condições para criar no ambiente de trabalho contribuindo tanto para práticas organizacionais como para o surgimento de novos estudos a partir da análise da relação com diferentes construtos. Moraes e Borges-Andrade (2010b) ao validarem uma das adaptações da medida de Brandão (2009), que culminou no instrumento publicado por Brandão e Borges-Andrade (2011), apontam que estudos acerca das relações entre as variáveis de estratégias de aprendizagem e outras relativas tanto ao próprio indivíduo quanto ao contexto de trabalho passam a ter maior relevância.

Além disso, tratando especificamente das escalas sobre estratégias de aprendizagem e condições para criar no ambiente de trabalho, este estudo tem em seus objetivos a identificação de evidências de validade dos instrumentos voltados para cada constructo, considerados pertinentes para os avanços nas respectivas áreas.

Em Estratégias de Aprendizagem, Moraes e Borges-Andrade (2010a) explicam que para que essa linha de estudos possa ter continuidade, é preciso desenvolver medidas confiáveis de estratégias de aprendizagem no trabalho. Revisando trabalhos com esta finalidade no período de 1998 à 2009, os autores apontam indícios cada vez mais consistentes de uma busca por medidas confiáveis (MORAES; BORGES-ANDRADE, 2010a).

Brandão e Borges-Andrade (2011) no trabalho de construção e validação da escala de Estratégias de Aprendizagem, sugerem verificar a manutenção da estrutura fatorial proposta em estudos conduzidos em outras organizações diferentes da indústria bancária. De forma semelhante, Bruno-Faria e Veiga (2015) recomendam para estudos futuros que o 
instrumento ICCAT seja aplicado em outras amostras para verificar se a estrutura fatorial é mantida.

No trabalho de Bruno-Faria (2010), ao tratar ainda do instrumento ICC, a autora explica que a construção de medidas é uma forma de possibilitar a avaliação de aspectos que contribuem para o gerenciamento do trabalho, assim como para disponibilizar um instrumento que possa ser útil para o desenvolvimento de diferentes pesquisas. Assim, este trabalho pode contribuir para o desenvolvimento de ambas as áreas de pesquisa que buscam avançar no propósito construção e aplicação de técnicas de pesquisa em novos estudos.

O próximo capítulo detalhará a metodologia empregada para o desenvolvimento desta pesquisa. 


\section{METODOLOGIA DE PESQUISA}

Este Capítulo destina-se a descrever a pesquisa realizada. Partindo de uma descrição geral do tipo da pesquisa e estratégias adotadas, é feita a caracterização da organização escolhida para a pesquisa, bem como definidas a população e amostra com as devidas justificativas. São descritos também os instrumentos utilizados e os procedimentos adotados para a coleta e análise dos dados obtidos.

\subsection{Tipo de Pesquisa}

O estudo realizado pode ser classificado como de natureza descritiva correlacional. Segundo a taxonomia adotada por Vergara (2005), pesquisas dessa natureza expõem características de determinada população ou fenômeno podendo estabelecer correlações entre variáveis e definir sua natureza. Por se tratar de uma pesquisa cuja intenção é identificar associações entre estratégias de aprendizagem e condições para criar no contexto do trabalho, esse enquadramento como correlacional se justifica dado ao não compromisso de explicar o fenômeno que se procura descrever, embora sirva de base para tal explicação (VERGARA, 2005).

O delineamento da pesquisa tem como abordagem principal o emprego de métodos quantitativos de coleta de dados. Essa escolha se dá pela oportunidade apresentada de utilização de instrumentos estatísticos evidenciados na literatura que podem identificar e posteriormente correlacionar as variáveis de interesse: estratégias de aprendizagem e condições para criar. O método utilizado se baseia no levantamento de dados ou survey que segundo Gil (2002) é caracterizado pela interrogação direta das pessoas cujo comportamento se deseja conhecer e, mediante análise quantitativa, são obtidas conclusões correspondentes aos dados coletados.

Quanto aos meios de investigação, a pesquisa caracteriza-se como de campo por se tratar de uma investigação empírica realizada no local onde ocorre o fenômeno ou que dispõe de elementos para explicá-lo (VERGARA, 2005). Alinhado ao delineamento de pesquisa e a abordagem adotada, a pesquisa de campo contribui por ser possível a utilização dos 
instrumentos de investigação adequados como a aplicação de questionários (VERGARA, 2005).

Os dados foram coletados com os próprios indivíduos que identificam o uso de estratégias de aprendizagem no trabalho e as condições que influenciam a expressão de sua criatividade. Assim, a pesquisa utilizou dados primários. Cabe ressaltar que o procedimento de coleta de dados ocorreu em um momento especifico figurando um retrato da situação atual da organização pesquisada. Portanto, trata-se de uma pesquisa de corte transversal.

As duas próximas seções tratam das informações sobre a organização e a definição da população e amostra deste estudo.

\subsection{Caracterização da Organização}

As organizações escolhidas para este estudo foram as Associações Atléticas Banco do Brasil (AABBs), classificadas como clubes esportivos de lazer vinculadas ao Banco do Brasil S/A. São entidades sem fins lucrativos e de vida jurídica própria que oferecem serviços de entretenimento ligados a práticas esportivas, culturais e de lazer a seus associados. São exemplos de serviços oferecidos nos clubes: festas e eventos sociais, atividades de música e artes, a prática de diversas modalidades esportivas, disponibilização de áreas para lazer em geral (parque aquático, churrasqueira, quadras e campos de esporte, náutica, etc.), além da prestação de serviços à comunidade.

Algumas justificativas para a escolha destas organizações podem ser elencadas.

Criadas com o objetivo de oferecer atividades de lazer aos funcionários do Banco do Brasil, as primeiras AABBs surgiram há cerca de 87 anos. Estão presentes em todos os estados brasileiros e em mais de 800 municípios. Segundo informações do sítio oficial da Federação das AABBs (FENABB), esta é a maior rede de clubes ligada a uma única empresa brasileira, sendo desconhecida ainda uma rede com dimensões semelhantes no mundo.

As AABBs possuem como sócios efetivos os próprios funcionários, da ativa ou aposentados, do Banco do Brasil. Além destes, os clubes possuem outras categorizações de associados como os comunitários e parentes que não pertencem ao quadro funcional do Banco, mas que possuem ligação com este. Parentes de funcionários, pessoas ligadas a programas sociais do Banco do Brasil e a comunidade próxima são exemplos de sócios de outras categorias. Segundo dados fornecidos pela FENABB, juntas, as AABBs contabilizaram 
em 2015 cerca de 262 mil associados em todo Brasil. Para tanto, empregam mais de quatro mil funcionários em toda a rede de clubes.

Tendo em vista os dados levantados e dada sua robustez e representatividade como um conjunto de organizações estabelecidas no mercado nacional, julgou-se inicialmente uma opção válida para este estudo. Em seu trabalho sobre alinhamento organizacional em um clube social esportivo, Cruz Junior, Carvalho e Laurindo (2005) argumentam que os clubes são organizações representativas na sociedade, apesar de não serem associadas a grandes prestadores de serviço, pois empregam grandes contingentes de pessoas que trabalham em jornadas extensas de serviço durante todo o ano.

Além dos clubes propriamente ditos, o "Sistema AABB" é formado ainda por Conselhos Estaduais (CESABBs) e pela Federação Nacional das AABBs (FENABB). Essas entidades têm como função básica coordenar as ações entre as AABBs e as ações destas com o Banco do Brasil e com a sociedade em geral. Dada essa função administrativa, a FENABB, com apoio dos conselhos de cada estado, reúne periodicamente informações sobre as AABBs e consolidam em banco de dados próprio. Este banco, bem como outros documentos internos que tratam sobre a organização escolhida, foram disponibilizados para consulta e realização da pesquisa.

Cada clube possui uma administração própria e independente das demais. Entretanto, seguem um estatuto e regimentos internos baseados no modelo proposto pela federação e, dependendo de seu porte, devem possuir uma estrutura organizacional padronizada, salvo adaptações locais previamente autorizadas. A hierarquia de uma AABB de médio e grande porte pode ser exemplificada na figura do presidente, seguida dos vice-presidentes financeiro, administrativo, além de outros tipos de vice-presidentes de acordo com a necessidade do clube, cargos intermediários de gerente e supervisor e, por fim, do corpo técnico/administrativo. A Figura 7 apresenta essa representação hierárquica. 
Figura 7 - Modelo de Estrutura Hierárquica de uma AABB

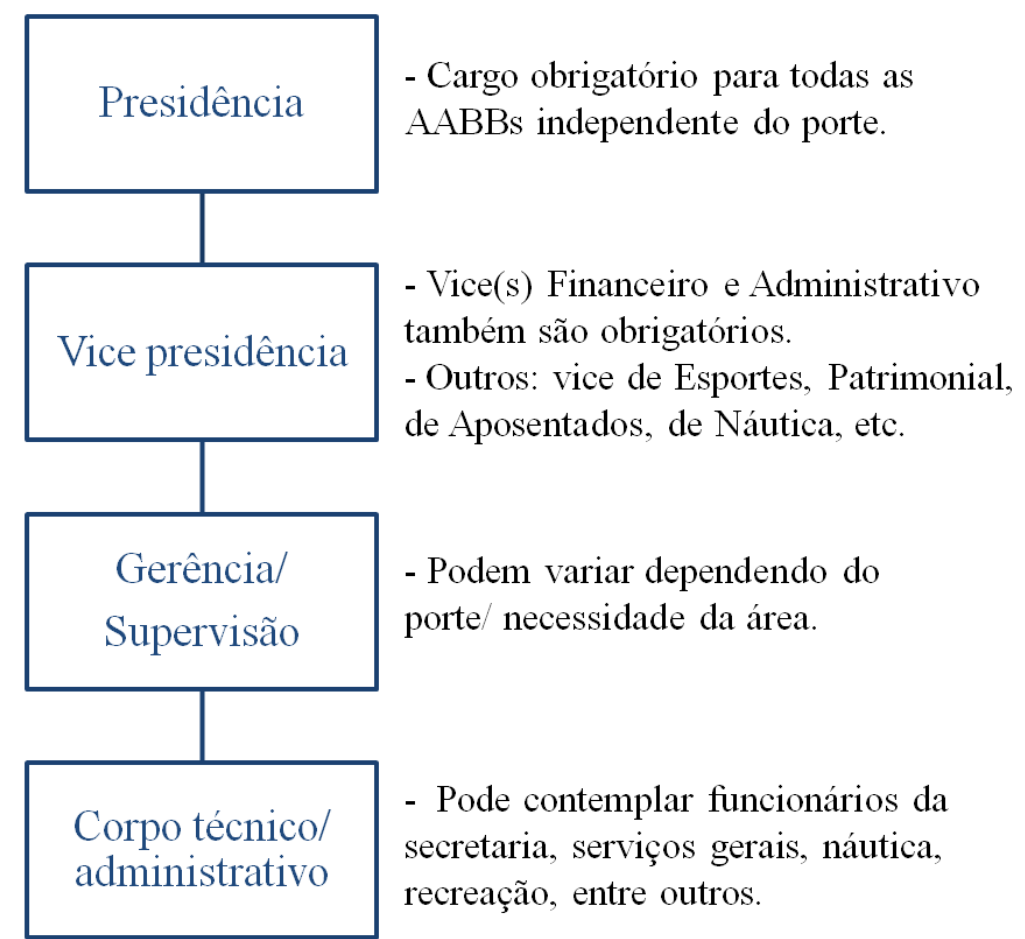

Fonte: Próprio Autor com base nos modelos de Estatuto e Regimento Interno propostos pela FENABB

Apesar de haver a possibilidade de diferenças entre as unidades do sistema AABB quanto ao modelo apresentado na Figura 7, considerando o padrão de estrutura e gestão organizacional adotado na organização, é esperado que o modelo represente adequadamente as múltiplas unidades da organização.

O serviço oferecido pelos clubes faz parte do ramo de atividades ligadas ao lazer e entretenimento. Esse segmento compreende múltiplos serviços e produtos semelhantes ou substitutos entre si voltados para esse propósito recreativo. Assim, não somente outras redes de clubes esportivos, mas academias, shoppings, parques, condomínios com áreas de lazer coletiva e diversos outros tipos de organizações concorrem potencialmente com o Sistema AABB. Cruz Junior, Carvalho e Laurindo (2005) destacam que principalmente os clubes situados nos grandes centros urbanos vivem nesse ambiente turbulento e competitivo, tanto que, muitas vezes, se associam em entidades para trocar experiências. Esse ambiente múltiplo e diversificado se mostra um grande desafio enfrentado por todas as AABBs que, apesar de pertencerem ao terceiro setor, se sustentam com base nos recursos providos pelos seus serviços. Assim, a necessidade de se tornarem diversificadas e competitivas aproxima as AABBs dos propósitos apresentados para a realização deste estudo sobre criatividade e aprendizagem visto que, segundo Souza (2009), demandas por diversidade de produtos e 
serviços com qualidade e baixo custo, obrigam, de um lado, as organizações a investirem na qualificação de trabalhadores e, do outro, trabalhadores a desenvolverem estratégias, com ou sem suporte organizacional, para aprender novas formas de executar atividades ou produzir novos produtos.

De acordo com as justificativas apresentadas neste trabalho da necessidade dos gestores em conhecer os recursos disponíveis em uma organização, os fatores que os influenciam e a interação entre eles, a pesquisa realizada se mostra de grande utilidade prática para o Sistema AABB. Entender os mecanismos informais de aprendizagem empregados por sua força de trabalho, os aspectos que influenciam na expressão da criatividade no ambiente de trabalho das AABBs e as relações que podem influenciar estes dois fenômenos de forma conjunta representam um passo importante para a obtenção de ganhos de inovação e desempenho para essas organizações.

\subsection{População e Amostra}

A população pesquisada é composta de funcionários efetivos de todas as AABBs que compõem a rede de clubes. Não foram considerados os funcionários de empresas terceirizadas que executam serviços de qualquer natureza para os clubes. Segundo dados do ano de 2015 fornecidos pela federação das AABBs (FENABB), o quadro efetivo totalizou 4.693 funcionários distribuídos em 859 AABBs de diferentes municípios em todos os estados brasileiros. O Quadro 10 apresenta um panorama da proporção de funcionários e associados de acordo com o porte e localização dos clubes, segundo dados da FENABB.

Quadro 10 - Perfil da População

\begin{tabular}{|l|c|c|}
\hline \multicolumn{1}{|c|}{ Estratificação pelo porte do clube: } & $\mathbf{N}^{\mathbf{0}}$ de associados: & $\mathbf{N}^{\mathbf{0}}$ de funcionários: \\
\hline Clubes de pequeno porte (58\%) & $38.200(15 \%)$ & $626(13 \%)$ \\
\hline Clubes de médio porte (36\%) & $124.961(48 \%)$ & $1.752(37 \%)$ \\
\hline Clubes de grande porte (6\%) & $98.857(38 \%)$ & $2.315(49 \%)$ \\
\hline Estratificação pela localização do clube: & $\mathbf{N}^{\mathbf{0}}$ de associados: & $\mathbf{N}^{\mathbf{0}}$ de funcionários: \\
\hline Sul (30\%) & $45.997(18 \%)$ & $687(15 \%)$ \\
\hline Sudeste (26\%) & $65.455(25 \%)$ & $1.681(36 \%)$ \\
\hline Nordeste (25\%) & $80.401(30 \%)$ & $1.290(27 \%)$ \\
\hline Centro-Oeste (13\%) & $41.622(16 \%)$ & $737(15 \%)$ \\
\hline Norte (5\%) & $28.543(11 \%)$ & $308(7 \%)$ \\
\hline
\end{tabular}

Fonte: Próprio Autor com base no dados fornecidos pela FENABB 
O critério de definição do tamanho da amostra se deu de forma probabilística, porém a amostra se caracterizou ser por conveniência, dado que a participação dos pesquisados se deu por disponibilidade e facilidade de acesso (VERGARA, 2005).

Findo o prazo de coleta de questionários, 220 participações foram registradas representando um total de 4,69\% da população de funcionários definida para este estudo. Após a realização dos procedimentos de exclusão e tratamento dos dados, 198 questionários foram considerados válidos e compuseram a amostra da pesquisa.

Na seção seguinte são apresentadas as informações sobre os instrumentos de medida utilizados.

\subsection{Instrumento de medida}

Dois instrumentos foram utilizados neste estudo. Um voltado para identificar as estratégias de aprendizagem utilizadas pelos indivíduos no contexto de trabalho e outro para identificar os fatores favoráveis e desfavoráveis à expressão da criatividade nesse mesmo contexto. As características de cada instrumento estão apresentadas a seguir.

O instrumento utilizado para identificar a utilização de estratégias de aprendizagem no contexto do trabalho consiste na escala desenvolvida por Brandão e Borges-Andrade (2011). Além das justificativas sobre a escolha da relação de estratégias de aprendizagem apresentadas no referencial teórico, outros requisitos foram considerados. Os estudos na área,

principalmente aqueles voltados ao desenvolvimento de escalas, demonstram um embasamento referencial majoritariamente pautado sobre os estudos seminais de Warr e Allan (1998), Warr e Downing (2000) e Holman, Epitropaki e Fernie (2001). Portanto, a escala escolhida para este trabalho seguiu o mesmo embasamento, sendo utilizada uma das escalas identificadas no Quadro 7 apresentado anteriormente.

Complementando a análise, a escala selecionada atende aos requisitos mínimos de confiabilidade estatística praticados com bons índices de consistência interna variando entre 0,79 e 0,92 (Alfa de Cronbach) e possibilita o estudo correlacional com o instrumento que analisa as condições para criar.

A escala de Brandão e Borges-Andrade (2011) desenvolvida para identificar a frequência com que as estratégias de aprendizagem no trabalho são utilizadas é composta por 26 itens distribuídos em 5 fatores respondidos em escala de concordância, variando de 1 
(Nunca faço) a 10 (sempre faço). Os fatores e seus respectivos itens são apresentados na Tabela 1 e o questionário utilizado com a descrição de cada item da escala encontra-se no Apêndice A.

Tabela 1 - Fatores e Itens do Instrumento sobre Estratégias de Aprendizagem no Trabalho

\begin{tabular}{l|c|c|l}
\hline \multicolumn{1}{c|}{ Fatores } & Alfa( $\boldsymbol{\alpha})$ & $\mathbf{N}^{\mathbf{0}}$ de itens & \multicolumn{1}{c}{ Itens } \\
\hline Reflexão Ativa & 0,92 & 9 & $18,22,26,25,10,21,9,17$ e 6 \\
\hline Busca de Ajuda Interpessoal & 0,88 & 5 & $20,1,13,19$ e 2 \\
\hline $\begin{array}{l}\text { Busca de Ajuda em Material } \\
\text { Escrito }\end{array}$ & 0,79 & 5 & $12,15,11,16$ e 14 \\
\hline Reprodução & 0,79 & 4 & $7,5,8$ e 4 \\
\hline Aplicação Prática & 0,82 & 3 & 3,23 e 24 \\
\hline
\end{tabular}

Fonte: Brandão e Borges-Andrade (2011, p.453)

O instrumento utilizado para identificar os fatores favoráveis e desfavoráveis à expressão da criatividade no contexto pesquisado trata-se das escalas desenvolvidas por Bruno-Faria e Veiga (2015) chamado Indicadores de Condições para Criar no Ambiente de Trabalho (ICCAT). A escolha dessa ferramenta se deu pela intenção de fazer uso de uma escala validada estatisticamente no contexto nacional que possuísse bons índices de confiabilidade, no caso com Alfa de Cronbach entre 0,74 e 0,92, e que pudesse ser utilizada em diferentes contextos organizacionais. Segundo Bruno-Faria e Alencar (1998) que idealizaram os primeiros moldes para a elaboração do ICCAT, o instrumento destina-se a empregados de todos os níveis de qualquer organização.

O instrumento de Bruno-Faria e Veiga (2015) é constituído de duas escalas Likert de concordância variando de 1 (Discordo pouco) à 5 (Concordo Plenamente). A primeira escala é composta de 36 itens divididos em seis fatores de aspectos favoráveis à criatividade. A segunda escala, composta de 24 itens, é dividida em três fatores de aspectos desfavoráveis à criatividade no ambiente de trabalho. Os fatores e seus respectivos itens estão elencados na Tabela 2.

Tabela 2 - Fatores e Itens do Instrumento Indicador de Condições para Criar no Ambiente de Trabalho (ICCAT)

\begin{tabular}{l|c|c|c}
\multicolumn{1}{c|}{ Fatores Favoráveis } & $\mathbf{A l f a ( \alpha )}$ & $\mathbf{N}^{\mathbf{0}}$ de itens & \multicolumn{1}{c}{ Itens } \\
\hline Suporte do Gerente Imediato & 0,92 & 6 & $15,20,23,14,6$ e 32 \\
\hline Atividades Desafiantes & 0,87 & 6 & $35,34,17,21,54$ e 5 \\
\hline $\begin{array}{l}\text { Ações Estratégias } \\
\text { Organizacionais em Apoio a Ideias } \\
\text { Novas }\end{array}$ & 0,83 & 7 & $9,51,33,55,16,22$ e 47 \\
\hline Clima Entre Colegas de trabalho & 0,87 & 6 & $19,39,18,42,2$ e 37 \\
\hline Liberdade de Ação & 0,89 & 5 & $4,3,36,41$ e 53 \\
\hline Características do Ambiente Físico & 0,74 & 6 & $40,46,52,1,60,38$ \\
\hline
\end{tabular}




\begin{tabular}{l|c|c|c}
\hline \multicolumn{1}{c|}{ Fatores Desfavoráveis } & Alfa( $\boldsymbol{\alpha})$ & $\mathbf{N}^{\mathbf{0}}$ de itens & \multicolumn{1}{c}{ Itens } \\
\hline Atuação Inadequada do Gerente & 0,88 & 9 & $25,26,44,31,48,12,27,57$ e 8 \\
\hline $\begin{array}{l}\text { Dificuldades de comunicação e } \\
\text { rigidez das normas e regras na } \\
\text { organização }\end{array}$ & 0,87 & 9 & $30,29,59,58,45,28,49,11$ e 10 \\
\hline $\begin{array}{l}\text { Excesso de Serviço e Escassez de } \\
\text { Tempo }\end{array}$ & 0,84 & 6 & $24,13,50,7,56$ e 43 \\
\hline Fonte: Bruno-Faria e Veiga (2015, p.499-501)
\end{tabular}

A relação descrita dos itens do ICCAT encontra-se no questionário no Apêndice A deste trabalho. Seguindo as orientações de Bruno-Faria e Veiga (2015), os itens dos fatores favoráveis e desfavoráveis à criatividade foram unidos desordenadamente para assim aferir os aspectos simultaneamente visto que ambos são dinâmicos e inter-relacionados.

$\mathrm{O}$ questionário utilizado para a coleta de dados foi dividido em quatro partes. $\mathrm{Na}$ primeira parte foi feita uma apresentação da pesquisa com instruções de preenchimento, informações sobre critérios de confidencialidade e termo de consentimento livre e esclarecido. As duas partes seguintes do questionário continham as escalas de Brandão e Borges-Andrade (2011) e de Bruno-Faria e Veiga (2015), acompanhados de instruções de preenchimento e perguntas adicionais ao final de cada instrumento. As perguntas realizadas na parte sobre criatividade no trabalho foram:

- Indique na escala de 0 a 10 , sendo $0=$ nem um pouco e $10=$ totalmente criativo, o quanto você se considera criativo em seu ambiente de trabalho.

- Indique na escala de 0 a 10 , sendo $0=$ nem um pouco e $10=$ totalmente, o quanto os resultados alcançados na área em que você trabalha são decorrentes de ações criativas.

A pergunta, aberta e não obrigatória, realizada na parte sobre aprendizagem informal no trabalho foi:

- Caso haja, destaque aqui as práticas mais utilizadas para aprender em seu ambiente de trabalho.

Para ambos os instrumentos, ICCAT e de Estratégias de Aprendizagem, foram incluídas em suas escalas a opção "não se aplica" caso o pesquisado considerasse que algum dos itens não fosse condizente com o seu contexto de trabalho. Julgou-se pertinente a inclusão dessa opção devido a grande diversidade de tarefas e atribuições executadas entre os pesquisados na organização.

Por fim, a última parte dos questionários era composta de informações referentes a variáveis sociodemográficas, variáveis do trabalho de cada participante e ao final foi 
disponibilizado um espaço para os participantes fazerem contribuições e solicitarem os resultados da pesquisa. As variáveis demográficas perguntadas foram:

- Sexo;

- Idade;

- Formação; e

- Local onde trabalha (localização da AABB onde trabalha e Estado).

As variáveis do trabalho perguntadas foram:

- Tempo de empresa;

- Área da organização onde trabalha; e

- Se exerce cargo de chefia.

As variáveis "idade" e "tempo de empresa" foram medidas em anos.

A seguir serão apresentadas as informações a respeito de como se deu os procedimentos de coleta e análise dos dados.

\subsection{Procedimentos de coleta de dados}

O questionário utilizado para a coleta de dados foi disponibilizado via internet em formato digital utilizando o Software SurveyMonkey. Por meio dessa ferramenta foi possível gerar um link de acesso ao questionário, além de gerenciar o andamento dos dados recebidos.

Após realizado o contato com a presidência da Federação das AABBs (FENABB) solicitando o consentimento para a realização da pesquisa, o acesso ao questionário via link foi repassado para todos os presidentes de clubes via e-mail institucional enviado pela própria FENABB com instruções para que o questionário fosse respondido pelo maior número possível de funcionários do clube. Para facilitar o acesso ao questionário eletrônico, foi utilizado um dos mecanismos oferecidos pelo software de acesso via outros dispositivos com acesso à internet como tablets e smartphones.

O questionário foi disponibilizado no dia 03/12/15 com expectativa de finalização no dia 18/12/15. Durante o período foram feitos contatos com presidentes de AABBs reforçando o pedido de participação e apoio. Novos encaminhamentos foram feitos além do período previamente determinado concluindo a aplicação do questionário no dia 15/01/16, totalizando 43 dias de acesso. 


\subsection{Procedimentos de análise de dados}

Os dados foram tabulados e transpostos para o software Statistical Package for Social Science (SPSS), compondo um único banco de dados. Inicialmente, foi realizada a limpeza da base por meio de análises de ausência de dados e da ocorrência de casos atípicos, sendo que o tratamento dos dados aplicados a esses casos está descrito no Capítulo 5. Em seguida, foram realizados testes exploratórios de pressupostos para realização de análises multivariadas de dados, com ênfase na distribuição e relacionamento entre os dados (normalidade, linearidade, colinearidade e singularidade).

O passo seguinte foi avaliar se os instrumentos utilizados apresentavam evidências de validade para este estudo por meio de análise fatorial das escalas feita separadamente. Assim, a análise da percepção dos participantes quanto às Condições para Criar e Estratégias de Aprendizagem pode ser realizada a partir dos escores fatoriais das escalas adaptadas.

Por fim, para verificar a relação entre as condições para criar e as estratégias de aprendizagem percebidas pelos participantes da pesquisa, foram realizadas análises de correlação de Spearman, uma vez que, conforme será apresentado em detalhes no Capítulo 5, os dados não apresentaram uma distribuição normal.

O próximo capítulo apresenta os resultados obtidos a partir da metodologia de pesquisa descrita e estes são analisados em seguida à luz do referencial teórico levantado na pesquisa. 


\section{RESULTADOS E DISCUSSÃO}

Neste Capítulo serão apresentados os resultados obtidos e interpretados neste trabalho conjuntamente com a análise e discussão a partir da literatura levantada na área. Inicialmente é feita a caracterização da amostra analisada. Na seção seguinte são descritos os procedimentos de tratamento dos dados coletados visando assegurar a qualidade das análises. A próxima seção detalha os resultados de evidência de validação dos instrumentos por meio da análise fatorial para que, em seguida, seja relatada a análise da percepção dos pesquisados quanto aos construtos estudados. Ao final do capítulo são analisadas as possíveis relações envolvendo às condições para criar e as estratégias de aprendizagem que caracterizam o objetivo principal desta pesquisa.

\subsection{Caracterização dos participantes}

A caracterização da amostra é apresentada na Tabela 3 e os aspectos de destaque são descritos em seguida.

Tabela 3 - Perfil da amostra

\begin{tabular}{|c|c|}
\hline \multicolumn{2}{|c|}{ Variáveis demográficas } \\
\hline Sexo: & Idade (em anos): \\
\hline $59,6 \%$ Masculino & Mínimo: 17 \\
\hline $33,3 \%$ Feminino & Máximo: 76 \\
\hline $7,1 \%$ Não informado & Média: 43,35 \\
\hline & Desvio Padrão: 13,11 \\
\hline & Não informado: $7,1 \%$ \\
\hline Região (Local onde trabalha): & Formação: \\
\hline $28,79 \%$ Sul & $41,41 \%$ Ensino Superior \\
\hline $27,78 \%$ Sudeste & 25,76\% Pós-Graduação \\
\hline $19,70 \%$ Nordeste & 23,23\% Ensino Médio \\
\hline $11,62 \%$ Centro-Oeste & $7,07 \%$ Outros \\
\hline $3,03 \%$ Norte & $1,01 \%$ Ensino Fundamental \\
\hline $9,09 \%$ Não informado & 7,1 \% Não informado \\
\hline \multicolumn{2}{|c|}{$\begin{array}{l}\text { Variáveis do trabalho } \\
\end{array}$} \\
\hline Tempo de Empresa (em anos): & Área da organização onde trabalha: \\
\hline Mínimo: 0,25 (3 meses) & 70,2\% Administrativo/Financeiro \\
\hline Máximo: 50 & $9,1 \%$ Outros \\
\hline Média: 8,57 & 7,6\% Desportes/Entretenimento \\
\hline Desvio Padrão: 8,61 & $5,6 \%$ Serviços Gerais \\
\hline Não informado: $7,1 \%$ & $7,6 \%$ Não informado \\
\hline Exerce cargo de chefia? & Porte da AABB onde trabalha \\
\hline $64,1 \%$ exercem & $54,04 \%$ Grande porte \\
\hline $28,8 \%$ não exercem & $25,25 \%$ Médio porte \\
\hline $7,1 \%$ não informado & $11,62 \%$ Pequeno porte \\
\hline & $9,09 \%$ não informado \\
\hline
\end{tabular}


Da amostra de 198 participantes da pesquisa, 7,1\% não preencheram a última parte de caracterização dos participantes, apesar das demais partes do questionário terem sido concluídas. Um possível motivo para a existência desse percentual foi identificado e corrigido no início da aplicação do questionário. Tal motivo consistiu na dificuldade de submissão de dados relatada pelos primeiros respondentes devido ao não cumprimento de regras estabelecidas para o preenchimento dos campos abertos como "Idade" e "Tempo de Empresa" que deveriam ser respondidos apenas com números, por exemplo. Para evitar a não submissão por esse motivo, as regras aplicadas para campos abertos foram retiradas, tornando essas respostas opcionais. As respostas a essas questões, quando informadas, foram corrigidas posteriormente na análise de dados. Os tratamentos realizados foram:

- Nos campos "Idade" e "Tempo de Empresa" foram alterados, por exemplo, termos como "7 anos" e "um ano e meio" para "7" e "'1,5" respectivamente.

- No campo "Local onde trabalha" foram relatados casos de preenchimento do nome da $\mathrm{AABB}$, apenas do município ou com a indicação do Estado. Todos esses casos foram modificados para o modelo padrão "AABB + nome do município" assim como é praticado pela base de dados da FENABB. Para identificação do Estado a qual pertence o município, foi acrescida uma coluna no banco de resposta própria para essa informação.

- No campo "Formação", ao especificar a formação "Outros", quatro casos indicaram respostas como "superior incompleto". Nesses casos a resposta foi deslocada para a resposta "Ensino médio".

Outros possíveis motivos para essa ausência dos dados podem estar em falhas na conexão de internet ou do próprio software ao transitar de uma parte para outra no questionário ou, ainda, no tamanho do questionário tornando o preenchimento cansativo e provocando sua desistência.

Os Gráficos 2 e 3 apresentam a distribuição das variáveis "Idade" e "Tempo de Empresa" de acordo com faixas medidas em anos. 
Gráfico 2 - Frequência da Amostra por Faixa de Idade (Em Anos)

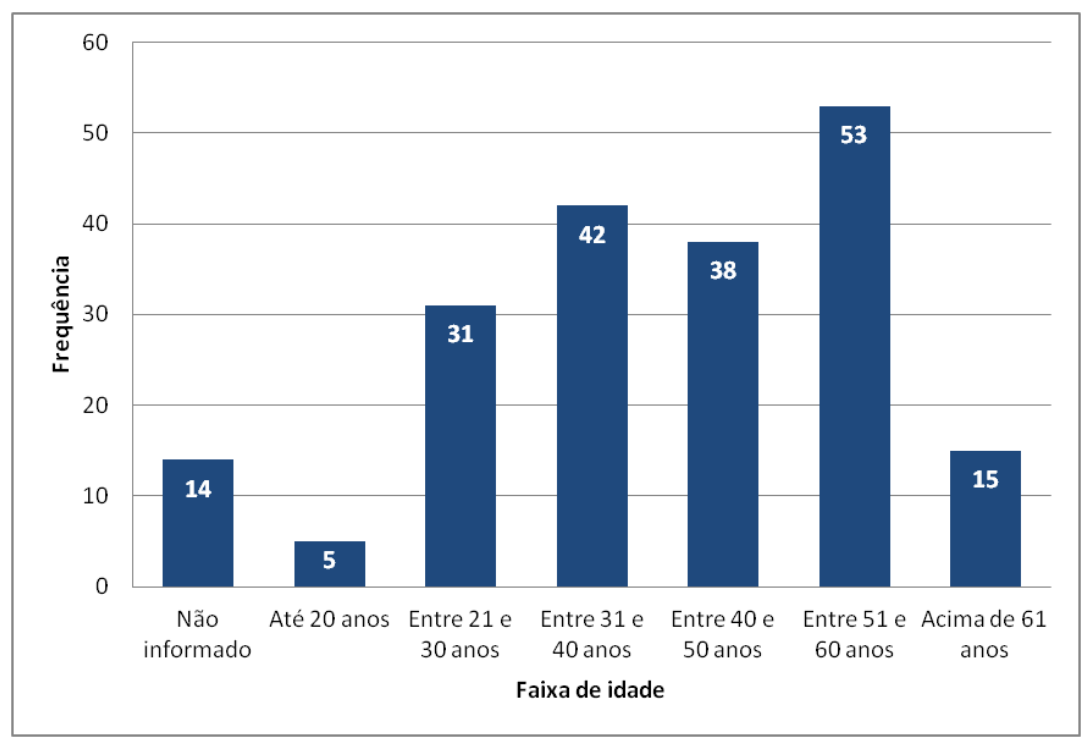

Gráfico 3 - Frequência da Amostra por Faixa de Tempo de Empresa (Em Anos)

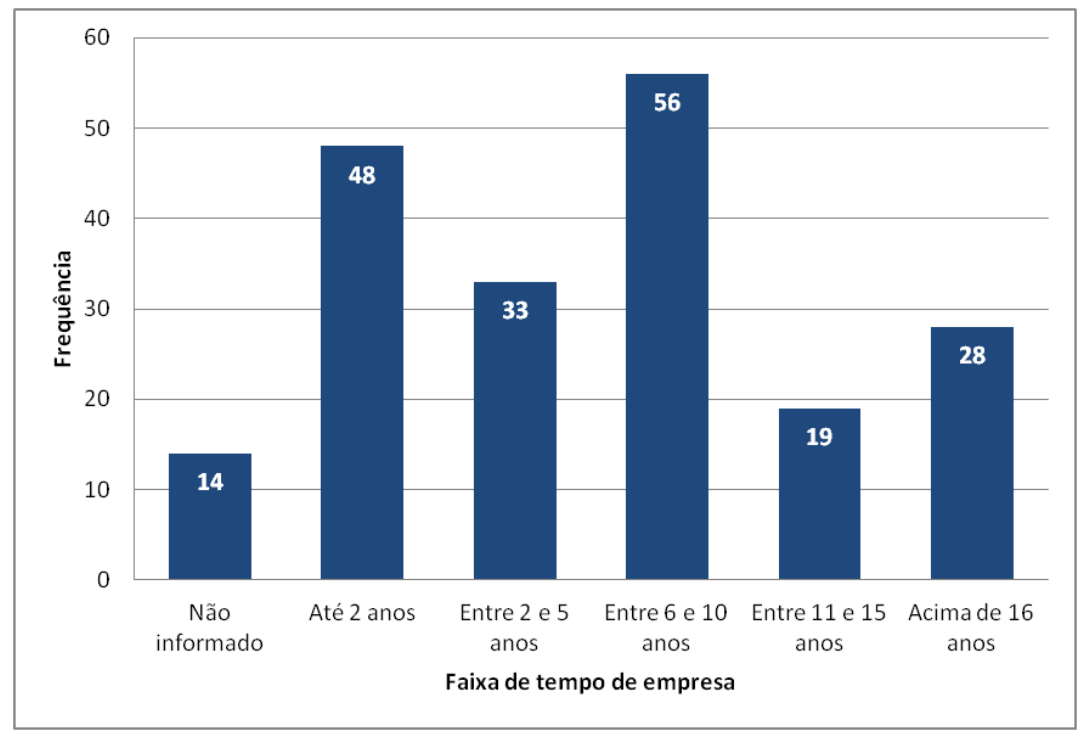

A pesquisa contou com participantes de 89 AABBs de diferentes municípios em 23 estados brasileiros mais o Distrito Federal. Não houve participantes dos estados de Roraima (RR), Pará (PA) e Acre (AC), todos da região norte.

Devido ao fato do item "Em qual AABB trabalha?" ter sido um campo de preenchimento aberto, houveram respostas cuja identificação da AABB, e consequentemente da região e porte do clube, não foi possível de ser realizada. Ao todo, quatro casos não puderam ser identificados e foram considerados como não respondidos. Assim, a porcentagem de casos não informados foi de $9,1 \%$. 
Quanto à formação acadêmica dos participantes, outros tipos de formação foram relatados. Foram eles: Fundamental incompleto, Técnico em Administração e Técnico em Contabilidade. Todos apresentaram apenas um caso cada.

Quanto à área da organização onde o participante trabalha, das opções dadas inicialmente aos respondentes, não houve respostas para o item "Alimentação/Bar". Em contrapartida, houve uma quantidade elevada de respostas para outras áreas $(9,1 \%)$. As principais áreas destacadas foram: Presidência $(4,04 \%)$, Sociocultural $(2,52 \%)$, Comunicação \& Marketing $(1,51 \%)$ e "Todas as áreas" (1,01\%).

A resposta "outra (especifique)" para a pergunta "Em qual área trabalha?" preenchida pelos participantes era esperada dada a diversidade de áreas que as AABBs possuem devido, principalmente, ao seu porte. Segundo a FENABB, clubes de até 200 associados são considerados de pequeno porte, até 1000 associados são de médio porte e acima de 1000 associados são AABBs de grande porte. Áreas como Sociocultural e de Comunicação \& Marketing são mais comuns em AABBs de grande porte e a não delimitação clara de áreas como no caso "todas as áreas" é característico de clubes de pequeno porte, dadas suas necessidades e limitações orçamentárias.

A ausência de participantes das áreas de "Alimentação/Bar" e a baixa ocorrência $(5,6 \%)$ de participantes de "Serviços Gerais" podem ser explicadas por dois motivos distintos. Primeiro motivo pode estar no fato dos clubes frequentemente firmarem contratos com empresas terceirizadas para a realização dos serviços destinados a essas áreas. Portanto, assim como foi direcionado inicialmente para os clubes, tais funcionários não-efetivos do clube não compreendem a população da pesquisa.

O segundo motivo reside no fato da pesquisa ter sido realizada via questionário eletrônico, necessitando de acesso a internet. Grande parte das tarefas e serviços prestados pelos funcionários de áreas operacionais, como são os casos de "Alimentação/Bar" e "Serviços Gerais", não requerem o uso de tecnologias que possam aproximá-los da pesquisa eletrônica. Uma prática adotada para mitigar esse distanciamento foi a disponibilização do questionário para preenchimento em outros dispositivos como Smartphones mas, a conexão mais limitada à internet, o tamanho do questionário e o desconhecimento dessa possibilidade de preenchimento podem ter dificultado a utilização do recurso.

O último motivo apresentado pode contribuir ainda na explicação do elevado número de respondentes da área "Administrativo/Financeiro" (70,2\%) que possuem um acesso mais 
facilitado à pesquisa por trabalharem com atividades que exigem computadores e conexão via internet.

Por fim, o surgimento de participantes que indicaram como pertencentes da "presidência" e o fato da amostra demonstrar um percentual maior de participantes que exercem cargos de chefia $(64,1 \%)$ podem vir a ser explicados pelo procedimento de coleta empregado na pesquisa. Como não há uma relação unificada de e-mails de todos os funcionários do Sistema AABB, o link de acesso ao questionário foi enviado para todos os presidentes de AABBs com a solicitação de que estes repassassem o acesso à todos os funcionários efetivos de seu clube. A utilização desse repasse por meio de intermediários pode não ter ocorrido de forma satisfatória podendo ter ocorrido a disponibilização do acesso apenas aos funcionários mais próximos à presidência, não havendo condições para a participação pelos funcionários efetivos das áreas operacionais do clube.

Quanto às questões feitas ao final do preenchimento de cada instrumento, 7,6\% dos 198 questionários não obtiveram respostas. A questão "Indique na escala de 0 a 10 , sendo $0=$ nem um pouco e $10=$ totalmente criativo, o quanto você se considera criativo em seu ambiente de trabalho" e "Indique na escala de 0 a 10 , sendo $0=$ nem um pouco e $10=$ totalmente, o quanto os resultados alcançados na área em que você trabalha são decorrentes de ações criativas" obtiveram respostas com média e desvio padrão (DV) 7,84 (1,31) e 7,67 $(1,55)$, respectivamente. Logo, apesar de uma certa dispersão nas respostas, os respondentes da pesquisa se consideram criativos e consideram que resultados da área onde atuam é fruto de ações criativas.

Para a questão "Caso haja, destaque aqui as práticas mais utilizadas para aprender em seu ambiente de trabalho" foram relatadas as respostas: " Benchmarking com outros colegas da organização", "Interação com demais áreas do trabalho", "Cursos e treinamentos internos", "Instruções normativas" e " Leitura constante de informações relacionadas à minha atividade e consulta a colegas e parceiros".

Assim, considerando todos os participantes que responderam à pesquisa, 59,6\% são homens, com média de idade de 43 anos, variando entre 17 e 76 anos e com ensino superior completo, predominantemente. O tempo de empresa médio corresponde a oito anos, variando entre 3 meses e 50 anos. Quanto ao local de atuação, 56,6\% estão lotados nas regiões Sul e Sudeste, 70,2\% pertencem a área administrativa e 64,1\% exercem cargos de gestão na organização em que atuam. 
A seção seguinte trata do tratamento dos dados necessário para realização das análises estatísticas.

\subsection{Análise exploratória e tratamento dos dados}

Inicialmente, foram identificados e tratados os casos de ausência de dados que, de acordo com Hair et al. (2009) podem ter impactos significantes sobre a análise, particularmente aquelas de natureza multivariada. Esta fase contou com a análise de frequência de dados omissos que resultou na exclusão de questionários incompletos e no tratamento de itens considerados não aplicáveis pelos participantes.

$\mathrm{Na}$ análise de itens considerados não aplicáveis pelos participantes, foram analisadas as frequências de ocorrência da marcação da opção "não se aplica" e estes foram transformados em casos omissos (missing) sistemáticos. Com isso, foram identificados casos omissos em todos os itens dos dois instrumentos utilizados. Foram excluídos todos os questionários com mais de $15 \%$ de casos omissos no preenchimento dos dois instrumentos aplicados. onze questionários foram excluídos por essa razão, permanecendo 209 questionários válidos.

Os questionários excluídos por excesso de casos omissos foram analisados na intenção de identificar padrões no perfil dos respondentes que deixaram de responder os itens ou no conjunto de itens com respostas ausentes. Quanto ao perfil dos respondentes não foram identificadas características comuns como gênero, idade, formação, região ou cargo que justificasse a não aplicabilidade dos itens. Quanto ao conjunto de itens com maiores casos de respostas do tipo "não se aplica" também não foram observadas polaridades significantes.

Além da ausência de dados pela marcação da opção "não se aplica", a ocorrência de questionários incompletos foi outro motivo para as onze exclusões citadas anteriormente. $\mathrm{O}$ software utilizado para realizar a coleta de dados foi programado para bloquear o avanço de uma parte do questionário para a parte seguinte caso algum item não tivesse sido respondido. Isso fez com que alguns questionários ficassem incompletos, pois não houve prosseguimento no preenchimento por parte do pesquisado.

Por meio de análises de frequência dos dados, não foram identificados casos de questionários duplicados ou de respostas fora da amplitude permitida pelas escalas aplicadas. 
O software de coleta de dados foi configurado para aceitar somente respostas dentro das escalas estipuladas para cada instrumento.

A análise seguinte realizada na base de dados se concentrou na identificação e tratamento de casos considerados atípicos ou outliers que, segundo Tabachnick e Fidell (2012) podem distorcer resultados estatísticos. Foram identificados 11 casos univariados em ambos os instrumentos, que ocorrem quando as respostas são dadas a uma mesma variável com valores extremos.

A análise de casos extremos multivariados, formados quando os valores formam combinações não usuais ou padrão entre duas ou mais variáveis, foi realizada por meio do cálculo da distância de Mahalanobis. Nenhum caso extremo multivariado foi identificado.

Considerando as análises multivariadas realizadas com e sem os 11 casos que apresentaram outliers, optou-se pela exclusão destes questionários restando para as etapas seguintes de análise um total amostral de 198 questionários válidos.

Em seguida foram realizados testes para verificar a normalidade da distribuição dos dados coletados. Nessa parte, foram verificados aspectos específicos da não normalidade por meio das análises de assimetria e curtose, além da verificação de desvio da distribuição normal como um todo por meio dos testes de Kolmogorov-Smirnov, indicados por Field (2009).

Verificando a assimetria por meio da análise dos coeficientes, os valores dos itens da escala de estratégias de aprendizagem apresentaram variação entre $|0,91|$ e $|2,33|$. Da escala de condições favoráveis à criatividade os itens variaram entre $|0,52|$ e $|2,54|$, enquanto os itens da escala de condições desfavoráveis variaram entre $|0,05|$ e $|1,30|$. Segundo Field (2009), quanto mais distante esses valores estiverem de zero, maior a possibilidade de que os dados não sejam normais. Assim, os resultados, em sua maioria apontando assimetrias predominantemente negativas, indicam a não linearidade dos dados da amostra.

De forma semelhante, os valores encontrados na análise dos coeficientes de curtose também apresentaram valores afastados de zero, também sugerindo a não normalidade dos dados segundo Field (2009). Os itens da escala de estratégias de aprendizagem apresentaram variação entre $|0,29|$ e $|8,02|$. A escala de condições favoráveis à criatividade apresentou variação entre $|0,08|$ e $|7,07|$ e a escala de condições desfavoráveis apresentaram valores entre $|0,26|$ e $|1,42|$. Em sua maioria, os dados apresentaram um formato pontiagudo para a distribuição devido aos valores positivos de curtose. 
Segundo Hair et al. (2009), se os valores de assimetria e curtose forem próximos a zero, o desvio da normalidade é considerado pequeno, até 1,96 (nível de significância de 0,05) é tido como uma distribuição próxima da normalidade e caso seja maior do que esse valor crítico, a distribuição pode ser considerada fora da normalidade. Portanto, os dados coletados para os itens pesquisados apresentam uma distribuição não-normal.

Por fim, para a análise do pressuposto de normalidade dos dados, optou-se pela realização do método Kolmogorov-Smirnov que compara os escores da amostra a uma distribuição normal de mesma média e variância (FIELD, 2009). O teste realizado apontou que os dados diferem da normal ao nível de significância de $5 \%(\mathrm{p}<0,05)$, indicando a não normalidade da distribuição analisada. Assim, considerando os demais testes realizados, a distribuição dos dados da amostra aqui estudada foi considerada não normal.

A próxima seção apresenta os procedimentos de validação empregados para garantir a precisão das medidas utilizadas sobre Condições para Criar e Estratégias de Aprendizagem no ambiente de trabalho.

\subsection{Evidências de validade dos instrumentos de medida}

Para avaliar as evidências de validade da estrutura fatorial dos instrumentos ICCAT e de Estratégias de aprendizagem utilizados na pesquisa, foram empregados métodos de análise fatorial que, segundo Hair et al. (2009) fornece importantes ferramentas para verificar a estrutura da interrelações entre variáveis correlacionadas. Dentre as utilidades dessa técnica, Laros (2008) destaca o uso imprescindível da análise fatorial como um processo de validação de instrumentos psicológicos.

Para realização da análise fatorial, foram considerados os tratamentos na base de dados quanto a casos omissos e extremos (outliers uni e multivariados). Quanto à distribuição dos dados, a técnica de análise fatorial apresenta certa robustez à falta de normalidade dos dados (TABACHNICK; FIDELL, 2012; LAROS, 2008). Assim, optou-se por não realizar alterações dado esse pressuposto, apesar de serem adotados métodos que buscaram otimizar os resultados da análise fatorial considerando a condição de não normalidade.

Apesar da robustez quanto à normalidade, outras análises exploratórias que pressupõem a aplicação da análise fatorial foram realizadas como tamanho da amostra, colinearidade, singularidade e linearidade. Tais pressupostos podem impactar em maior ou 
menor grau nos resultados obtidos com a análise fatorial e devem ser verificados segundo recomendam Tabachnick e Fidell (2012) e Hair et al. (2009).

O tamanho da amostra é um pressuposto frequentemente discutido por pesquisadores que trabalham com análise fatorial, sendo o mais comum a utilização da proporção participantes por variáveis (HAIR et al., 2009). A proporção mínima sugerida por Tabachnick e Fidell (2012) e Hair et al. (2009) é de cinco respondentes por item. A maior escala é composta por 36 itens, sendo necessários 180 casos para realização da análise fatorial. Considerando a amostra de 198 casos válidos após o tratamento dos dados, considerou-se o critério atendido.

Como critério para análise de multicolinearidade e singularidade, foram examinadas as matrizes de correlação entre as variáveis de cada escala separadamente a fim de identificar casos extremos (igual a 1) ou superiores à 0,9 (FIELD, 2009). Neste caso, as variáveis são altamente correlacionadas podendo torná-las redundantes para a análise, devendo ser excluídas.

Segundo Hair et al. (2009), a linearidade é uma suposição implícita em todas as técnicas multivariadas baseadas em medidas correlacionais de associação, incluindo análise fatorial e regressão múltipla. Para identificar possíveis casos de não linearidade, foram examinadas as magnitudes das correlações entre pares de itens em cada escala para procurar ausências de correlação.

Assim, com base no resultado já apresentado do critério de tamanho da amostra e nos resultados dos demais pressupostos apresentados na análise da matriz de correlação de cada escala, estas foram avaliadas quanto ao atendimento dos pressupostos para a análise fatorial.

Para verificar a fatorabilidade da matriz de dados foram realizadas inspeções visuais na matriz de correlação, análises do determinante da matriz e do índice de adequação da amostra.

$\mathrm{Na}$ análise da matriz de correlação, metade das correlações entre os itens da escala devem ser superiores a 30\%. Segundo Hair et al. (2009), essa média geral de intercorrelações deve garantir que a matriz de dados tenha um número mínimo de interações que justifiquem a análise fatorial.

$\mathrm{Na}$ análise do determinante da matriz, foi realizado o teste de esfericidade de Bartlett que testa a hipótese nula de que a matriz de correlação é uma matriz identidade (LAROS, 2008). O valor do teste deve ser baixo e diferente de zero para que a hipótese nula seja rejeitada e a análise fatorial faça sentido. 
Por fim, o índice de adequação da amostra Kaiser Meyer Olkin (KMO) foi considerado na análise. Kaiser (1974 apud FIELD, 2009) recomenda valores maiores do que 0,5 para este teste. Valores entre 0,5 e 0,7 são classificados como medíocres, entre 0,7 e 0,8 são bons, 0,8 e 0,9 são ótimos e acima de 0,9 são excelentes (FIELD, 2009).

Com base nas três análises citadas, as matrizes de dados foram avaliadas quanto sua fatorabilidade.

Em seguida, realizou-se a verificação do número de fatores a serem extraídos. O método utilizado para essa extração inicial foi por meio da análise dos Componentes Principais (PC). Este método tem como foco central a redução do número de variáveis em componentes que expliquem a maior parte da variância original das variáveis. Os critérios considerados para definir o número de componentes foram:

a) Critério de autovalor: são considerados os autovalores (eigenvalues) iguais ou superiores a 1.

b) Critério de relevância do fator de Harman: são considerados os valores com variância explicada por fator de pelo menos $3 \%$

c) Critério da análise paralela: são considerados os valores próprios empíricos superiores aos valores aleatórios gerados por métodos estatísticos que consideram a quantidade de itens e o tamanho da amostra (PATIL et al., 2008). Este critério estatístico garante precisão maior na definição do número de fatores (LAROS, 2008).

d) Critério teórico: é considerada a teoria que embasa o tema e foram considerados os componentes originais propostos pelos autores dos instrumentos.

Todos os critérios foram considerados para a extração e análise dos fatores segundo o método de fatoração dos eixos principais (PAF). A escolha desse método segue as recomendações de Costello e Osborne (2005) para obtenção dos melhores resultados quando a amostra apresenta distribuição não normal. Para facilitar a interpretação dos fatores dada a possibilidade de ocorrência de variáveis com cargas fatoriais elevadas em mais de um fator, adotou-se a rotação oblíqua Oblimin, pois se esperam correlações entre as variáveis (DAMÁSIO, 2012).

Dependendo do critério adotado, o número de fatores extraídos pode variar. A análise fatorial foi realizada inicialmente sempre de acordo com o critério teórico. Este não se mostrando compatível empiricamente, adotou-se o critério de análise paralela, seguido dos 
critérios de autovalor e de relevância do fator como auxilio nas análises. A estrutura que demonstrou melhor ajuste foi interpretada e considerada para a medição e análise dos construtos pesquisados.

Para verificar a estabilidade da estrutura fatorial e representatividade dos itens, foram avaliadas as cargas fatoriais e o sentido teórico de cada variável. Variáveis com cargas fatoriais inferiores a 0,3 ou com cargas em mais de um fator cuja diferença seja igual ou menor do que 0,1 são passíveis de exclusão (NEIVA; ABBAD; TRÓCCOLI, 2011). Ainda, para melhor visualização, as cargas fatoriais inferiores a 0,4 foram omitidas.

A interpretação do sentido teórico dos fatores contou com a análise do conteúdo de cada item procurando identificar traços latentes que justifiquem seu agrupamento à luz do referencial teórico utilizado.

Por fim, a consistência interna dos fatores identificados em cada escala foram medidas por meio do índice de confiabilidade (Alpha de Cronbach) que, segundo Field (2009) considera valores superiores à 0,7 como aceitáveis.

Considerando ainda a análise de consistência interna dos fatores, Field (2009) sugere a investigação de acréscimos no valor da confiabilidade caso um item seja deletado. Os resultados obtidos para essa análise, indicaram, de modo geral, que a exclusão de itens nas diferentes escalas analisadas não resultariam em acréscimos relevantes de confiabilidade e, em função disto estes resultados não estão apresentados.

As subseções 5.3.1, 5.3.2 e 5.3.3 apresentam os resultados alcançados com a análise fatorial realizada para as escalas de Condições Favoráveis à Criatividade, Condições Desfavoráveis à Criatividade e de Estratégias de Aprendizagem, respectivamente, segundo os critérios apresentados nessa seção.

\subsubsection{Análise fatorial e consistência interna da escala de Condições Favoráveis à Criatividade}

A verificação da fatorabilidade da matriz de correlação das variáveis da escala de Condições Favoráveis à Criatividade mostrou que na inspeção visual da matriz, 64,6\% das correlações foram superiores a 0,3 não havendo nenhuma superior à 0,80 . $O$ menor coeficiente chegou a 0,07, indicando uma correlação bem fraca. O determinante da matriz se mostrou significativo $(\mathrm{p}<0,001)$ e o índice de adequação da amostra $(\mathrm{KMO})$ foi superior a 0,8 
como apresentado na Tabela 4. Desta forma, os resultados apontaram uma matriz adequada e fatorável.

Tabela 4 - KMO e Teste de Bartlett da Matriz de Correlação da Escala de Condições Favoráveis à Criatividade

\begin{tabular}{ll|r}
\hline \multicolumn{2}{c|}{ Índice de Adequação da Amostra Kaiser-Meyer-Olkin } & 0,864 \\
\hline \multirow{2}{*}{ Teste de Esfericidade de } & Qui-quadrado Aprox & 2659,639 \\
Bartlett & Gl & 630 \\
& Sig. & 0,000 \\
\hline
\end{tabular}

A análise dos diferentes critérios para definição do número de fatores indicou entre quatro a oito fatores. O critério teórico, relativo ao número de fatores previamente identificados nos estudos anteriores, foi o primeiro a ser analisado pelo método de fatoração (PAF) e se mostrou pouco ajustável aos dados deste estudo visto as seguintes ocorrências: a) elevado número de variáveis com cargas fatoriais próximas em múltiplos fatores; b) ausência de carga fatorial relevante para algumas variáveis; e c) grande quantidade de variáveis explicando fatores diferentes dos originalmente propostos pelas autoras do instrumento.

Dessa forma, optou-se pela investigação de uma nova estrutura fatorial baseada no critério de análise paralela. Assim, a estrutura que se mostrou mais adequada foi composta por quatro fatores, explicando $51,21 \%$ da variância total. O número de itens foi reduzido em relação à escala original de 36 para 30 itens com cargas fatoriais variando entre 0,43 e 0,80 . A consistência interna dos fatores extraídos variou de 0,75 a 0,92 .

A Tabela 5 apresenta a estrutura empírica da escala, as cargas fatoriais, a comunalidade $\left(\mathrm{h}^{2}\right)$ dos itens, os índices de consistência interna dos fatores, bem como os valores próprios e percentuais de variância explicada dos fatores.

Tabela 5 - Estrutura Fatorial da Escala de Condições Favoráveis à Criatividade

\begin{tabular}{|c|c|c|c|c|c|}
\hline Variáveis & F1 & F2 & F3 & F4 & $\mathbf{h}^{2}$ \\
\hline $\begin{array}{l}\text { 20. Meu gerente me estimula na busca por soluções originais para a } \\
\text { resolução de problemas cotidianos. }\end{array}$ & 0,78 & & & & 0,71 \\
\hline $\begin{array}{l}\text { 14. O gerente elogia as ideias novas e de valor que são apresentadas } \\
\text { pelos empregados. }\end{array}$ & 0,76 & & & & 0,71 \\
\hline $\begin{array}{l}\text { 15. Meu gerente me estimula a dar sugestões quanto ao aprimoramento } \\
\text { dos serviços e/ou produtos que a Organização oferece. }\end{array}$ & 0,74 & & & & 0,66 \\
\hline $\begin{array}{l}\text { 6. O gerente oferece o apoio que necessito na realização de trabalhos } \\
\text { que exigem a produção de ideias novas. }\end{array}$ & 0,70 & & & & 0,65 \\
\hline $\begin{array}{l}\text { 32. O gerente incentiva os empregados a participar da solução dos } \\
\text { problemas de trabalho. }\end{array}$ & 0,69 & & & & 0,48 \\
\hline $\begin{array}{l}\text { 23. Meu gerente me estimula a experimentar novas formas de executar } \\
\text { o trabalho. }\end{array}$ & 0,66 & & & & 0,66 \\
\hline
\end{tabular}




\begin{tabular}{|c|c|c|c|c|c|}
\hline Variáveis & F1 & $\mathbf{F} 2$ & F3 & F4 & $\mathbf{h}^{2}$ \\
\hline $\begin{array}{l}\text { 33. A Organização contribui para a produção de novas ideias no } \\
\text { ambiente de trabalho a partir da abertura à participação de } \\
\text { consultores externos. }\end{array}$ & 0,64 & & & & 0,37 \\
\hline 42. Meus colegas elogiam quando apresento uma boa ideia no trabalho. & 0,60 & & & & 0,54 \\
\hline $\begin{array}{l}\text { 18. Meus colegas me estimulam a dar sugestões que contribuam para os } \\
\text { resultados da organização. }\end{array}$ & 0,60 & & & & 0,61 \\
\hline $\begin{array}{l}\text { 37. Sinto-me incentivado a produzir ideias novas a partir do convívio } \\
\text { com meus colegas de trabalho. }\end{array}$ & 0,54 & & & & 0,64 \\
\hline $\begin{array}{l}\text { 22. A Organização oferece acesso a uma variedade de fontes de } \\
\text { informação (livros, artigos, vídeos, dentre outros) que contribuem para } \\
\text { o surgimento de ideias novas e de valor. }\end{array}$ & 0,54 & & & & 0,32 \\
\hline $\begin{array}{l}\text { 47. Na minha Organização, as estratégias são claras e bem definidas o } \\
\text { que facilita a proposição de novas ideias. }\end{array}$ & 0,44 & & & & 0,45 \\
\hline $\begin{array}{l}\text { 51. A Organização tem como uma de suas diretrizes a busca da } \\
\text { criatividade. }\end{array}$ & 0,44 & & & & 0,34 \\
\hline $\begin{array}{l}\text { 55. A Organização oferece diferentes oportunidades de interação com } \\
\text { outras instituições que favorecem a expressão de ideias novas e de } \\
\text { valor. }\end{array}$ & 0,43 & & & & 0,45 \\
\hline $\begin{array}{l}\text { 52. Eu tenho os materiais de que necessito para a realização do meu } \\
\text { trabalho. }\end{array}$ & & 0,80 & & & 0,63 \\
\hline 40. Tenho mobiliário suficiente para guardar meu material de trabalho. & & 0,71 & & & 0,58 \\
\hline $\begin{array}{l}\text { 60. Disponho dos recursos tecnológicos necessários ao exercício de } \\
\text { minhas funções como, por exemplo, telefone, computador com acesso a } \\
\text { internet. }\end{array}$ & & 0,62 & & & 0,38 \\
\hline $\begin{array}{l}\text { 1. O mobiliário onde trabalho é adequado, o que ajuda a evitar doenças } \\
\text { osteomoleculares (DORT ou LER). }\end{array}$ & & 0,51 & & & 0,50 \\
\hline $\begin{array}{l}\text { 38. Tenho o silêncio necessário, onde trabalho, para a realização de } \\
\text { minhas tarefas. }\end{array}$ & & 0,49 & & & 0,41 \\
\hline $\begin{array}{l}\text { 46. O espaço físico no local de trabalho é adequado para o número de } \\
\text { funcionários. }\end{array}$ & & 0,46 & & & 0,30 \\
\hline $\begin{array}{l}\text { 4. Sinto-me à vontade para dar ideias novas no trabalho, mesmo que } \\
\text { sejam bem diferentes das ideias dos outros. }\end{array}$ & & & 0,77 & & 0,58 \\
\hline 5. Sinto entusiasmo para realizar as atividades que me são destinadas. & & & 0,74 & & 0,59 \\
\hline 3. Tenho liberdade para oferecer sugestões onde trabalho. & & & 0,66 & & 0,51 \\
\hline 21. As tarefas que realizo no meu trabalho exigem o melhor de mim. & & & 0,57 & & 0,46 \\
\hline 54. Sinto que realizo trabalhos importantes para a Organização. & & & 0,56 & & 0,43 \\
\hline $\begin{array}{l}\text { 36. Tenho liberdade para decidir como realizar as tarefas a mim } \\
\text { atribuídas. }\end{array}$ & & & 0,53 & & 0,42 \\
\hline $\begin{array}{l}\text { 41. Tenho liberdade para propor novas formas de fazer as atividades } \\
\text { no trabalho. }\end{array}$ & & & 0,50 & & 0,55 \\
\hline $\begin{array}{l}\text { 35. As minhas tarefas no trabalho me estimulam na busca de novos } \\
\text { conhecimentos para sua realização. }\end{array}$ & & & 0,45 & & 0,32 \\
\hline 39. O clima entre os colegas é de confiança e respeito mútuo. & & & & 0,66 & 0,56 \\
\hline $\begin{array}{l}\text { 19. No meu local de trabalho, as pessoas mostram boa vontade em } \\
\text { ajudar umas às outras. }\end{array}$ & & & & 0,65 & 0,54 \\
\hline Auto valor (Eigenvalues): & 10,48 & 2,23 & 1,65 & 1,01 & \\
\hline \% da Variância explicada & 34,93 & 7,44 & 5,49 & 3,36 & \\
\hline Número de itens & 14 & 6 & 8 & 2 & \\
\hline Alpha de Cronbach & 0,92 & 0,77 & 0,83 & 0,75 & \\
\hline
\end{tabular}

Nota. Foram omitidas as cargas fatoriais inferiores a 0,4 
O Fator 1, denominado Estímulos a novas ideias por colegas, gerente imediato e ações organizacionais, é composto de 14 itens relacionados a ações promovidas pela equipe de trabalho, colegas e chefes, e pela própria organização voltadas à estimulação ativa em favor da expressão criativa no ambiente de trabalho.

O novo fator, em comparação à escala original, é formado pela união dos fatores Suporte do gerente imediato, Ações organizacionais em apoio a ideias novas e por itens que pertenciam inicialmente ao fator Clima entre colegas de trabalho.

$\mathrm{Na}$ tentativa de identificar o traço latente que justificaria a união das variáveis, percebe-se um aspecto recorrente na descrição dos itens de práticas ou mobilizações ativas de incentivo, estímulo ou reforço à produção de ideias, apresentação de sugestões e resolução de problemas. O que difere os itens reside na fonte da ação, dividida em colegas de trabalho, gerente imediato e ações organizacionais, assim como se diferenciavam os três fatores que originaram este novo componente.

Espera-se que o Fator 1 possa refletir as práticas e comportamentos deliberados de diferentes atores e características do ambiente de trabalho em favor da produção de ideias e resolução de problemas. Hitt (1975) e Locke e Kirkpatrick (1995), citados por Alencar (2012), argumentam que a criatividade precisa ser explicitamente valorizada, o que requer um líder que reforce continuamente essa visão e uma cultura implementada para esse objetivo.

Considerando a organização das variáveis na escala original, os itens "A minha organização realiza diferentes ações para incentivar que os trabalhadores expressem sua criatividade" e "A Organização incentiva a produção de ideias novas a partir de diferentes ações (ex:concursos, banco de ideias, programas de criatividade, estímulo à apresentação de novos projetos, treinamentos etc.)", ambos pertencentes originalmente ao fator Ações e estratégias organizacionais em apoio a ideias novas, foram excluídos por apresentarem cargas na explicação de outros fatores, além do Fator 1, com uma diferença menor do que 0,1 .

Neste Fator, o item com maior carga fatorial foi "Meu gerente me estimula na busca por soluções originais para a resolução de problemas cotidianos" $(0,78)$ e o item de menor carga, não somente do fator mais de toda a escala, foi "A Organização oferece diferentes oportunidades de interação com outras instituições que favorecem a expressão de ideias novas e de valor" $(0,43)$.

$\mathrm{O}$ item "Meu gerente me estimula a experimentar novas formas de executar o trabalho" apresentou cargas fatoriais relevantes no Fator $1(0,65)$ e no Fator $3(0,3)$. Essa 
ocorrência pode ser justificada dada a proximidade do conteúdo do item com um dos temas do fator relacionado à abertura para experimentação de novidades.

O Fator 2, denominado Características do Ambiente Físico, formado por seis itens, trata das condições físicas oferecidas no ambiente de trabalho como mobília, espaço físico, materiais e recursos tecnológicos que favoreçam na realização do trabalho e na produção de novas ideias.

Esse fator confirmou o componente original proposto por Bruno Faria e Veiga (2015), não havendo exclusão ou realocação dos itens agrupados inicialmente. A carga fatorial mais alta de toda a escala pertence a este fator no item "Eu tenho os materiais de que necessito para a realização do meu trabalho" $(0,80)$. O item com carga mais baixa do Fator 2 foi "O espaço físico no local de trabalho é adequado para o número de funcionários" $(0,46)$.

No primeiro item da escala, " O mobiliário onde trabalho é adequado, o que ajuda a evitar doenças osteomoleculares (DORT ou LER)", foi identificada ambivalência no Fator 2 $(0,51)$ e Fator $1(0,31)$

O Fator 3, nomeado Liberdade de ação e atividades desafiantes, unificou dois fatores originalmente distintos, sendo composto de oito itens que tratam de aspectos relacionados ao sentimento de conforto e bem estar para expressar ideias e opiniões, atrelada a execução de atividades que exigem novas competências e soluções e que são valorizadas pelo funcionário.

A análise do sentido teórico que possa justificar a união empírica dos fatores destaca o tipo de atividade a ser executada como um elemento determinante na explicação desse fator. Atividades menos rotineiras, com múltiplas situações e resultados possíveis, exige maior flexibilidade quanto às ações a serem tomadas e tornam, por vezes, a atividade mais complexa e dinâmica, exigindo assim mais da cognição e capacidade de resolução de problemas por parte dos funcionários.

$\mathrm{Na}$ união de dois fatores originalmente propostos pelas autoras da escala, três itens foram excluídos devido a ambivalência de cargas com diferenças menores do que 0,1 . Os itens excluídos foram "Tenho liberdade para expor minhas ideias onde trabalho", que pertencia ao fator Liberdade de ação, e "As tarefas que realizo são estimulantes" e "O grau de dificuldade das tarefas que realizo me estimula a pensar em novas ideias", do fator Atividades desafiantes.

O Fator 3 apresentou como item de maior carga "Sinto-me à vontade para dar ideias novas no trabalho, mesmo que sejam bem diferentes das ideias dos outros" $(0,77)$ e de menor 
carga "As minhas tarefas no trabalho me estimulam na busca de novos conhecimentos para sua realização".

O Fator 4, denominado Clima entre colegas de trabalho, composto de apenas dois itens, trata especificamente de características do relacionamento entre as pessoas envolvidas na execução das atividades que contribuem para a construção de um clima favorável à expressão de novas ideias.

Como relatado no Fator 1, os itens "Meus colegas elogiam quando apresento uma boa ideia no trabalho", " Sinto-me incentivado a produzir ideias novas a partir do convívio com meus colegas de trabalho" e "Meus colegas me estimulam a dar sugestões que contribuam para os resultados da organização", que complementavam o fator clima entre colegas de trabalho na escala original, foram realocados e passaram a compor um novo fator voltado às ações ativas de estímulo e incentivo a produção de ideias.

Analisando os itens remanescentes, "O clima entre os colegas é de confiança e respeito mútuo" $(0,67)$ e "No meu local de trabalho, as pessoas mostram boa vontade em ajudar umas às outras" $(0,65)$, percebe-se a diferença em comparação com os itens realocados no sentido destes não estarem focados diretamente na promoção da criatividade. O intuito dos itens é avaliar aspectos do relacionamento entre os colegas de trabalho que indiretamente impactam na expressão da criatividade como ajuda mútua e confiança.

Cabe destacar que apesar da limitação do estudo ao fazer uso de uma escala com um fator com menos de três itens como recomendam as boas práticas (HAIR et al.,2009), optouse por manter o fator ao invés de reduzir o número de fatores para garantir uma estrutura fatorial mais próxima da teoria e da estrutura originalmente proposta por Bruno-Faria e Veiga (2015).

Por fim, para compreender a relação entre os fatores de Condições Favoráveis à Criatividade, é apresentada a matriz de correlação entre os fatores na Tabela 6.

Tabela 6 - Matriz de Correlação entre Fatores da Escala de Condições Favoráveis à Criatividade

\begin{tabular}{lcccc}
\hline & $\begin{array}{c}\text { Estímulos a novas } \\
\text { ideias por colegas, } \\
\text { gerente imediato e } \\
\text { ações organizacionais }\end{array}$ & $\begin{array}{c}\text { Característic } \\
\text { as do } \\
\text { Ambiente } \\
\text { Físico }\end{array}$ & $\begin{array}{c}\text { Liberdade } \\
\text { de ação e } \\
\text { atividades } \\
\text { desafiantes }\end{array}$ & $\begin{array}{c}\text { Clima } \\
\text { entre } \\
\text { colegas de } \\
\text { trabalho }\end{array}$ \\
\hline $\begin{array}{l}\text { Estímulos a novas ideias por colegas, } \\
\text { gerente imediato e ações } \\
\text { organizacionais }\end{array}$ & 1,00 & & \\
$\begin{array}{l}\text { Características do Ambiente Físico } \\
\begin{array}{l}\text { Liberdade de ação e atividades } \\
\text { desafiantes }\end{array}\end{array}$ & 0,27 & 1,00 & 1,00 \\
Clima entre colegas de trabalho & $-0,40$ & $-0,38$ & $-0,18$ \\
\hline
\end{tabular}




\subsubsection{Análise fatorial e consistência interna da escala de Condições Desfavoráveis à Criatividade}

A matriz de correlação das variáveis da escala de Condições Desfavoráveis à Criatividade apresentou $79,71 \%$ de correlações entre 0,30 e 0,79. O menor coeficiente evidenciado foi de 0,14. O teste de esfericidade de Bartlett foi significativo $(p<0,001)$ e o índice de adequação da amostra (KMO) foi superior a 0,9, como apresentado na Tabela 7. Esses resultados apontam adequação e a fatorabilidade da matriz de dados para a escala.

Tabela 7 - KMO e Teste de Bartlett da Matriz de Correlação da Escala de Condições Desfavoráveis à Criatividade

\begin{tabular}{ll|r}
\hline \multicolumn{2}{c|}{ Índice de Adequação da Amostra Kaiser-Meyer-Olkin } & 0,906 \\
\hline \multirow{2}{*}{ Teste de Esfericidade de } & Qui-quadrado Aprox & 1770,323 \\
Bartlett & Gl & 276 \\
& Sig. & 0,000 \\
\hline
\end{tabular}

A identificação do número mínimo de componentes pelo método PC revelou, assim como na escala apresentada anteriormente, valores diferentes de acordo com o critério adotado, variando de dois a quatro componentes. O critério teórico analisado pelo PAF se mostrou ajustável empiricamente de forma a optar-se pela manutenção do número de componentes em três, assim como foi proposto originalmente por Bruno-Faria e Veiga (2015).

A estrutura fatorial de três fatores alcançou uma variância total explicada de 56,14\%. A escala teve um item excluído, passando a ser composta por 23 itens. Todos os Alphas de Cronbach dos fatores extraídos foram próximos a 0,88 .

A Tabela 8 apresenta a estrutura empírica da escala, as cargas fatoriais, comunalidades $\left(\mathrm{h}^{2}\right)$, índices de consistência interna dos fatores, além de valores próprios e percentuais de variância explicada dos fatores. 
Tabela 8 - Estrutura Fatorial da Escala de Condições Desfavoráveis à Criatividade

\begin{tabular}{|c|c|c|c|c|}
\hline Variáveis & F1 & $\mathbf{F 2}$ & $\mathbf{F 3}$ & $\mathbf{h}^{2}$ \\
\hline $\begin{array}{l}\text { 28. O sistema de comunicação da organização dificulta a } \\
\text { disseminação de informaçôes entre as diferentes áreas na } \\
\text { organização. }\end{array}$ & 0,74 & & & 0,55 \\
\hline $\begin{array}{l}\text { 49. Na Organização, o excesso de burocracia dificulta a expressão } \\
\text { da criatividade. }\end{array}$ & 0,73 & & & 0,55 \\
\hline $\begin{array}{l}\text { 29. A rigidez das regras na organização dificulta o surgimento de } \\
\text { novas ideias. }\end{array}$ & 0,72 & & & 0,63 \\
\hline $\begin{array}{l}\text { 30. A estrutura atual da Organização dificulta a comunicação entre } \\
\text { as áreas impedindo o compartilhamento de ideias. }\end{array}$ & 0,71 & & & 0,59 \\
\hline $\begin{array}{l}\text { 45. Falta flexibilidade nos normativos da organização o que dificulta } \\
\text { a aceitação de ideias novas. }\end{array}$ & 0,67 & & & 0,50 \\
\hline $\begin{array}{l}\text { 58. Há dificuldades de comunicação entre os setores que criam e os } \\
\text { que executam as normas na minha Organização. }\end{array}$ & 0,65 & & & 0,55 \\
\hline $\begin{array}{l}\text { 59. As regras que temos que seguir na Organização dificultam a } \\
\text { introdução de ideias criativas. }\end{array}$ & 0,61 & & & 0,68 \\
\hline $\begin{array}{l}\text { 11. A falta de compartilhamento de informações entre as áreas } \\
\text { dificulta a proposição de novas ideias úteis à organização. }\end{array}$ & 0,59 & & & 0,39 \\
\hline $\begin{array}{l}\text { 10. Os normativos internos não permitem alterações a partir de } \\
\text { sugestões dos empregados. }\end{array}$ & 0,48 & & & 0,25 \\
\hline $\begin{array}{l}\text { 24. O excesso de serviços impede que eu tenha tempo para refletir } \\
\text { sobre o melhor modo de realizá-los. }\end{array}$ & & 0,80 & & 0,72 \\
\hline $\begin{array}{l}\text { 13. As atividades pelas quais sou responsável exigem mais tempo do } \\
\text { que disponho. }\end{array}$ & & 0,74 & & 0,58 \\
\hline 50. Não tenho o tempo necessário para desenvolver novas ideias & & 0,72 & & 0,68 \\
\hline $\begin{array}{l}\text { 56. A falta de pessoal para a realização do trabalho limita o tempo } \\
\text { para criar. }\end{array}$ & & 0,64 & & 0,65 \\
\hline $\begin{array}{l}\text { 7. Não tenho tempo para experimentar novas formas de execução } \\
\text { das tarefas sob a minha responsabilidade. }\end{array}$ & & 0,64 & & 0,49 \\
\hline $\begin{array}{l}\text { 43. As atividades que realizo caracterizam-se pela constante } \\
\text { interrupção para resolver algo urgente, dificultando a produção de } \\
\text { ideias novas e de valor. }\end{array}$ & & 0,59 & & 0,53 \\
\hline $\begin{array}{l}\text { 25. Quando proponho uma ideia nova, é comum que o gerente se } \\
\text { aposse dela como se fosse sua. }\end{array}$ & & & 0,84 & 0,65 \\
\hline $\begin{array}{l}\text { 48. Meu gerente imediato tem receio de que eu apresente melhor } \\
\text { desempenho do que ele no trabalho. }\end{array}$ & & & 0,77 & 0,66 \\
\hline $\begin{array}{l}\text { 44. O gerente acredita que somente é correta a maneira como ele } \\
\text { realiza o trabalho. }\end{array}$ & & & 0,74 & 0,64 \\
\hline $\begin{array}{l}\text { 57. O gerente não discute ideias novas com seus colaboradores } \\
\text { devido ao desconhecimento das atividades do setor. }\end{array}$ & & & 0,67 & 0,52 \\
\hline $\begin{array}{l}\text { 26. O gerente costuma acatar apenas as ideias dos colaboradores } \\
\text { que ele tem mais afinidade. }\end{array}$ & & & 0,58 & 0,61 \\
\hline $\begin{array}{l}\text { 27. Os gestores não costumam ouvir ideias de pessoas que ocupam } \\
\text { menor nível hierárquico. }\end{array}$ & & & 0,52 & 0,57 \\
\hline $\begin{array}{l}\text { 8. Meu gerente não submete as ideias que o grupo de trabalho } \\
\text { propõe à avaliação de seus superiores hierárquicos, visando análise } \\
\text { e possível aprovação. }\end{array}$ & & & 0,52 & 0,36 \\
\hline $\begin{array}{l}\text { 31. O gerente toma decisões sobre atividades sem consultar aqueles } \\
\text { que irão realizá-las. }\end{array}$ & & & 0,51 & 0,54 \\
\hline Auto valor (Eigenvalues): & 10,17 & 2,56 & 1,44 & \\
\hline \% da Variância explicada & 42,37 & 9,52 & 4,24 & \\
\hline Número de itens & 9 & 6 & 8 & \\
\hline Alpha de Cronbach & 0,887 & 0,885 & 0,888 & \\
\hline
\end{tabular}

Nota: Foram omitidas as cargas fatoriais inferiores a 0,4 
O Fator 1, denominado Dificuldade de comunicação e rigidez das normas e regras na organização, foi formado por nove itens que, segundo Bruno-Faria e Veiga (2015, p.497) constituem:

Obstáculos à troca de informações entre áreas e/ou setores da organização que
dificultam a criatividade, grau elevado de padronização no modo de realizar as
atividades e o excesso de regras existentes na organização que dificultam a
expressão da criatividade dos trabalhadores.

O item "O sistema de comunicação da organização dificulta a disseminação de informações entre as diferentes áreas na organização" $(0,74)$ apresentou a maior carga no fator enquanto o item "Os normativos internos não permitem alterações a partir de sugestões dos empregados" $(0,48)$ foi o mais baixo do fator e da escala como um todo.

O Fator 2, denominado Excesso de serviço e escassez de tempo, agrupou seis itens, bem como originalmente proposto pela escala, que tratam da relação tempo versus volume de trabalho que dificultam na criação de soluções e ideias.

O item com maior poder de explicação do fator foi "O excesso de serviços impede que eu tenha tempo para refletir sobre o melhor modo de realizá-los" $(0,80)$ e o de menor poder foi "As atividades que realizo caracterizam-se pela constante interrupção para resolver algo urgente, dificultando a produção de ideias novas e de valor" $(0,59)$. O item "A falta de pessoal para a realização do trabalho limita o tempo para criar" apresentou carga relevante no Fator 1(0,33) além do Fator $2(0,64)$.

O Fator 3, denominado Atuação inadequada do gerente, foi reduzido para oito itens em sua composição em relação a escala original, e diz respeito a comportamentos do gestor que dificultam ou impedem a expressão de novas ideias em sua equipe de trabalho.

O item excluído por apresentar ambivalência com baixa amplitude foi "Os gerentes costumam acatar apenas ideias que sejam semelhantes às que ele apresenta". O item mais expressivo, não somente no fator mas em toda a escala foi "Quando proponho uma ideia nova, é comum que o gerente se aposse dela como se fosse sua" $(0,84)$ e o item de menor cargo do fator foi "O gerente toma decisões sobre atividades sem consultar aqueles que irão realizá-las" $(0,51)$.

Dois itens apresentaram ambivalências significativas com os fatores 3 e 1. Foram eles: "O gerente costuma acatar apenas as ideias dos colaboradores que ele tem mais afinidade" (Fator 3: 0,58 e Fator 1: 0,37) e "Os gestores não costumam ouvir ideias de pessoas que ocupam menor nível hierárquico" (Fator 3: 0,52 e Fator 1: 0,33). 
$\mathrm{Na}$ Tabela 9 encontra-se a matriz de correlação entre os fatores da escala de Condições Desfavoráveis à Criatividade.

Tabela 9 - Matriz de Correlação entre Fatores da Escala de Condições Desfavoráveis à Criatividade

\begin{tabular}{lccc}
\hline & $\begin{array}{c}\text { Dificuldade de comunicação } \\
\text { e rigidez das normas e } \\
\text { regras na organização }\end{array}$ & $\begin{array}{c}\text { Excesso de } \\
\text { serviço e escassez } \\
\text { de tempo }\end{array}$ & $\begin{array}{c}\text { Atuação } \\
\text { inadequada } \\
\text { do gerente }\end{array}$ \\
\hline $\begin{array}{l}\text { Dificuldade de comunicação e rigidez das } \\
\text { normas e regras na organização }\end{array}$ & 1,00 & & \\
$\begin{array}{l}\text { Excesso de serviço e escassez de tempo } \\
\text { Atuação inadequada do gerente }\end{array}$ & 0,54 & 1,00 & 1,00 \\
\hline
\end{tabular}

Analisando o coeficiente de correlação entre os fatores, segundo os parâmetros recomendados por Field (2009), foi observado que todas as correlações são positivas de efeito médio $( \pm 0,3)$ e alto $( \pm 0,5)$, sugerindo a interdependência entre si e a possibilidade de serem subfatores de um fator de segunda ordem. Para estudos futuros caberiam análises considerando um fator geral para a escala de Condições Desfavoráveis à Criatividade.

\subsubsection{Análise fatorial e consistência interna da escala de Estratégias de Aprendizagem}

$\mathrm{Na}$ análise de fatorabilidade da matriz de correlação da escala de Estratégia de Aprendizagem, foi percebida na inspeção visual da matriz que $69,54 \%$ das correlações foram superiores a 0,3 e inferiores à 0,9 . O menor coeficiente apontou uma correlação de 0,04. Como apresentado na Tabela 10, o teste de esfericidade de Bartlett foi significativo $(\mathrm{p}<0,001)$ e o KMO foi superior a 0,8. Assim, os índices de fatorabilidade e adequação da matriz foram adequados.

Tabela 10 - KMO e Teste de Bartlett da Matriz de Correlação da Escala de Condições Desfavoráveis à Criatividade

\begin{tabular}{ll|r}
\hline \multicolumn{2}{c|}{ Índice de Adequação da Amostra Kaiser-Meyer-Olkin } & 0,892 \\
\hline \multirow{2}{*}{ Teste de Esfericidade de } & Qui-quadrado Aprox & 3076,550 \\
Bartlett & Gl & 325 \\
& Sig. & 0,000 \\
\hline
\end{tabular}

Da mesma forma que ocorreu com as escalas de Condições para Criar, o número mínimo de componentes pelo método PC indicou valores diferentes de acordo com cada 
critério adotado, variando de três a cinco componentes. A análise segundo o critério teórico sugeriu uma estrutura de cinco componentes que foi analisada utilizando o método PAF e mostrou conflitos com a proposta empírica estudada. O principal problema evidenciado residiu na eliminação de variáveis ambivalentes que resultaram na exclusão de um dos fatores originais por falta de itens relacionados a ele.

Diante do não ajuste empírico da estrutura original, o número de fatores foi reduzido como indicado pelo de análise paralela. Foram realizadas análises de fatoração com três e quatro componentes e julgou-se mais adequada a estrutura formada por quatro componentes pela maior porcentagem de explicação da variância total, de 69,01\% e maior proximidade à estrutura original proposta por Brandão e Borges-Andrade (2011). O número de itens foi reduzido de 26 para 25 itens com cargas fatoriais entre 0,92 e 0,41 .

A Tabela 11 apresenta a estrutura empírica da escala, as cargas fatoriais e comunalidade $\left(\mathrm{h}^{2}\right)$ dos itens, os índices de consistência interna autovalores e valores percentuais de variância explicada de cada fator.

Tabela 11 - Estrutura Fatorial da Escala de Estratégias de Aprendizagem

\begin{tabular}{|c|c|c|c|c|c|}
\hline Variáveis & F1 & F2 & F3 & F4 & $\mathbf{h}^{2}$ \\
\hline $\begin{array}{l}\text { 22. Procuro compreender como o meu trabalho está relacionado aos } \\
\text { resultados obtidos nas diferentes áreas da organização }\end{array}$ & 0,90 & & & & 0,83 \\
\hline $\begin{array}{l}\text { 18. Busco entender como diferentes aspectos do meu trabalho estão } \\
\text { relacionados entre si }\end{array}$ & 0,86 & & & & 0,70 \\
\hline $\begin{array}{l}\text { 17. Para aprimorar a execução de minhas atividades, procuro } \\
\text { compreender melhor cada procedimento e tarefa do meu trabalho }\end{array}$ & 0,85 & & & & 0,83 \\
\hline $\begin{array}{l}\text { 9. Quando faço meu trabalho, penso em como ele está relacionado } \\
\text { ao negócio e às estratégias da organização }\end{array}$ & 0,84 & & & & 0,64 \\
\hline $\begin{array}{l}\text { 10. Tento compreender como a atuação das diferentes áreas da } \\
\text { organização influencia a execução do meu trabalho }\end{array}$ & 0,84 & & & & 0,75 \\
\hline $\begin{array}{l}\text { 26. Tento conhecer como as diferentes áreas da organização estão } \\
\text { relacionadas entre si }\end{array}$ & 0,81 & & & & 0,80 \\
\hline $\begin{array}{l}\text { 25. Busco compreender as relações entre as demandas feitas por } \\
\text { outras áreas da organização e a finalidade do meu trabalho }\end{array}$ & 0,78 & & & & 0,78 \\
\hline $\begin{array}{l}\text { 21. Para melhor execução do meu trabalho, reflito sobre como ele } \\
\text { contribui para atender as expectativas dos clientes }\end{array}$ & 0,78 & & & & 0,74 \\
\hline $\begin{array}{l}\text { 6. Analisando criticamente a execução do meu trabalho, tento } \\
\text { compreendê-lo melhor }\end{array}$ & 0,65 & & & & 0,62 \\
\hline $\begin{array}{l}\text { 23. Procuro aprimorar algum procedimento de trabalho, } \\
\text { experimentando na prática novas maneiras de executá-lo }\end{array}$ & 0,62 & & & & 0,64 \\
\hline $\begin{array}{l}\text { 24. Testo novos conhecimentos aplicando-os na prática do meu } \\
\text { trabalho }\end{array}$ & 0,53 & & & & 0,64 \\
\hline $\begin{array}{l}\text { 7. Visando executar melhor minhas atividades de trabalho, busco } \\
\text { repetir automaticamente ações e procedimentos memorizados }\end{array}$ & & 0,93 & & & 0,82 \\
\hline $\begin{array}{l}\text { 8. Para executar melhor o meu trabalho, procuro repetir } \\
\text { mentalmente informações e conhecimentos recém-adquiridos }\end{array}$ & & 0,80 & & & 0,69 \\
\hline $\begin{array}{l}\text { 4. Para aprimorar a execução do meu trabalho, busco memorizar } \\
\text { dados ( } n^{\circ} \text { de rubricas, contas, transações em sistemas, etc.) }\end{array}$ & & 0,63 & & & 0,50 \\
\hline
\end{tabular}




\begin{tabular}{|c|c|c|c|c|c|}
\hline Variáveis & F1 & $\mathbf{F 2}$ & F3 & $\mathbf{F 4}$ & $\mathbf{h}^{2}$ \\
\hline $\begin{array}{l}\text { 5. Para melhor execução do meu trabalho, procuro seguir sempre os } \\
\text { mesmos procedimentos }\end{array}$ & & 0,62 & & & 0,39 \\
\hline $\begin{array}{l}\text { 14. Quando estou em dúvida sobre algo no trabalho, consulto } \\
\text { normativos e instruções editadas pela organização }\end{array}$ & & & 0,80 & & 0,65 \\
\hline $\begin{array}{l}\text { 15. Para obter as informações de que necessito para o trabalho, leio } \\
\text { informativos e matérias publicadas na agência de notícias }\end{array}$ & & & 0,75 & & 0,51 \\
\hline $\begin{array}{l}\text { 11. Quando tenho dúvidas sobre algo no trabalho, procuro ajuda em } \\
\text { publicações, informativos, fascículos e relatórios da empresa }\end{array}$ & & & 0,68 & & 0,60 \\
\hline $\begin{array}{l}\text { 12. Consultando informações disponíveis na intranet, busco } \\
\text { compreender melhor as atividades que executo no trabalho }\end{array}$ & & & 0,59 & & 0,63 \\
\hline $\begin{array}{l}\text { 16. Visando obter informações importantes à execução do meu } \\
\text { trabalho, consulto a Internet }\end{array}$ & & & 0,44 & & 0,42 \\
\hline $\begin{array}{l}\text { 19. Procuro obter novos conhecimentos e informações consultando } \\
\text { colegas de outras equipes }\end{array}$ & & & & 0,83 & 0,79 \\
\hline $\begin{array}{l}\text { 2. Quando tenho dúvidas sobre algo no trabalho, consulto colegas de } \\
\text { outras áreas da empresa }\end{array}$ & & & & 0,75 & 0,50 \\
\hline $\begin{array}{l}\text { 1. Busco ajuda dos meus colegas quando necessito de informações } \\
\text { mais detalhadas sobre o trabalho }\end{array}$ & & & & 0,61 & 0,54 \\
\hline $\begin{array}{l}\text { 20. Consulto colegas de trabalho mais experientes, quando tenho } \\
\text { dúvidas sobre algum assunto relacionado ao meu trabalho }\end{array}$ & & & & 0,54 & 0,68 \\
\hline $\begin{array}{l}\text { 13. Peço ajuda aos meus colegas de equipe quando necessito } \\
\text { aprender algo sobre meu trabalho }\end{array}$ & & & & 0,42 & 0,50 \\
\hline Auto valor (Eigenvalues): & 11,71 & 2,70 & 1,88 & 1,33 & \\
\hline \% da Variância explicada & 45,99 & 10,41 & 7,37 & 5,24 & \\
\hline Número de itens & 11 & 4 & 5 & 5 & \\
\hline Alpha de Cronbach & 0,95 & 0,83 & 0,831 & 0,835 & \\
\hline
\end{tabular}

Nota. Foram omitidas as cargas fatoriais inferiores a 0,4

O Fator 1, nomeado Aplicação prática e reflexão ativa, foi composto de 11 itens pertencentes a dois fatores da escala original de Brandão e Borges-Andrade (2011) que tratam da experimentação prática de conhecimentos que estão sendo aprendidos, aliado à reflexão sistêmica do indivíduo quanto ao trabalho e seus demais componentes relacionados.

Este não é o primeiro trabalho envolvendo a identificação de evidências de validade em escalas de estratégias de aprendizagem que resultou na união do fator comportamental de aplicação prática com as estratégias cognitivas de reflexão ativa ou suas variantes originalmente propostas por Warr e Allan (1998), reflexão intrínseca e extrínseca. Na escala de Pantoja (2004) e nos trabalhos subsequentes que envolveram a validação dessa escala (LOPES-RIBEIRO, 2005; BEVILÁQUA-CHAVES, 2007; CARVALHO-SILVA, 2009), um dos fatores identificados diz respeito a aplicação prática e reflexão intrínseca tratados conjuntamente. Na descrição desse fator, Beviláqua-Chaves (2007, p.37) explica que este fator trata de estratégias de aprendizagem que

se referem às tentativas do indivíduo de colocar em prática e testar as informações e conhecimentos enquanto aprende. Envolvem também a sua opinião acerca da busca de entendimento, acerca dos relacionamentos e interdependências existentes entre todas as partes que constituem o seu trabalho. 
$\mathrm{Na}$ unificação dos fatores, o item "Experimento na prática novas formas de executar o meu trabalho", originalmente do fator Aplicação prática, foi excluído por apresentar ambivalência com amplitude menor do que 0,1. Os itens extremos foram "Procuro compreender como o meu trabalho está relacionado aos resultados obtidos nas diferentes áreas da organização" $(0,90)$ e "Testo novos conhecimentos aplicando-os na prática do meu trabalho" $(0,53)$.

O Fator 2, denominado Reprodução, composto por quatro itens, diz respeito às práticas de repetição e memorização de informações livre de análises de significado. Este fator foi confirmado quanto a sua estrutura em relação a escala original e possui como variáveis de maior e menor cargas fatoriais os itens "Visando executar melhor minhas atividades de trabalho, busco repetir automaticamente ações e procedimentos memorizados" $(0,93)$ e "Para melhor execução do meu trabalho, procuro seguir sempre os mesmos procedimentos" $(0,62)$, respectivamente.

O Fator 3, denominado Busca de ajuda em material escrito, também condizente com a escala original, foi composta por cinco itens que "remete a pesquisa e a localização de informações em documentos, manuais, normativos, livros e outras fontes não-sociais" (BRANDÃO; BORGES-ANDRADE, 2011, p. 452) na intenção de fixar um conhecimento aprendido. O item "Quando estou em dúvida sobre algo no trabalho, consulto normativos e instruções editadas pela organização" $(0,80)$ apresentou maior carga no fator enquanto o item "Visando obter informações importantes à execução do meu trabalho, consulto a Internet" $(0,44)$ foi o menos significativo dos itens, tanto para o fator quanto para a escala como um todo.

Por fim, o Fator 4, denominado Busca de ajuda interpessoal, foi composto de cinco itens referentes a ação do indivíduo na obtenção de apoio social na aprendizagem. Este fator confirma a escala original com os itens extremos "Procuro obter novos conhecimentos e informações consultando colegas de outras equipes" (0,83) e "Peço ajuda aos meus colegas de equipe quando necessito aprender algo sobre meu trabalho" $(0,42)$ e ambivalência no item "Consulto colegas de trabalho mais experientes, quando tenho dúvidas sobre algum assunto relacionado ao meu trabalho" $(0,54)$ com o Fator $1(0,32)$.

Na Tabela 12 é apresentada a matriz de correlação entre os fatores da Escala de Estratégias de Aprendizagem. 
Tabela 12 - Matriz de Correlação entre Fatores da Escala de Estratégias de Aprendizagem

\begin{tabular}{ccccc}
\hline & $\begin{array}{c}\text { Aplicação } \\
\text { prática e } \\
\text { reflexão ativa }\end{array}$ & Reprodução & $\begin{array}{c}\text { Busca de ajuda } \\
\text { em material } \\
\text { escrito }\end{array}$ & $\begin{array}{c}\text { Busca de } \\
\text { ajuda } \\
\text { interpessoal }\end{array}$ \\
\hline Aplicação prática e reflexão ativa & 1,00 & & & \\
Reprodução & 0,29 & 1,00 & & \\
Busca de ajuda em material escrito & 0,47 & 0,10 & 1,00 & \\
Busca de ajuda interpessoal & 0,61 & 0,17 & 0,45 & 1,00 \\
\hline
\end{tabular}

Considerando as análises realizadas e o aporte teórico das medidas, avaliou-se como adequados os instrumentos empregados pela pesquisa para mensurar os construtos analisados. A sessão seguinte apresenta os resultados percebidos pelos participantes sobre Condições para Criar e Estratégias de Aprendizagem em seu ambiente de trabalho.

\subsection{Condições para Criar e Estratégias de Aprendizagem percebidas}

Visando descrever a percepção dos participantes da pesquisa quanto às condições favoráveis e desfavoráveis à criatividade e descrever a frequência com que utilizam estratégias de aprendizagem em seu ambiente de trabalho, inicialmente foram calculados os escores fatoriais, a partir das médias das respostas dos itens pertencentes a cada fator, e foram realizadas análises estatísticas descritivas (média e desvio padrão) dos escores fatoriais.

As médias e desvio padrão (DP) de todos os fatores são apresentados em ordem decrescente nas Tabelas 13 e 14.

Tabela 13 - Média e Desvio Padrão dos fatores de Condições Favoráveis e Desfavoráveis à Criatividade no Ambiente de Trabalho

\begin{tabular}{l|c|c}
\hline \multicolumn{1}{c|}{ Fatores de Condições Favoráveis à Criatividade } & Média & DP \\
\hline Liberdade de Ação e Atividades Desafiantes & 4,53 & 0,52 \\
\hline Características do Ambiente Físico & 4,06 & 0,77 \\
\hline Clima entre Colegas de trabalho & 3,99 & 0,98 \\
\hline Estímulos a novas ideias por colegas, gerente imediato e ações organizacionais & 3,95 & 0,75 \\
\hline \multicolumn{1}{c|}{ Fatores de Condições Desfavoráveis à Criatividade } & Média & DP \\
\hline Excesso de Serviço e Escassez de Tempo & 2,89 & 1,15 \\
\hline Dificuldades de comunicação e rigidez das normas e regras na organização & 2,68 & 1,01 \\
\hline Atuação Inadequada do Gerente & 2,23 & 1,03 \\
\hline
\end{tabular}

No que diz respeito às condições favoráveis à expressão da criatividade no contexto de trabalho pesquisado, em uma escala de 1 a 5, em que 1 significa "Discordo Totalmente" e 5, "Concordo Totalmente", os respondentes percebem a Liberdade de ação e atividades desafiantes (média $=4,53$ e DP $=0,52$ ) como aspecto mais presente em seu ambiente de 
trabalho, seguido de Características do ambiente físico (média $=4,06$ e DP $=0,77$ ). Os aspectos favoráveis à expressão da criatividade menos percebidos foram aqueles relacionados a Estímulos a novas ideias por colegas, gerente imediato e ações organizacionais. (média = $3,95$ e DP $=0,75)$.

Quanto às condições desfavoráveis à expressão da criatividade, de acordo com a mesma escala de 1 a 5, foi percebido o Excesso de serviço e a escassez de tempo. (média = $2,89$ e DP $=1,15)$ como aspecto mais presente no ambiente de trabalho. Atuação inadequada do gerente (média $=2,23$ e DP $=1,03$ ) foi o aspecto desfavorável menos percebido.

$\mathrm{Na}$ procura de suposições que expliquem os resultados obtidos sobre as condições para criar no ambiente de trabalho das AABBs, algumas particularidades do serviço prestado e de características organizacionais dos clubes podem ser consideradas.

Segundo descrito na caracterização da organização estudada, a estrutura organizacional dos clubes que fazem parte do Sistema AABB apresenta nenhum ou poucos níveis intermediários de comando, dependendo de seu porte e necessidade. Somado a isso, a diversidade de serviços e opções de entretenimento oferecidos (parques aquáticos, eventos de recreação, churrasqueiras, quadras e campos de esporte, etc.) não requerem cargos de chefia específicos para cada tipo de serviço prestado. Assim, poucos gestores supervisionam diferentes funcionários com funções muito diversificadas. Tais características podem ser o motivo do alto grau de autonomia percebido pelos funcionários dos clubes.

Da mesma forma, o fato de haver um número reduzido de supervisores para cada serviço aliado à diversidade de trabalhos supervisionados pode levar a uma sobrecarga de trabalho para os gerentes e ter sido a razão pela qual a atuação inadequada dos gerentes ter sido o aspecto desfavorável à criatividade mais indicado pelos pesquisados. É recomendável que esses motivos sejam investigados em estudos futuros.

Outra característica relevante diz respeito ao expediente praticado pela organização. Por trabalhar com serviços voltados ao lazer e entretenimento, os empregados dos clubes estão sujeitos a jornadas de trabalho que contemplam finais de semana e eventos noturnos. Talvez, essa peculiaridade explique a percepção do excesso de serviço e escassez de tempo como um aspecto desfavorável à expressão criativa.

De forma geral, os aspectos favoráveis à criatividade foram mais percebidos do que os fatores desfavoráveis, levantando indícios de um ambiente de trabalho mais favorável à expressão da criatividade. 
Os dados parecem indicar que, segundo a percepção dos participantes da pesquisa, o ambiente de trabalho das $\mathrm{AABBs}$ se mostra propício à expressão da criatividade mais em função da natureza diversificada dos serviços oferecidos e pelo ambiente de lazer e entretenimento do que necessariamente pelo incentivo deliberado por parte da equipe de trabalho, gestores e da organização. Se confirmada essa proposição, o estabelecimento de política que atue sobre o ambiente de trabalho dos clubes pode apresentar um potencial em favor da criatividade ainda maior, caso esta passe a ser incentivada nesse contexto por meio ações, práticas e comportamentos de apoio a produção criativa.

Tabela 14 - Média e Desvio Padrão dos fatores de Estratégias de Aprendizagem no Trabalho

\begin{tabular}{l|c|c}
\multicolumn{1}{c|}{ Fatores de Estratégias de Aprendizagem } & Média & DP \\
\hline Aplicação Prática e Reflexão Ativa & 8,75 & 1,14 \\
\hline Busca de Ajuda Interpessoal & 8,63 & 1,24 \\
\hline Busca de Ajuda em Material Escrito & 8,27 & 1,62 \\
\hline Reprodução & 7,68 & 1,77 \\
\hline
\end{tabular}

Tratando das estratégias de aprendizagem utilizadas pelos participantes em seu ambiente de trabalho, em uma escala de 1 a 10, na qual 1 significa "Nunca faço" e 10 "Sempre faço", as estratégias relacionadas a Aplicação Prática e Reflexão Ativa (média = 8,75 e DP $=1,14$ ) e Busca de Ajuda Interpessoal (média = 8,63 e DP =1,24) foram percebidas como as mais praticadas. A estratégia de aprendizagem menos utilizada segundo o relato dos participantes foi a Reprodução (média $=7,68$ e DP =1,77).

De forma geral, todas as estratégias de aprendizagem demonstraram ser em maior ou menor grau, praticadas no ambiente de trabalho da rede de clubes estudada. Novamente, para justificar essa constatação, é possível analisar as características relacionadas à autonomia e grau de liberdade na execução de múltiplos serviços altamente diversificados como elementos que podem reforçar a utilização de práticas informais aprendizagem. Pantoja e BorgesAndrade (2009, p.57), buscando categorizar diferentes ocupações profissionais que são mais impactadas por determinados tipos de estratégias de aprendizagem, argumentam que

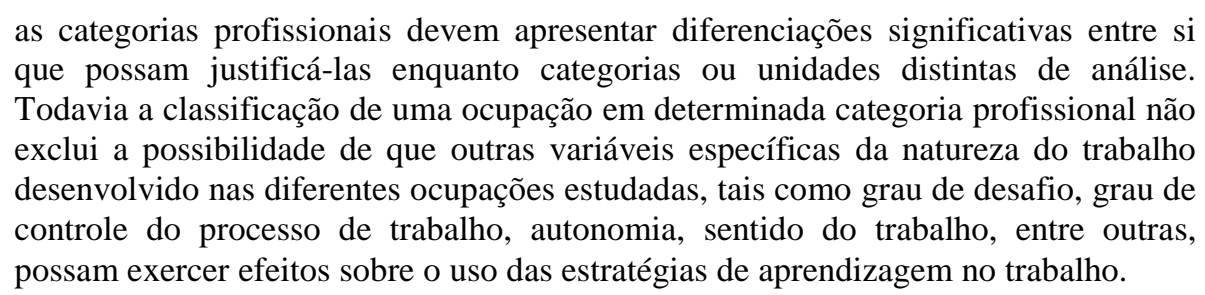

A sessão seguinte relata os resultados quanto à relação entre Condições para Criar e Estratégias de Aprendizagem. 


\subsection{Relação entre Condições para Criar e Estratégias de Aprendizagem}

A análise da relação entre as condições para criar no ambiente de trabalho e o emprego de estratégias de aprendizagem foi realizada em duas etapas. Primeiro foram realizadas as correlações entre Condições Favoráveis à Criatividade e Estratégias de Aprendizagem. Em seguida foram feitas as correlações entre as Condições Desfavoráveis à Criatividade e as Estratégias de Aprendizagem.

Inicialmente haviam sido formuladas hipóteses sobre as possíveis correlações existentes entre as condições para criar e estratégias de aprendizagem com base nos fatores proposto por Bruno-Faria e Veiga (2015) e Brandão e Borges-Andrade (2011), respectivamente. Entretanto, após a análise fatorial das escalas, identificou-se estruturas fatoriais diferentes das iniciais, sendo necessário redefinir as hipóteses tendo como base as novas estruturas das escalas. Considerando que os fatores unificados compreendem e conservam os aspectos dos fatores originais, as hipóteses iniciais foram adaptadas segundo o esquema apresentado na Figura 8.

Figura 8 - Hipóteses de Pesquisa na Nova Estrutura Fatorial

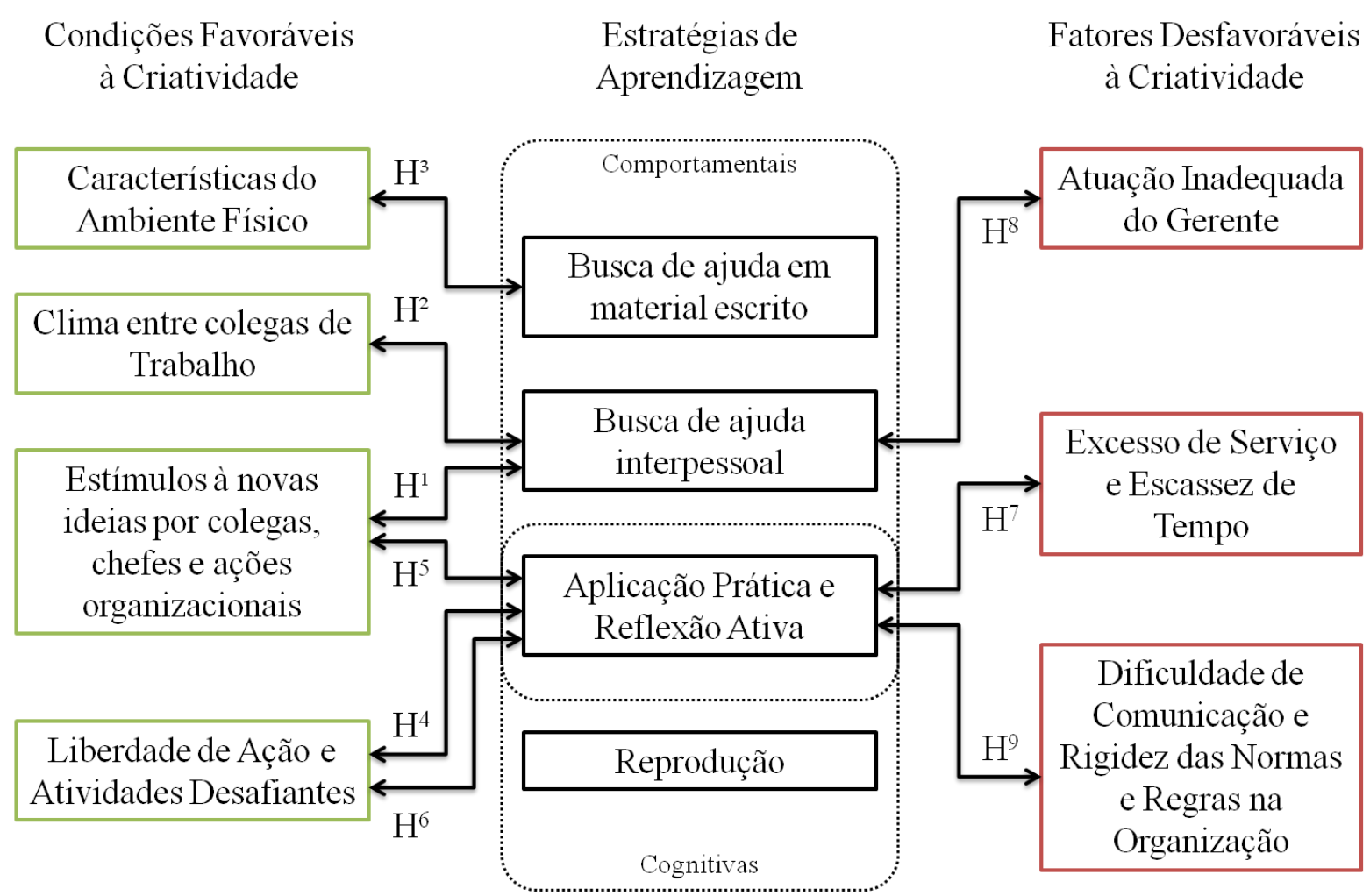


Dessa forma, as hipótese iniciais foram assim reformuladas com base no mesmo referencial adotado:

- $H^{1}$ : Condições favoráveis à criatividade referentes aos Estímulos a novas ideias por colegas, chefes e ações organizacionais estão relacionadas positivamente com a utilização de estratégias de aprendizagem de Busca de Ajuda Interpessoal.

- $H^{2}$ : Condições favoráveis à criatividade referentes ao Clima entre Colegas de Trabalho estão relacionadas positivamente com a utilização de estratégias de aprendizagem de Busca de Ajuda Interpessoal.

- $H^{3}$ : Condições favoráveis à criatividade referentes a Características do Ambiente Físico estão relacionadas positivamente com a utilização de estratégias de aprendizagem de Busca de Ajuda em Material Escrito.

- $H^{4}$ : Condições favoráveis à criatividade referentes a Liberdade de ação $e$ atividades desafiantes estão relacionadas positivamente com a utilização de estratégias de aprendizagem de Aplicação prática e reflexão ativa.

- $H^{5}$ : Condições favoráveis à criatividade referentes a Estímulos a novas ideias por colegas, chefes e ações organizacionais estão relacionadas positivamente com a utilização de estratégias de aprendizagem de Aplicação prática $e$ reflexão ativa.

- $H^{6}$ : Condições favoráveis à criatividade referentes a Liberdade de ação $e$ atividades desafiantes estão relacionadas positivamente com a utilização de estratégias de aprendizagem de Aplicação prática e reflexão ativa.

- $H^{7}$ : Condições desfavoráveis à criatividade referentes ao Excesso de Serviço e Escassez de Tempo estão relacionadas negativamente com a utilização de estratégias de aprendizagem de Aplicação prática e reflexão ativa.

- $\quad H^{8}$ : Condições desfavoráveis à criatividade referentes a Atuação Inadequada do Gerente estão relacionadas negativamente com a utilização de estratégias de aprendizagem de Busca de Ajuda Interpessoal.

- $H^{9}$ : Condições desfavoráveis à criatividade referentes a Dificuldade de comunicação e rigidez das normas e regras na organização estão relacionadas negativamente com a utilização de estratégias de aprendizagem de Aplicação prática e reflexão ativa. 
Como foi citado na seção 3.2 de hipóteses da pesquisa no Capítulo 3, além das hipóteses inicialmente levantadas, identificadas pela letra " $H^{n "}$, outras relações são possíveis de serem evidenciadas empiricamente e foram identificadas pela letra " $X^{n}$ ". Um esquema com todas as relações evidenciadas, inicialmente previstas e novas, será apresentado ao final do capítulo.

O método de análise da correlação utilizou o coeficiente de Spearman dado que a distribuição dos dados coletados não atendeu os pressupostos de normalidade. A utilização deste teste estatístico não paramétrico classifica os dados antes de aplicar a equação de Pearson (FIELD, 2009). O coeficiente de correlação deve variar entre -1 e +1 , indicando em seus extremos, respectivamente, um relacionamento negativo perfeito e um relacionamento positivo perfeito (FIELD, 2009).

Para medir o tamanho do efeito da correlação com base nos valores de seus coeficientes, Field (2009) indica como medida mais comumente usada o valor de $|0,1|$ representando um efeito baixo, $|0,3|$ representando um efeito médio e $|0,5|$ um efeito grande.

Ao final desta seção é apresentado um quadro resumo das relações descritas a seguir.

A Tabela 15 apresenta a matriz de correlação entre os fatores da escala de Condições Favoráveis à Criatividade e de Estratégias de aprendizagem com os respectivos coeficientes de correlação (Coef.) e níveis de significância (Sig.).

Tabela 15 - Correlação entre os fatores de Condições Favoráveis à Criatividade e Estratégias de Aprendizagem.

\begin{tabular}{|c|c|c|c|c|c|}
\hline & & $\begin{array}{c}\text { Busca de } \\
\text { ajuda } \\
\text { interpessoal }\end{array}$ & $\begin{array}{c}\text { Aplicação } \\
\text { prática e } \\
\text { reflexão ativa }\end{array}$ & Reprodução & $\begin{array}{c}\text { Busca de ajuda } \\
\text { em material } \\
\text { escrito }\end{array}$ \\
\hline \multirow{2}{*}{$\begin{array}{l}\text { Características do ambiente } \\
\text { físico }\end{array}$} & Coef. & $\mathbf{0 , 2 0 7}{ }^{\text {*** }}$ & $0,166^{*}$ & & $0,201^{\text {*** }}$ \\
\hline & Sig. & 0,006 & 0,028 & & 0,008 \\
\hline \multirow{2}{*}{$\begin{array}{l}\text { Clima entre colegas de } \\
\text { trabalho }\end{array}$} & Coef. & $0,201^{* *}$ & & & \\
\hline & Sig. & 0,008 & & & \\
\hline \multirow{2}{*}{$\begin{array}{l}\text { Liberdade de ação e } \\
\text { atividades desafiantes }\end{array}$} & Coef. & 0,330 *** & $0,431^{* * *}$ & & $0,313^{* * *}$ \\
\hline & Sig. & $\mathbf{0 , 0 0 0}$ & 0,000 & & 0,000 \\
\hline \multirow{2}{*}{$\begin{array}{l}\text { Estímulos a novas ideias por } \\
\text { colegas, chefes e ações } \\
\text { organizacionais }\end{array}$} & Coef. & $0,246^{* * *}$ & $0,312^{\text {*** }}$ & $0,204^{* * *}$ & $0,285^{* * *}$ \\
\hline & Sig. & 0,001 & 0,000 & 0,007 & 0,000 \\
\hline
\end{tabular}

As análises apontaram 11 correlações entre os fatores de Condições Favoráveis para Criar com as Estratégias de Aprendizagem. As correlações mais significativas $(\mathrm{p}<0,01)$ tiveram coeficientes de efeito pequeno e médio variando entre 0,2 e 0,43 . A única correlação significativa à $95 \%$ teve um coeficiente de 0,17 . 
Analisando as correlações apresentadas na Tabela 15 é possível identificar associações que foram anteriormente hipotetizadas segundo a Figura 6 na seção 3.2. Além disso, como antecipado, outras relações não previstas inicialmente foram encontradas.

Segundo os resultados encontrados, todas as relações identificadas entre os fatores de Condições favoráveis à Criatividade e os fatores de Estratégias de Aprendizagem apresentaram correlações positivas. Esse é um indicativo de que à medida que aspectos favoráveis à expressão da criatividade são mais percebidos, a utilização de estratégias de aprendizagem pelos funcionários da organização no ambiente de trabalho também são mais frequentes.

Esse indicativo positivo é mais evidente em se tratando da estratégia de aprendizagem Busca de ajuda interpessoal que está correlacionada com todos os fatores de condições favoráveis com uma alta significância $(\mathrm{p}<0,01)$. Assim, à medida que o ambiente se torna mais favorável à criatividade, percebe-se também uma maior predisposição dos funcionários a buscar auxilio de outras pessoas para aprender. Essa constatação confirma as seguintes hipóteses:

- $\quad H^{1}$ : Condições favoráveis à criatividade referentes a Estímulos a novas ideias por colegas, chefes e ações organizacionais estão relacionadas positivamente com a utilização de estratégias de aprendizagem de Busca de Ajuda Interpessoal. (Coef.: 0,25)

- $H^{2}$ : Condições favoráveis à criatividade referentes ao Clima entre Colegas de Trabalho estão relacionadas positivamente com a utilização de estratégias de aprendizagem de Busca de Ajuda Interpessoal. (Coef.: 0,20)

Além disso, as seguintes relações foram identificadas:

- $X^{I}$ : Condições favoráveis à criatividade referentes a Características do ambiente físico estão relacionadas positivamente com a utilização de estratégias de aprendizagem de Busca de ajuda interpessoal. (Coef.:0,21)

- $X^{2}$ : Condições favoráveis à criatividade referentes a Liberdade de ação $e$ atividades desafiantes estão relacionadas positivamente com a utilização de estratégias de aprendizagem de Busca de ajuda interpessoal. (Coef.: 0,33).

Esse resultado destaca a importância de se estudar a relação entre a busca por condições de trabalho favoráveis à expressão da criatividade e as práticas informais de aprendizagem em contextos que primam pelo trabalho em equipe. Qualquer aspecto que favoreça a expressão criativa dos indivíduos nesse contexto estaria associado positivamente 
com a frequência de utilização de práticas informais de auxílio interpessoal no aprendizado. Uma equipe que se sinta em um ambiente cada vez mais favorável à criação, também pode vir a ser uma equipe que interage na busca de aprender.

O fator de condição favorável à criatividade Estímulos a novas ideias por colegas, chefes e ações organizacionais indicou correlação com todas as estratégias de aprendizagem. Dessa forma à medida que o incentivo ativo por parte de colegas, chefes e por ações promovidas pela organização para gerar ideias é trabalhado, é possível que se perceba um maior emprego de diversas técnicas informais para garantir o aprendizado dos funcionários. Assim, além da confirmação já apresentada da hipótese 1, a seguinte hipótese também pode ser confirmada:

- $\quad H^{5}$ : Condições favoráveis à criatividade referentes a Estímulos a novas ideias por colegas, chefes e ações organizacionais estão relacionadas positivamente com a utilização de estratégias de aprendizagem de Aplicação prática $e$ reflexão ativa. (Coef.: 0,31)

Adicionalmente, as seguintes relações puderam ser evidenciadas:

- $\quad X^{3}$ : Condições favoráveis à criatividade referentes a Estímulos a novas ideias por colegas, chefes e ações organizacionais estão relacionadas positivamente com a utilização de estratégias de aprendizagem de Reprodução. (Coef.: 0,20)

- $\quad X^{4}$ : Condições favoráveis à criatividade referentes a Estímulos a novas ideias por colegas, chefes e ações organizacionais estão relacionadas positivamente com a utilização de estratégias de aprendizagem de Busca de ajuda em material escrito. (Coef.: 0,29)

Analisando os resultados obtidos nas organizações estudadas, chama atenção o fato de apesar dos estímulos à novas ideias impulsionadas pela equipe de trabalho e ações organizacionais impactarem na utilização de todas as estratégias de aprendizagem aqui analisadas, este aspecto das condições favoráveis é o menos percebido em relação aos demais fatores (média $=3,95$ e DP $=0,75$ ). Essa constatação aponta uma das principais melhorias a serem trabalhadas pelos gestores das $\mathrm{AABBs}$ que queiram melhorar o aprendizagem de seus funcionários em seu contexto de trabalho.

Analisando tal relação é possível supor a presença de um terceiro fenômeno influenciando os aspectos de condições para criar e estratégias de aprendizagem. Esse fenômeno consiste na motivação desenvolvida pelo indivíduo em aprender ou no interesse 
pelo seu desenvolvimento no trabalho à medida que percebe uma intenção deliberada da organização ou da equipe de trabalho em estimulá-lo a ser criativo no serviço.

Segundo Alencar (1995), inúmeras pesquisas têm apontado para a motivação intrínseca como um fator muito poderoso para a criatividade. Um indivíduo motivado, com alto grau de envolvimento, apresentará certamente alto nível de dedicação ao trabalho (ALENCAR, 1995). Da mesma forma, Carvalho-Silva (2008), estudando a relação entre o clima social da organização, motivação dos indivíduos para aprender e o uso de estratégias para aprender informalmente no trabalho, evidenciou empiricamente a motivação como uma importante preditora do uso de estratégias de aprendizagem. Assim, seria de grande relevância investigar esse tipo de interação com outros fenômenos em pesquisas futuras sobre o tema.

A correlação mais alta alcançada entre os fatores das Condições Favoráveis à Criatividade e os fatores de Estratégia de Aprendizagem foi entre Liberdade de ação $e$ atividades desafiantes e aplicação prática e reflexão ativa (Coef.: 0,43). Com isso, as seguintes hipóteses foram confirmadas por meio desses fatores:

- $H^{4}$ : Condições favoráveis à criatividade referentes a Liberdade de ação $e$ atividades desafiantes estão relacionadas positivamente com a utilização de estratégias de aprendizagem de Aplicação prática e reflexão ativa.

- $H^{6}$ : Condições favoráveis à criatividade referentes a Liberdade de ação $e$ atividades desafiantes estão relacionadas positivamente com a utilização de estratégias de aprendizagem de Aplicação prática e reflexão ativa.

Além disso, ambos os fatores foram as condições favoráveis e estratégias de aprendizagem mais evidenciadas nas organizações pesquisadas. Constata-se aqui a relação mais significativa e presente no sistema de clubes pesquisado baseado em experimentações e aprendizado atrelado a própria execução de serviços desafiantes que requerem flexibilidade e autonomia.

O fator Liberdade de ação e atividades desafiantes apresentou ainda correlação com a utilização da estratégia de aprendizagem Busca de ajuda em material escrito (Coef.: 0,31). Ou seja:

- $X^{5}$ : Condições favoráveis à criatividade referentes a Liberdade de ação $e$ atividades desafiantes estão relacionadas positivamente com a utilização de estratégias de aprendizagem de Busca de ajuda em material escrito. 
Com esta última, o fator Liberdade de ação e atividades desafiantes apresentou as três correlações de maior efeito entre as escalas de Condições Favoráveis à Criatividade e de Estratégias de Aprendizagem, variando o coeficiente de correlação entre 0,43 e 0,31.

Dessa forma, pode-se inferir que em ambientes de trabalho marcados pela complexidade e dinamismo, que demandam um maior grau de autonomia e/ou recursos tecnológicos ou materiais, é possível identificar os maiores efeitos da relação existente entre condições para criar e estratégias de aprendizagem. Da mesma forma, apesar de serem necessários mais estudos sobre o assunto, seria possível supor que os maiores efeitos da associação entre os dois construtos podem ser percebidos nas pessoas mais alinhadas com esse tipo de contexto. Esse perfil é descrito por Alencar (1998) que identifica nas pessoas caracterizadas pela iniciativa, independência de pensamento e ação, flexibilidade, persistência e autoconfiança, maiores chances de aproveitar e desenvolver ideias criativas.

A correlação entre o fator de condição favorável à criatividade Características do ambiente físico e o fator de estratégia de aprendizagem Busca de ajuda em material escrito obteve um dos menores efeitos significativos à 0,01 (Coef.: 0,20). Tal correlação, confirma a seguinte hipótese:

- $H^{3}$ : Condições favoráveis à criatividade referentes a Características do Ambiente Físico estão relacionadas positivamente com a utilização de estratégias de aprendizagem de Busca de Ajuda em Material Escrito.

Por fim, a menor correlação evidenciada entre as duas escalas foi entre Características do Ambiente Físico e Aplicação prática e reflexão ativa (Coef.: 0,17). Esta foi a única correlação significativa a 0,05. Assim:

- $X^{6}$ : Condições favoráveis à criatividade referentes a Características do Ambiente Físico estão relacionadas positivamente com a utilização de estratégias de aprendizagem de Aplicação prática e reflexão ativa.

A Tabela 16 apresenta a matriz de correlação entre os fatores da escala de Condições Desfavoráveis à Criatividade e de Estratégias de aprendizagem com os respectivos coeficientes de correlação (Coef.) e níveis de significância (Sig.). 
Tabela 16 - Correlação entre os fatores de Condições Desfavoráveis à Criatividade e Estratégias de Aprendizagem.

\begin{tabular}{|c|c|c|c|c|c|}
\hline & & $\begin{array}{c}\text { Busca de } \\
\text { ajuda } \\
\text { interpessoal } \\
\end{array}$ & $\begin{array}{c}\text { Aplicação } \\
\text { prática e } \\
\text { reflexão ativa } \\
\end{array}$ & Reprodução & $\begin{array}{c}\text { Busca de ajuda } \\
\text { em material } \\
\text { escrito } \\
\end{array}$ \\
\hline $\begin{array}{l}\text { Excesso de serviço e escassez } \\
\text { de tempo }\end{array}$ & $\begin{array}{l}\text { Coef. } \\
\text { Sig. }\end{array}$ & $\begin{array}{r}-, 198 \\
, 009\end{array}$ & & & \\
\hline $\begin{array}{l}\text { Atuação inadequada do } \\
\text { gerente }\end{array}$ & $\begin{array}{l}\text { Coef. } \\
\text { Sig. }\end{array}$ & $\begin{array}{r}-, 162^{*} \\
, 032\end{array}$ & $\begin{array}{r}-, 153^{*} \\
, 043\end{array}$ & & \\
\hline $\begin{array}{l}\text { Dificuldade de comunicação e } \\
\text { rigidez das normas e regras } \\
\text { na organização }\end{array}$ & $\begin{array}{l}\text { Coef. } \\
\text { Sig. }\end{array}$ & & & & \\
\hline
\end{tabular}

Nota: $* * \mathrm{p}<0,01$ e $* \mathrm{p}<0,05$

Quanto a relação entre Condições Desfavoráveis à criatividade e as Estratégias de Aprendizagem, foram identificadas correlações negativas de pequeno efeito em três associações de fatores, variando entre -0,20 e -0,15.

Assim como na análise de correlação anterior, na Tabela 16 é possível identificar associações previstas anteriormente como destacado na Figura 6 na seção 3.2 e novas relações não indicadas inicialmente foram encontradas. Entretanto, também houveram hipóteses não evidenciadas empiricamente.

Todas as relações identificadas entre os fatores de Condições Desfavoráveis à Criatividade e os fatores de Estratégias de Aprendizagem apresentaram correlações negativas apontando que, à medida que aspectos desfavoráveis à expressão da criatividade são mais percebidos, a utilização de algumas estratégias de aprendizagem no ambiente de trabalho também passam a ser menos frequentes.

Não foram identificadas relações entre o fator de condições desfavoráveis Dificuldade de comunicação e rigidez das normas e regras na organização com qualquer uma das estratégias de aprendizagem investigadas. Assim, com base nessa pesquisa, não é possível afirmar que aspectos organizacionais como rigidez burocrática e obstáculos na comunicação entre áreas e setores impactam na frequência com que são observadas as práticas informais de aprendizagem no ambiente de trabalho.

Analisando essa constatação, parece razoável a não identificação dessa relação dado que as estratégias de aprendizagem, vistas como uma prática informal dos próprios indivíduos, não possuem relação clara com as normas e regras definidas pela organização.

Os fatores da escala de Estratégia de Aprendizagem Reprodução e Busca de ajuda em material escrito não apresentaram correlações significativas com qualquer fator da escala de Condições Desfavoráveis à Criatividade. Dessa forma, não é possível afirmar com base nos 
dados levantados que condições desfavoráveis à expressão criativa em maior ou menor grau impactam na utilização de estratégias de aprendizagem pelos funcionários da organização.

A maior correlação identificada foi entre o fator de Excesso de serviço e escassez de tempo de condições desfavoráveis à criatividade com o fator Busca de ajuda interpessoal de estratégia de aprendizagem (Coef.: -0,20), sendo a única correlação à nível de significância de 0,01. Em outras palavras:

- $\quad X^{7}$ : Condições desfavoráveis à criatividade referentes ao Excesso de serviço $e$ escassez de tempo estão relacionadas negativamente com a utilização das estratégias de aprendizagem Busca de ajuda interpessoal.

Assim, constata-se que quanto maior a demanda extra de atividades e maior a falta de tempo disponível para outras tarefas, menos serão utilizadas técnicas de aprendizagem informal voltadas à busca de auxilio interpessoal.

Analisando a percepção dos dois fatores no ambiente dos clubes pesquisados, é possível identificar que a condição desfavorável mais evidenciada (média $=2,89$ e DP $=$ 1,15), impacta na estratégia de aprendizagem Busca de ajuda interpessoal (segunda estratégia mais utilizada pelos funcionários das $\mathrm{AABBs}$ ) (média = 8,63 e DP = 1,24). Esta constatação reflete uma possibilidade de melhoria latente a ser trabalhada pelos gestores a fim de otimizar a aprendizagem e o emprego do potencial criativo de seus funcionários por meio de ações que impactem ambos os fenômenos. Melhorando a condição desfavorável de escassez de tempo e excesso de serviço, poderá estar favorecendo ou reforçando a aprendizagem por meio da ajuda interpessoal.

As demais correlações identificadas entre condições desfavoráveis e estratégias de aprendizagem foram entre os fatores Atuação inadequada do gerente e Busca de ajuda interpessoal (Coef.: -0,16) e entre os fatores Atuação inadequada do gerente e Aplicação prática e reflexão ativa (Coef.: -0,15), ambas à um nível de significância de 0,05 . A primeira correlação confirma a seguinte hipótese:

- $\quad H^{8}$ : Condições desfavoráveis à criatividade referentes a Atuação Inadequada do Gerente estão relacionadas negativamente com a utilização de estratégias de aprendizagem de Busca de Ajuda Interpessoal.

A menor correlação entre as escalas de Condições Desfavoráveis à criatividade e de Estratégias de Aprendizagem indica que: 
- $\quad X^{8}$ : Condições desfavoráveis à criatividade referentes a Atuação inadequada do gerente estão relacionadas negativamente com a utilização das estratégias de aprendizagem de Aplicação prática e reflexão ativa.

Com isso, constata-se a condição desfavorável à criatividade menos percebida ("Atuação inadequada do gerente"; média = 2,23 e DP = 1,03) está correlacionada com as duas estratégias de aprendizagem mais utilizadas pelos funcionários no ambiente de trabalho pesquisado ("Busca de Ajuda Interpessoal" e "Aplicação prática e reflexão ativa"; médias = 8,63 e 8,75 e DP $=1,24$ e 1,14, respectivamente). Esse fato constitui um ponto bastante positivo para o Sistema $\mathrm{AABB}$ quando se trata de minimizar aspectos desfavoráveis à criatividade que podem interferir também na aprendizagem no contexto de trabalho.

Portanto, cabe destacar a importância da manutenção da liderança positiva para que não hajam comportamentos que desfavoreçam â expressão criativa. Tratando do papel do Líder na organização, Parolin (2003), citando os trabalhos de Moscovici (1997 apud PAROLIN, 2003) sobre trabalho em grupo, considera que se o indivíduo aprender a pensar criticamente, enfrentar situações novas sem pânico e de forma mais livre ou criativa, confiar em si e nos outros, descobrir e desenvolver suas potencialidades, no sentido de torna-se mais autêntico e produtivo, poderá estar melhor preparado para enfrentar as mudanças.

Duas outras hipóteses levantadas inicialmente não foram confirmadas empiricamente por meio dos resultados obtidos nessa pesquisa:

- $H^{7}$ : Condições desfavoráveis à criatividade referentes ao Excesso de Serviço e Escassez de Tempo estão relacionadas negativamente com a utilização de estratégias de aprendizagem de Aplicação prática e reflexão ativa.

- $H^{9}$ : Condições desfavoráveis à criatividade referentes a Dificuldade de comunicação e rigidez das normas e regras na organização estão relacionadas negativamente com a utilização de estratégias de aprendizagem de Aplicação prática e reflexão ativa.

Assim, das nove hipóteses de correlação sugeridas com base no referencial teórico levantado antes da coleta e análise dos dados, seis puderam ser confirmadas empiricamente e oito novas associações foram identificas. A Figura 9 apresenta uma versão atualizada das correlações identificadas nesta pesquisa considerando as hipóteses iniciais, novas relações identificadas e o tamanho do efeito das correlações. 
Figura 9 - Hipóteses Iniciais e Novas Relações

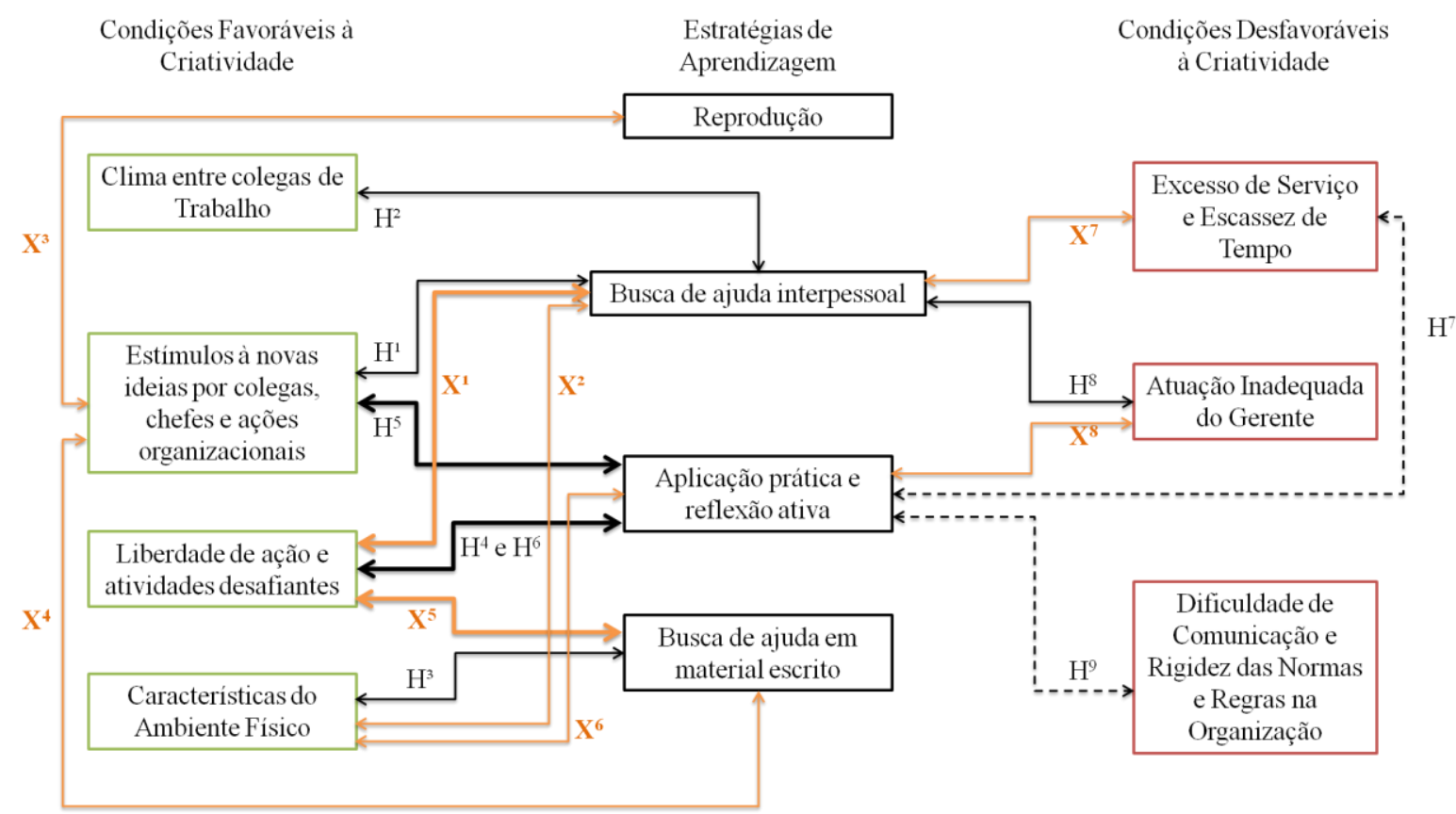

Legenda:

Hipótese inicial $(H)$ confirmada (efeito médio):

Hipótese inicial $(H)$ confirmada (efeito pequeno):

Hipótese inicial $(H)$ não confirmada:

Nova relação $(X)$ identificadas (efeito médio)

Nova relação $(X)$ identifícadas (efeito pequeno):

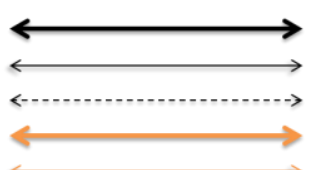

Nota: tamanho do efeito da correlação segundo Field (2009): pequeno $( \pm 0,1)$, médio $( \pm 0,3)$ e grande $( \pm 0,5)$

De forma geral, as relações identificadas são apresentadas, na ordem que foram relatadas no capítulo, no Quadro 11. 
Quadro 11 - Relações entre Condições para Criar e Estratégias de Aprendizagem

\begin{tabular}{|c|c|c|c|c|}
\hline $\begin{array}{l}\text { Fator de Condições para Criar } \\
\text { (Favorável e Desfavorável) }\end{array}$ & $\begin{array}{c}\text { Está relacionado com a } \\
\text { Estratégia de } \\
\text { Aprendizagem }\end{array}$ & $\begin{array}{l}\text { Direção } \\
\text { da } \\
\text { relação }\end{array}$ & $\begin{array}{c}\text { Tamanho } \\
\text { do efeito } \\
\text { da relação }\end{array}$ & $\begin{array}{l}\text { Hipótese } \\
\text { ou nova } \\
\text { relação }\end{array}$ \\
\hline $\begin{array}{l}\text { Estímulos a novas ideias por colegas, } \\
\text { chefes e ações organizacionais }\end{array}$ & Busca de Ajuda Interpessoal & Positivo & $\begin{array}{l}\text { Pequeno: } \\
\text { Coef.: } 0,25 \\
p<0,01\end{array}$ & $\mathrm{H}^{1}$ \\
\hline Clima entre Colegas de Trabalho & Busca de Ajuda Interpessoal & Positivo & $\begin{array}{l}\text { Pequeno: } \\
\text { Coef.: } 0,20 \\
\mathrm{p}<0,01\end{array}$ & $\mathrm{H}^{2}$ \\
\hline Características do ambiente físico & Busca de ajuda interpessoal & Positivo & $\begin{array}{l}\text { Pequeno: } \\
\text { Coef.:0,21, } \mathrm{p} \\
<0,01\end{array}$ & $\mathrm{X}^{1}$ \\
\hline $\begin{array}{l}\text { Liberdade de ação e atividades } \\
\text { desafiantes }\end{array}$ & Busca de ajuda interpessoal & Positivo & $\begin{array}{l}\text { Coef.: } 0,33 \\
p<0,01\end{array}$ & $X^{2}$ \\
\hline $\begin{array}{l}\text { Estímulos a novas ideias por colegas, } \\
\text { chefes e ações organizacionais }\end{array}$ & $\begin{array}{l}\text { Aplicação prática e reflexão } \\
\text { ativa }\end{array}$ & Positivo & $\begin{array}{l}\text { Médio: } \\
\text { Coef.: } 0,31 \\
\mathrm{p}<0,01\end{array}$ & $\mathrm{H}^{5}$ \\
\hline $\begin{array}{l}\text { Estímulos a novas ideias por colegas, } \\
\text { chefes e ações organizacionais }\end{array}$ & Reprodução & Positivo & $\begin{array}{l}\text { Pequeno: } \\
\text { Coef.: } 0,20, \\
\mathrm{p}<0,01\end{array}$ & $X^{3}$ \\
\hline $\begin{array}{l}\text { Estímulos a novas ideias por colegas, } \\
\text { chefes e ações organizacionais }\end{array}$ & $\begin{array}{l}\text { Busca de ajuda em material } \\
\text { escrito }\end{array}$ & Positivo & $\begin{array}{l}\text { Pequeno: } \\
\text { Coef.: } 0,29 \\
p<0,01\end{array}$ & $X^{4}$ \\
\hline $\begin{array}{l}\text { Liberdade de ação e atividades } \\
\text { desafiantes }\end{array}$ & $\begin{array}{l}\text { Aplicação prática e reflexão } \\
\text { ativa }\end{array}$ & Positivo & $\begin{array}{l}\text { Médio: } \\
\text { Coef.: } 0,43, \\
\mathrm{p}<0,01\end{array}$ & $H^{4}$ \\
\hline $\begin{array}{l}\text { Liberdade de ação e atividades } \\
\text { desafiantes }\end{array}$ & $\begin{array}{l}\text { Aplicação prática e reflexão } \\
\text { ativa }\end{array}$ & Positivo & $\begin{array}{l}\text { Médio: } \\
\text { Coef.: } 0,43, \\
p<0,01\end{array}$ & $H^{6}$ \\
\hline $\begin{array}{l}\text { Liberdade de ação e atividades } \\
\text { desafiantes }\end{array}$ & $\begin{array}{l}\text { Busca de ajuda em material } \\
\text { escrito }\end{array}$ & Positivo & $\begin{array}{l}\text { Médio: } \\
\text { Coef.: } 0,31 \\
\mathrm{p}<0,01\end{array}$ & $X^{5}$ \\
\hline Características do Ambiente Físico & $\begin{array}{l}\text { Busca de Ajuda em Material } \\
\text { Escrito }\end{array}$ & Positivo & $\begin{array}{l}\text { Pequeno: } \\
\text { Coef.: } 0,20, \\
\mathrm{p}<0,01\end{array}$ & $H^{3}$ \\
\hline Características do Ambiente Físico & $\begin{array}{l}\text { Aplicação prática e reflexão } \\
\text { ativa }\end{array}$ & Positivo & $\begin{array}{l}\text { Pequeno: } \\
\text { Coef.: } 0,17 \\
\mathrm{p}<0,05\end{array}$ & $X^{6}$ \\
\hline $\begin{array}{l}\text { Excesso de serviço e escassez de } \\
\text { tempo }\end{array}$ & Busca de ajuda interpessoal & Negativo & $\begin{array}{l}\text { Pequeno: } \\
\text { Coef.: }-0,20, \\
p<0,01\end{array}$ & $X^{7}$ \\
\hline Atuação Inadequada do Gerente & Busca de Ajuda Interpessoal & Negativo & $\begin{array}{l}\text { Pequeno: } \\
\text { Coef.: }-0,16, \\
p<0,05\end{array}$ & $H^{8}$ \\
\hline Atuação inadequada do gerente & $\begin{array}{l}\text { Aplicação prática e reflexão } \\
\text { ativa }\end{array}$ & Negativo & $\begin{array}{l}\text { Pequeno: } \\
\text { Coef.: }-0,15, \\
\mathrm{p}<0,05\end{array}$ & $X^{8}$ \\
\hline
\end{tabular}

As considerações finais deste trabalho são apresentadas no próximo capítulo. 


\section{CONSIDERAÇÕES FINAIS}

Este trabalho teve como objetivo identificar as relações existentes entre as condições para criar e o uso de estratégias de aprendizagem no ambiente de trabalho de uma rede de clubes de abrangência nacional. A partir da percepção dos funcionários pesquisados, buscouse identificar o relacionamento entre os aspectos favoráveis e desfavoráveis à expressão da criatividade e a frequência com que estratégias de aprendizagem são utilizadas no ambiente de trabalho.

$\mathrm{Na}$ coleta de dados da pesquisa foi disponibilizado um questionário eletrônico estruturado para todos os clubes tendo como público alvo funcionários efetivos da organização. Sobre os dados coletados foram feitas análises descritivas e exploratórias, além de técnicas multivariadas de análise.

A identificação de evidências de validade dos instrumentos de medida foi um dos objetivos do trabalho e teve como resultado três escalas com bons índices de confiabilidade interna. A escala de Condições Favoráveis à Criatividade demonstrou melhor ajuste com uma estrutura fatorial de quatro fatores. Considerando a escala original, dois fatores foram mantidos (Características do Ambiente Físico e Clima entre colegas de trabalho) e outros quatro fatores formaram dois novos fatores (Estímulos a novas ideias por colegas, gerente imediato e ações organizacionais e Liberdade de ação e atividades desafiantes). Ao todo, seis itens foram retirados para formar a nova estrutura com 30 itens. A escala de Condições Desfavoráveis à Criatividade confirmou sua estrutura fatorial, com a eliminação de apenas um item, passando a ser composta por 23 itens. Na escala de estratégias de aprendizagem, dois fatores foram aglomerados (Aplicação Prática e Reflexão Ativa) e a estrutura fatorial passou a ser formada por quatro fatores e 25 itens. Um item foi retirado.

Outro objetivo envolveu a análise da percepção dos participantes quanto às condições para criar e utilização das estratégias de aprendizagem.

De forma geral, aspectos favoráveis à expressão da criatividade foram percebidos de forma mais contundente do que os aspectos desfavoráveis à expressão criativa, sugerindo que, no Sistema $\mathrm{AABB}$, o ambiente de trabalho é propício à criatividade mas que, no entanto, devem ser objeto de atenção por parte dos gestores. Os aspectos favoráveis mais percebidos foram Liberdade de ação e atividades desafiantes e Características do ambiente físico. $\mathrm{O}$ aspecto favorável menos evidenciado foi Estímulos a novas ideias por colegas, gerente imediato e ações organizacionais. O aspecto desfavorável com maior número de respostas foi 
Excesso de Serviço e Escassez de Tempo, enquanto com menor número foi Atuação Inadequada do Gerente.

Em se tratando das estratégias de aprendizagem, de forma geral, todas as estratégias estudadas são praticadas pelos funcionários dos clubes em maior ou menor grau. As estratégias mais utilizadas, de acordo com os pesquisadores, são Aplicação Prática e Reflexão Ativa e Busca de Ajuda Interpessoal. A estratégia de aprendizagem menos praticada é Reprodução.

Como resultado principal da pesquisa foram identificadas relações associativas entre condições para criar no ambiente de trabalho e estratégias de aprendizagem. Seis das nove hipóteses levantadas inicialmente foram confirmadas empiricamente e outras oito relações não previstas também foram identificadas.

As condições favoráveis à criatividade têm relação positiva com a utilização das estratégias de aprendizagem, enquanto as condições desfavoráveis têm relação negativa.

Ao todo, foram identificadas mais relações significativas estatisticamente entre fatores de condições favoráveis à criar com as estratégias de aprendizagem (11) do que com as condições desfavoráveis à criatividade (3). O tamanho do efeito das relações identificadas foi médio (4) e pequeno (10).

A estratégia de aprendizagem Busca de ajuda interpessoal está relacionada com todos os fatores de condições para criar, exceto com Dificuldade de comunicação e rigidez das normas e regras na organização que não teve relação com nenhuma estratégia de aprendizagem. Isso pode demonstrar a relevância da compreensão sobre a relação entre a busca por condições de trabalho favoráveis à expressão da criatividade e a utilização de estratégias de aprendizagem em contextos de trabalho em equipe.

As relações de maior efeito entre condições para criar e estratégias de aprendizagem são do fator de condições favoráveis Liberdade de ação e atividades desafiantes com as estratégias de aprendizagem Aplicação prática e reflexão ativa, Busca de ajuda interpessoal e Busca de ajuda em material escrito. Assim, ambientes de trabalho complexos e dinâmicos, que requerem maior autonomia e recursos, parecem resultar em maiores efeitos entre condições para criar e estratégias de aprendizagem.

O aspecto de condição favorável à criatividade Estímulos a novas ideias por colegas, chefes e ações organizacionais está relacionado com todas as estratégias de aprendizagem podendo indicar um possível papel motivacional para aprender à medida que o funcionário é incentivado ativamente a buscar novidades. 
Com base nos resultados apontados, espera-se ter contribuído para a geração de novos conhecimentos nas áreas que tratam sobre os temas, principalmente por demonstrar empiricamente a relação entre condições para criar e estratégias de aprendizagem. Os dois fenômenos estão associados e podem vir a compor um modelo maior para a compreensão de fatores ambientais, sociais e do indivíduo sobre a criatividade e a aprendizagem nas organizações.

Outra contribuição valiosa está na compreensão por parte dos gestores do Sistema $\mathrm{AABB}$ sobre as condições que são oferecidas aos funcionários para expressar seu potencial criativo, sobre as práticas utilizadas por estes para garantir um aprendizado, e, principalmente sobre os aspectos que relaciona ambos. De posse dessas informações é possível configurar as práticas adotadas no ambiente de trabalho dos clubes de forma mais embasada para maximizar os ganhos com funcionários mais criativos e competentes no serviço.

Como limitações do estudo são apontados dois dificultadores observados no levantamento dos dados e na análise dos dados, relatados a seguir.

Quanto aos procedimentos de coleta de dados realizados, não houve contato direto com o público alvo de pesquisa para envio dos questionários. Com o repasse do acesso feito pela Federação das AABBs para os presidentes de cada uma das unidades da organização, estes ficaram responsáveis pelo repasse e mobilização dos funcionários para a pesquisa. Assim, não havendo garantias sobre a realização efetiva do repasse, é possível que muitos potenciais participantes da pesquisa não tiveram nem o conhecimento desta.

Algumas características dos dados levantados para realização do estudo podem ter representado limitações ao estudo. Tais características não permitiram a utilização de outras técnicas de análise multivariada, tais como regressão múltipla e modelos de equação estruturada. Hair et al. (2009) alerta para o risco de uso indiscriminado de técnicas estatísticas e a não observância de pressupostos para realização das análises. Portanto, para não comprometer os resultados da pesquisa, determinadas técnicas multivariadas menos robustas a violações de pressupostos estatísticos não foram utilizadas.

Com o intuito de aprofundar a análise dos dados, para além dos objetivos propostos neste estudo, e para dar continuidade a pesquisas nos temas deste estudo, algumas abordagens futuras podem ser sugeridas:

- Embasar, por meio de dados obtidos por métodos qualitativos (entrevistas, observações em campo, dentre outras), as suposições levantadas no estudo. 
- Analisar os resultados obtidos sobre a percepção dos pesquisados quanto às condições para criar e estratégias de aprendizagem comparando-os com variáveis sociodemográficas e variáveis do local de trabalho.

- Investigar na relação entre condições para criar e estratégias de aprendizagem evidências de previsão das variáveis de um em função das variáveis da outra. Para tanto, técnicas multivariadas baseadas em múltiplas variáveis independentes relacionadas com múltiplas variáveis dependentes seria o recomendado. Modelagem de equações estruturais e análise de correlação canônica são possibilidades para esses casos (HAIR et al., 2009).

Expandindo a pesquisa para outros contextos e abordagens, sugere-se a investigação da relação entre os dois fenômenos estudados em diferentes organizações e segmentos de negócio, bem como em amostras maiores e representativas.

Sugere-se ainda a elaboração de modelos que contemplem a relação das estratégias de aprendizagem e condições para criar com outras variáveis de contexto (clima, desempenho organizacional) e individuais ou em grupos (motivação, satisfação, competências, trabalho em equipe). Além disso, pode ser de grande valia estudos sobre o impacto da relação entre os construtos aqui pesquisados no contexto da aprendizagem formal.

A relação entre condições para criar e estratégias de aprendizagem faz parte de grande e complexo quebra-cabeças que procura compreender os aspectos mais relevantes da interação entre o indivíduo e o meio em que está inserido. Bem como neste trabalho, diversos outros fenômenos são estudados na intenção de identificar peças desse quebra-cabeças que, apesar de insolúvel em sua plenitude, refletem a constante busca pelo conhecimento necessário ao desenvolvimento e evolução do ser humano em seu contexto. 


\section{REFERÊNCIAS}

ABBAD, G. S.; CORRÊA, V. P.; MENESES, P. P. Avaliação de treinamentos a distância: relações entre estratégias de aprendizagem e satisfação com o treinamento. RAM - Revista de Administração Mackenzie, São Paulo, v.11, n.2, p.43-67, 2010.

ALENCAR, E. L. S. Criatividade. Brasília: Editora Universidade de Brasília 1993. 140 p

ALENCAR, E. L. S. Desenvolvendo a criatividade nas organizações: o desafio da inovação. RAE - Revista de Administração de Empresas, São Paulo, v.35, n.6, p.6-11, nov/dez. 1995.

ALENCAR, E. L. S. A gerência da criatividade: abrindo as janelas para a criatividade pessoal e nas organizações. São Paulo: Makron Books, 1996.

ALENCAR, E. L. S. Promovendo um ambiente favorável à criatividade nas organizações. RAE - Revista de Administração de Empresas, v.38, n.2, p.18-25, 1998.

ALENCAR, E. L. S. Creativity in Organizations: Facilitators and Inhibitors. In: MUMFORD, M. D. (Ed.). Handbook of organizational creativity. Academic Press, 2012. cap.5

AMABILE, T. M. et al. Assessing the work environment for creativity. Academy of management journal, v. 39, n. 5, p. 1154-1184, 1996.

ANDERSON, N. R.; WEST, M. A. Measuring climate for work group innovation: development and validation of the team climate inventory. Journal of organizational behavior, v. 19, n. 3, p. 235-258, 1998.

BEDANI, M. O impacto dos valores organizacionais na percepção de estímulos e barreiras à criatividade no ambiente de trabalho. RAM - Revista de Administração Mackenzie, v.13, n.3, 2012 .

BERINGS, M. G. M. C.; DOORNBOS, A. J.; SIMONS, P. R. Methodological practices in on-the-job learning research. Human resource development international, v. 9, n. 3, p. 333363, 2006.

BEVILÁQUA-CHAVES, A. Estratégias de aprendizagem no trabalho em contexto de mudança organizacional. 2007. 116 f. Dissertação (Mestrado em Psicologia Social, do Trabalho e das Organizações)-Universidade de Brasília, Brasília, 2007.

BORGES-ANDRADE, J. E.; MEIRA, M. As pesquisas sobre o comportamento organizacional no Brasil. [Resumo]. In: ASSOCIAÇÃO NACIONAL DE PESQUISA E PÓS-GRADUAÇÃO EM PSICOLOGIA (ORG.). CONGRESSO NORTE-NORDESTE DE PSICOLOGIA. 3. 2003. Resumo, v.1, p.386. João Pessoa: Brasil. 2003.

BRANDÃO, H. P. Aprendizagem, contexto, competência e desempenho: um estudo multinível. 2009. xi, 345., il. Tese (Doutorado em Psicologia Social, do Trabalho e das Organizações)-Universidade de Brasília, Brasília, 2009. 
BRANDÃO, H. P.; BORGES-ANDRADE, J. E. Desenvolvimento e validação de uma escala de estratégias de aprendizagem no trabalho. Psicologia: Reflexão e Crítica, v.24, n.3, p.448$457,2011$.

BRANDÃO, H. P.; BORGES-ANDRADE, J. E.; PUENTE-PALACIOS, K.; LAROS, J. A. Relationships between learning, context and competency: a multilevel study. BAR Brazilian Administration Review, v.9, n.1, p.1-22, 2012.

BRUNO-FARIA, M. F. Estímulos e barreiras à criatividade no ambiente de trabalho de uma instituição bancária. 1996. 188 f. Dissertação (Mestrado em Psicologia Social e do Trabalho). Instituto de Psicologia da Universidade de Brasília, Brasília, 1996.

BRUNO-FARIA, M. F.; ALENCAR, E. M. L. S. Estímulos e barreiras à criatividade no ambiente de trabalho. Revista de Administração, v.31, n.2, p.50-61, abr/jun. 1996.

BRUNO-FARIA, M. F.; ALENCAR, E. M. L. S. Indicadores de clima para a criatividade: um instrumento de medida da percepção de estímulos e barreiras à criatividade no ambiente de trabalho. Revista de Administração, n.33, v. 4, p. 86-91, 1998.

BRUNO-FARIA, M. F.; VEIGA, H. M. S.; MACEDO, L. F. Criatividade nas organizações: análise da produção científica nacional em periódicos e livros de Administração e Psicologia. Revista de Psicologia: Organizações e Trabalho. v.8, n.1, p.142-163, jan. /jun., 2008.

BRUNO-FARIA, M. F. Indicadores de Clima para a Criatividade no Ambiente de Trabalho. In: ALENCAR, E. M. L. S.; BRUNO-FARIA, M. F.; FLEITH, D. S. (Org.), Medidas de Criatividade: Teoria e Prática. Porto Alegre: Artmed, 2010. cap.6.

BRUNO-FARIA, M. F.; VEIGA, H. M. S. Indicadores de condições para criar no ambiente de trabalho: Evidências de validação empírica de uma medida. Revista de Administração. RAUSP, v.50, n.4, p.492-506, 2015.

CARVALHO-SILVA, A. R. Clima social da organização, motivação e aprendizagem no trabalho. 2008. 142 f., il. Dissertação (Mestrado em Psicologia Social, do Trabalho e das Organizações)-Universidade de Brasília, Brasília, 2008.

COELHO JUNIOR, F. A.; BORGES-ANDRADE, J. E. Uso do conceito de aprendizagem em estudos relacionados ao trabalho e organizações. Paideia, v.18, n.40, p.221-234, 2008.

COELHO JUNIOR, F. A.; MOURÃO, L. Suporte à aprendizagem informal no trabalho: uma proposta de articulação conceitual. RAM - Revista de Administração Mackenzie, v. 12, n. 6, Ed. Especial, p. 224-253, 2011.

COSTELlO, A. B.; OSBORNE, J. W. Best practices in exploratory factor analysis: four recommendations for getting the most from your analysis. Pract Assess Res Eval, v. 10, n. 7, 2005.

CRESPO, M. L. F. Construção de uma medida de clima criativo em organizações. Estud. psicol.(Campinas), v. 21, n. 2, p. 91-99, 2004. 
CRUZ JUNIOR, A. T.; CARVALHO, M. M.; LAURINDO, F. J. B. Estratégia e Estrutura: Em busca do alinhamento organizacional em um clube social esportivo. Gestão \& Produção, v. 12, n. 3, p. 429-441, 2005.

DAMÁSIO, B. F. Uso da análise fatorial exploratória em psicologia. Avaliação Psicológica, v.11, n.2, p.213-228, 2012.

EKVALL, G. Organizational climate for creativity and innovation. European journal of work and organizational psychology, v. 5, n. 1, p. 105-123, 1996.

FERNANDEZ, F. F. Estratégias de aprendizagem e domínio de competências em grupos de pesquisa. 2012. xii, 111 f., il. Dissertação (Mestrado em Administração)—Universidade de Brasília, Brasília, 2012.

FIELD, A. Descobrindo a Estatística usando o SPSS. Porto Alegre, Artmed, p. 688, 2009.

FREITAS, I. A.; BORGES-ANDRADE, H. P. Trilhas de aprendizagem como estratégia de TD\&E. In ANDRADE-BORGES, J. E.; ABBAD, G. da S.; MOURÃO, L. (Eds.), Treinamento, desenvolvimento e educação em organizações e trabalho: Fundamentos para a gestão de pessoas. Porto Alegre, RS: Artmed. 2006. p.97-113

FREITAS, A. D. G.; SANTANA, P. S.; RUAS, R. L. Criatividade nas Organizações e os processos de interação: Uma Análise Bibliométrica da Produção Internacional no Período de 2005 a 2015. In: V Encontro de Gestão de Pessoas e Relações de Trabalho (EnGPR). Salvador, 2015.

GIL, A. C. Como elaborar projetos de pesquisa. São Paulo, v. 5, p. 61, 2002.

HAIR, J. F. et al. Análise multivariada de dados. Bookman, 2009.

HENNESSEY, B. A.; AMABILE T. M. Creativity. Annual. Rev. Psychol. 61. p. 569-98, 2010

HOLMAN, D.; EPITROPAKI, O.; FERNIE, S. Understanding learning strategies in the workplace: a factor analytic investigation. Journal of Occupational and Organizational Psychology, v.74, n.5, p.675-681, 2001.

HOLMAN, D. et al. Job design and the employee innovation process: The mediating role of learning strategies. Journal of Business and Psychology, v. 27, n. 2, p. 177-191, 2012.

HORTA, D. M. O. Orientação para o mercado, criatividade, sucesso em novos produtos: um estudo de caso em uma empresa de Alta Tecnologia. 2006. 146f. Dissertação (Mestrado em Administração e Negócios). PUCRS, Faculdade de Administração, Contabilidade e Economia, Porto Alegre, 2006.

ISAKSEN, S. G.; LAUER, K. J.; EKVALL, G. Situational outlook questionnaire: A measure of the climate for creativity and change. Psychological reports, v. 85, n. 2, p. 665-674, 1999. 
ISIDRO-FILHO, A. Adoção de inovações apoiadas em tecnologia de informação e comunicação, formação de competências e estratégias de aprendizagem em hospitais. 2010. 102 f. Tese (Doutorado em Administração)-Universidade de Brasília, Brasília, 2010.

ISIDRO-FILHO, A.; GUIMARÃES, T. A.; PERIN, M. G.; LEUNG, R. Workplace learning strategies and professional competencies in innovation contexts in Brazilian hospitals. BAR Brazilian Administration Review, v.10, n.2, p.121-134, 2013.

JAMES, K.; DROWN, D. Organizations and creativity: trends in research, status of education and practice, agenda for the future. In: MUMFORD, M. D. (Ed.). Handbook of organizational creativity. Academic Press, 2012. cap. 2

LAROS, J. A. O uso da análise fatorial: algumas diretrizes para pesquisadores. In L. Pasquali (Ed.), Análise Fatorial Para Pesquisadores. p.181-202. Brasília: LabPAM, UnB. 2008.

LINS, M. P. B. E. Estratégias de aprendizagem no trabalho utilizadas por servidores do Tribunal de Contas da União que atuam em fiscalizações. 2009. 84 f. Monografia de pósgraduação, Universidade Gama Filho, Rio de Janeiro, 2009.

LINS, M. P. B. E. Predição de competências de liderança a partir do uso de estratégias de aprendizagem, horas de treinamento e motivação para aprender. 2011. $232 \mathrm{f}$. Dissertação (Mestrado em Psicologia Social, do Trabalho das Organizações, 2011.

LOPES-RIBEIRO, R. Motivação para aprendizagem informal no trabalho: construção de medidas e investigação de modelo teórico. 2005. x, 238 f. Dissertação (Mestrado) Universidade de Brasília, Instituto de Psicologia, 2005.

MATHISEN, G. E.; EINARSEN, S. A review of instruments assessing creative and innovative environments within organizations. Creativity Research Journal, v. 16, n. 1, p. 119-140, 2004.

MORAES, M. M.; LIMA,S. M. V. Estratégias para criar no trabalho: proposição teórica e validação psicométrica de medida. Paideia, v.19, n.44, p.367-377, 2009.

MORAES, V. V.; BORGES-ANDRADE, J. E. Aprendizagem relacionada ao trabalho. Revista Psicologia, v.10, n.2, p.112-128, 2010a.

MORAES, V. V.; BORGES-ANDRADE, J. E. Validação de escala de estratégias de aprendizagem no trabalho entre prefeitos (as) e secretários (as) municipais. Estudos de Psicologia, v.15, n.3, p.325-334, 2010b.

MUMFORD, M. D.; KIMBERLY, S. H.; ROBLEDO, I. C. Creativity in Organizations: Importance and Approaches. In: MUMFORD, M. D. (Ed.). Handbook of organizational creativity. Academic Press, 2012. cap.1

NEIVA, E. R.; ABBAD, G.; TRÓCCOLI, B. T. Roteiro para análise fatorial de dados. Brasília: Universidade de Brasília-UnB, Instituto de Psicologia, 2011. 
NEIVA, E. R.; PANTOJA, M. J. Aprendizagem e mudança organizacional: Das relações entre atitudes frente à mudança e estratégias de aprendizagem no trabalho. Interamerican Journal of Psychology, v.45, n.2, p.145-155, 2011.

PANTOJA, M. J. Estratégias de aprendizagem no trabalho e percepções de suporte à aprendizagem contínua: uma análise multinível. 2004. xiv, 199 f. Tese (Doutorado) Universidade de Brasília, Instituto de Psicologia, 2004.

PANTOJA, M. J. Mapeamento de Estratégias de Aprendizagem no Trabalho: exame de diferentes ocupações profissionais. In: ENCONTRO NACIONAL DOS PROGRAMAS DE PÓS-GRADUAÇÃO EM ADMINISTRAÇÃO, 29., 2005, Brasília. 2005.

PANTOJA, M. J.; BORGES-ANDRADE, J. E. Estratégias de aprendizagem no trabalho em diferentes ocupações profissionais. RAC - Eletrônica, v.3, n.1, p.41-62, 2009.

PANTOJA, J.; BORGES-ANDRADE, J. E.; LOPES-RIBEIRO, R. Desenvolvimento e validação de uma escala de medida de estratégias de aprendizagem no trabalho. In: CONGRESSO INTERAMERICANO DE PSICOLOGIA, 29., 2003, Lima: SI. Resumo, 2003.

PAROLIN, S. R. H. A criatividade nas organizações: um estudo comparativo das abordagens sociointeracionistas de apoio à gestão empresarial. Caderno de Pesquisas em Administração, v.10, n.1, p.9-26, 2003.

PAROLIN, S. R. H. et al. Etapa de processo de validação de instrumento de percepção da criatividade no ambiente organizacional pela ótica dos empregados. In: XXXI Encontro Nacional da ANPAD. Rio de Janeiro: EnANPAD, 2007.

PASQUALI, L. Análise Fatorial Para Pesquisadores. Brasília: LabPAM, UnB. p.320, 2008.

PASQUALI, L. Instrumentação psicológica: fundamentos e práticas. Porto Alegre: Artmed, p.560, 2010.

PATIL, V. H. et al. Efficient theory development and factor retention criteria: abandon the "eigenvalue greater than one" criterion. Journal of Business Research, v. 61, n. 2, p. 162$170,2008$.

PEREIRA, B.; MUSSI, C.; KNABBEN, A. Se sua empresa tiver um diferencial competitivo, então comece a recriá-lo: a influência da criatividade para o sucesso estratégico organizacional. In: XXII Encontro Nacional da ANPAD. Anais... Foz do Iguaçu: EnANPAD, p. 381-391, 1999.

PUCCIO, G. J.; CABRA, J. F. Organizational Creativity: A Systems Approach In: KAUFMAN, J. C.; STERNBERG, R. J. (Ed.). The Cambridge Handbook of Creativity. Cambridge University Press, 2010. cap. 8

RICKARDS, T.; JONES, L. J. Towards the identification of situational barriers to creative behaviors: The development of a self-report inventory. Creativity Research Journal, v. 4, n. 4, p. 303-315, 1991. 
ROBLEDO, I. C.; KIMBERLY, S. H.; PETERSON, D. R.; MUMFORD, M. D. Creativity in Organizations: Conclusions. In: MUMFORD, M. D. (Ed.). Handbook of organizational creativity. Academic Press, 2012. cap.27

RODRIGUES, L. D. D. M.; SILVA, R. L. Mas Afinal, como Influenciar a Criatividade nas Organizações?. Caderno de Pesquisas em Administração (REGE - Revista de Gestão), v.1, n.7, $2^{\circ}$ Trim. 1998.

SIEGEL, S. M.; KAEMMERER, W. F. Measuring the perceived support for innovation in organizations. Journal of Applied Psychology, v. 63, n. 5, p. 553, 1978.

SILVA, R. L.; RODRIGUES, L. D. D. M. Estimulando a criatividade das pessoas nas organizações. SINERGIA-Revista do Instituto de Ciências Econômicas, Administrativas e Contábeis, v.11, n.1, p.17-26, 2007.

SOUZA, C. S. Estratégias de aprendizagem e competências no trabalho. 2009. 152 f., il. Dissertação (Mestrado em Psicologia Social, do Trabalho e das Organizações)-Universidade de Brasília, Brasília, 2009.

TABACHNICK, B. G.; FIDELL, L. S. Using multivariate statistics. 6.ed., 2012.

TERRA, J. C. C. Gestão da criatividade. Revista de Administração da Universidade de São Paulo, v.35, n.3, 2000.

TUDDA, L.; SANTOS, A. A. B. Teorias para desenvolvimento da criatividade individual e organizacional. RAD - Revista Administração em Diálogo. v.13, n.1, 2011.

VALENTIM, M. L. P. Criatividade e inovação na atuação profissional. CRB-8 Digital, v.1, n.1, p.3-9, 2008.

VERGARA, S. C. Começando a definir a metodologia. In : Projetos e relatórios de pesquisa em administração. 6.ed. São Paulo: Atlas, 2005. cap. 4.

WARR, P.; ALLAN, C. Learning strategies and occupational training. International Review of Industrial and Organizational Psychology, v.13, p.83-121. 1998.

WARR, P.; DOWNING, J. Learning strategies, learning anxiety and knowledge acquisition. British Journal of Psychology, v.91, n.3, p.311-333, 2000.

ZERBINI, T. Estratégias de aprendizagem, reações aos procedimentos de um curso via internet, reações ao tutor e impacto do treinamento no trabalho. 2003. $154 \mathrm{f}$. Dissertação (Mestrado) - Universidade de Brasília, Instituto de Psicologia, 2003.

ZERBINI, T.; ABBAD, G. Impacto de treinamento no trabalho via internet. RAE eletrônica, v.4, n.2, 2005.

ZERBINI, T.; ABBAD, G. Estratégias de aprendizagem em curso a distância: validação de uma escala. PsicoUSF, v.13, n.2, p.177-187, 2008. 
ZERBINI, T.; CARVALHO, R. S.; ABBAD, G. Treinamento a distância via internet: construção e validação de escala de estratégias de aprendizagem. In: XXIX Encontro Nacional da ANPAD. Anais... Brasília: EnANPAD, 2005. 


\section{APÊNDICE}

\section{Apêndice A - Questionário contento os instrumentos de Condições para Criar e Estratégias de Aprendizagem no trabalho}

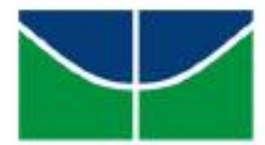

Universidade de Brasilia

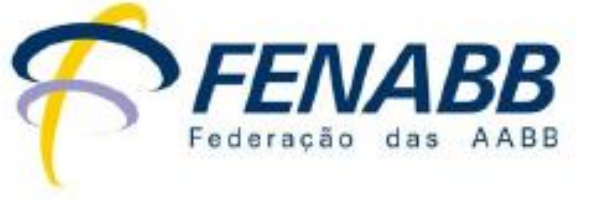

\section{Condições para Criar e Estratégias de Aprendizagem no Ambiente de Trabalho}

Apresentação da Pesquisa

Prezado(a),

Com o apoio da Federaçăo das AABB (FENABB), esta pesquisa cientifica tem como objetivo subsidiar um estudo sobre Criatividade e Aprendizagem no Sistema AABB. Para tanto, gostaria que respondesse todas as questōes sendo o mais sincero e imparcial possivel, baseado na percepçăo que tem sobre o seu ambiente de trabalho.

O questionário possui 3 blocos com os seguintes objetivos:

Bloco Criatividade: avaliar as condições para criar no ambiente de trabalho de sua organizaçăo;

Bloco Aprendizagem: identificar a frequếncia com que vocẻ utiliza estratégias de aprendizagem em seu contexto de trabalho.

Bloco Caracterizaçăo: coletar alguns dados a fim de levantar informaçōes gerais sobre os participantes da pesquisa.

As informaçāes aqui prestadas serão analisadas de forma agregada e sem a identificaçăo dos participantes, garantindo assim o sigilo e o anonimato dos respondentes. Năo existe resposta certa ou errada.

As questōes sinalizadas com " săo de preenchimento obrigatório. O tempo médio de resposta desta pesquisa é de aproximadamente 20 minutos.

Sua participaçăo é voluntária. Ao clicar em 'Próxima' e responder ao questionário, você manifesta concordância com o presente Termo de Consentimento Livre e Esclarecido.

Caso tenha aiguma dúvida, me coloco a disposição por e-mail e telefone/WhatsApp.

Obrigado por dedicar parte do seu tempo a esta pesquisa. 
* Ao lado de cada afirmativa, assinale o número que melhor corresponda a sua percepçăo sobre o ambiente em que desempenha a maior parte de suas atividades de trabalho, considerando a seguinte escala:

\begin{tabular}{|c|c|c|c|c|}
\hline 1 & 2 & 3 & 4 & 5 \\
\hline $\begin{array}{c}\text { Discordo } \\
\text { Plenamente }\end{array}$ & $\begin{array}{c}\text { Discordo } \\
\text { Pouco }\end{array}$ & Em dúvida & $\begin{array}{c}\text { Concordo } \\
\text { Pouco }\end{array}$ & $\begin{array}{c}\text { Concordo } \\
\text { Plenamente }\end{array}$ \\
\hline
\end{tabular}

Caso você entenda que a afirmativa năo se aplica ao seu ambiente de trabalho, assinale a opção "năo se aplica".

Nāo

se

$\begin{array}{llllll}1 & 2 & 3 & 4 & 5 & \text { aplica }\end{array}$

1. O mobiliário onde trabalho é adequado, o que ajuda a evitar doenças osteomusculares (DORT ou LER).

2. As conversas com os colegas no dia a dia de trabalho me estimulam a produzir novas ideias.

3. Tenho liberdade para oferecer sugestōes onde trabalho.

4. Sinto-me à vontade para dar ideias novas no trabalho, mesmo que sejam bem diferentes das ideias dos outros.

5. Sinto entusiasmo para realizar as atividades que me sāo destinadas.

6. O gerente oferece o apoio que necessito na realizaça de trabalhos que exigem a produçăo de ideias novas.

7. Nāo tenho tempo para experimentar novas formas de execuçāo das tarefas sob a minha responsabilidade.

8. Meu gerente não submete as ideias que o grupo de trabalho propōe à avaliaçăo de seus superiores hierárquicos, visando análise e possível aprovaçāo.

9. A minha organizaçăo realiza diferentes açōes para incentivar que os trabalhadores expressem sua criatividade.

10. Os normativos internos nāo permitem alteraçōes a partir de sugestōes dos empregados.

11. A falta de compartilhamento de informaçōes entre as áreas dificulta a proposiçāo de novas ideias úteis à organização. 
12. Os gerentes costumam acatar apenas ideias que sejam semelhantes as que ele apresenta.

13. As atividades pelas quais sou responsável exigem mais tempo do que disponho.

14. O gerente elogia as ideias novas e de valor que são apresentadas pelos empregados.

15. Meu gerente me estimula a dar sugestōes quanto ao aprimoramento dos serviços e/ou produtos que a Organização oferece.

16. A Organização incentiva a produçăo de ideias novas a partir de diferentes açбes (ex: concursos, banco de ideias, programas de criatividade, estimulo à apresentação de novos projetos, treinamentos etc.).

17. As tarefas que realizo são estimulantes.

18. Meus colegas me estimulam a dar sugestōes que contribuam para os resultados da organizaçăo.

19. No meu local de trabalho, as pessoas mostram boa vontade em ajudar umas às outras.

20. Meu gerente me estimula na busca por soluçōes originais para a resoluçāo de problemas cotidianos.

21. As tarefas que realizo no meu trabalho exigem o melhor de mim.

22. A Organizaçäo oferece acesso a uma variedade de fontes de informaçăo (livros, artigos, videos, dentre outros) que contribuem para o surgimento de ideias novas e de valor.

23. Meu gerente me estimula a experimentar novas formas de executar o trabalho.

24. O excesso de serviços impede que eu tenha tempo para refletir sobre o melhor modo de realizá-los.

25. Quando proponho uma ideia nova, é comum que o gerente se aposse dela como se fosse sua.

26. O gerente costuma acatar apenas as ideias dos colaboradores que ele tem mais afinidade.

27. Os gestores năo costumam ouvir ideias de pessoas que ocupam menor nivel hierárquico.

28. O sistema de comunicaçăo da organizaçăo dificulta a disseminaçăo de informaçōes entre as diferentes áreas na organizaçāo.

29. A rigidez das regras na organização dificulta o surgimento de novas ideias.

30. A estrutura atual da Organizaçăo dificulta a comunicaçăo entre as áreas impedindo o compartilhamento de ideias.

31. O gerente toma decisōes sobre atividades sem consultar aqueles que irăo realizá-las. 
32. O gerente incentiva os empregados a participar da solução dos problemas de trabalho.

33. A Organização contribui para a produçāo de novas ideias no ambiente de trabalho a partir da abertura à participaçăo de consultores externos.

34. O grau de dificuldade das tarefas que realizo me estimula a pensar em novas ideias.

35. As minhas tarefas no trabalho me estimulam na busca de novos conhecimentos para sua realizaçăo.

36. Tenho liberdade para decidir como realizar as tarefas a mim atribuidas.

37. Sinto-me incentivado a produzir ideias novas a partir do convivio com meus colegas de trabalho.

38. Tenho o silêncio necessário, onde trabalho, para a realizaçăo de minhas tarefas.

39. O clima entre os colegas é de confiança e respeito mútuo.

40. Tenho mobiliário suficiente para guardar meu material de trabalho.

41. Tenho liberdade para propor novas formas de fazer as atividades no trabalho.

42. Meus colegas elogiam quando apresento uma boa ideia no trabalho.

43. As atividades que realizo caracterizam-se pela constante interrupçăo para resolver algo urgente, dificultando a produçăo de ideias novas e de valor.

44. O gerente acredita que somente é correta a maneira como ele realiza o trabalho.

45. Falta flexibilidade nos normativos da organizaçāo o que dificulta a aceitaçăo de ideias novas.

46. O espaço fisico no local de trabalho é adequado para o número de funcionários.

47. Na minha Organização, as estratégias săo claras $e$ bem definidas o que facilita a proposiçăo de novas ideias.

48. Meu gerente imediato tem receio de que eu apresente melhor desempenho do que ele no trabalho.

49. $\mathrm{Na}$ Organizaçăo, o excesso de burocracia dificulta a expressăo da criatividade.

50. Nāo tenho o tempo necessário para desenvolver novas ideias

51. A Organização tem como uma de suas diretrizes a busca da criatividade.

52. Eu tenho os materiais de que necessito para a realização do meu trabalho.

53. Tenho liberdade para expor minhas ideias onde trabalho.

54. Sinto que realizo trabalhos importantes para a Organizaçăo.

55. A Organização oferece diferentes oportunidades de interaçăo com outras instituipōes que favorecem a expressāo de ideias novas e de valor. 
56. A falta de pessoal para a realização do trabalho limita o tempo para criar.

57. O gerente nầ discute ideias novas com seus colaboradores devido ao desconhecimento das afividades do setor.

58. Há dificuldades de comunicação entre os setores que criam e os que executam as normas na minha Organizaçāo

59. As regras que temos que seguir na Organizaçăo dificultam a introdução de ideias criativas.

60. Disponho dos recursos tecnológicos necessários ao exercicio de minhas funçбes como, por exemplo, telefone, computador com acesso a internet.

* Indique na escala de 0 a 10 , sendo $0=$ nem um pouco e $10=$ totalmente criativo, 0 quanto você se considera criativo em seu ambiente de trabalho.

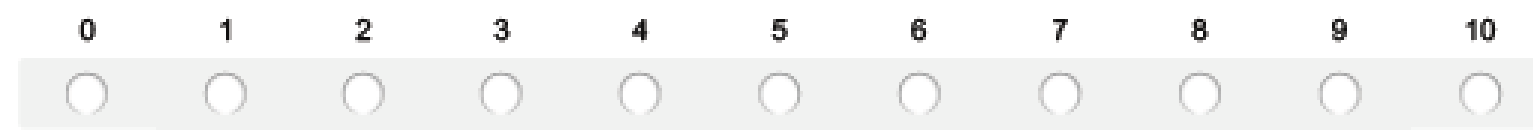

* Indique na escala de 0 a 10 , sendo $0=$ nem um pouco e $10=$ totalmente, $o$ quanto os resultados alcançados na área em que você trabalha são decorrentes de açōes criativas
0
1
2
3
4
5
6
7
89
10 
BLOCO APRENDIZAGEM - Estratégias de Aprendizagem no Ambiente de Trabalho

\section{O que são estratégias de aprendizagem?}

Săo práticas que as pessoas utilizam para auxiliar a aquisiçăo de conhecimentos e habilidades em seu contexto profissional. (Holman, Epitropaki e Fernie, 2001)

* Ao lado de cada afirmativa, assinale o número que melhor represente a frequência com que utiliza as estratégias de aprendizagem em seu ambiente de trabalho, considerando a seguinte escala:

\begin{tabular}{|c|c|c|c|c|c|c|c|c|c|}
\hline 1 & 2 & 3 & 4 & 5 & 6 & 7 & 8 & 9 & 10 \\
\hline Nunca & & & & & & & & & Sempr \\
\hline
\end{tabular}

Caso você entenda que a afirmativa não se aplica ao seu ambiente de trabalho, assinale a opção "năo se aplica".

1. Busco ajuda dos meus colegas quando necessito de informaços mais detalhadas sobre o trabalho.

2. Quando tenho dúvidas sobre algo no trabalho, consulto colegas de outras áreas da empresa.

3. Experimento na prática novas formas de executar o meu trabalho.

4. Para aprimorar a execuçāo do meu trabalho, busco memorizar dados ( $n^{\circ}$ de rubricas, contas, transaçōes em sistemas, etc.)

5. Para melhor execuçāo do meu trabalho, procuro seguir sempre os mesmos procedimentos.

6. Analisando criticamente a execuçăo do meu trabalho, tento compreende-to melhor.

7. Visando executar melhor minhas atividades de trabalho, busco repetir automaticamente açōes $e$ procedimentos memorizados. 
8. Para executar melhor o meu trabalho, procuro repetir mentalmente informaçōes e conhecimentos recémadquiridos.

9. Quando faço meu trabalho, penso em como ele está relacionado ao negócio e às estratégias da organizaçăo.

10. Tento compreender como a atuaçăo das diferentes áreas da organizaçăo influencia a execuçăo do meu trabalho.

11. Quando tenho dúvidas sobre algo no trabalho, procuro ajuda em publicaçōes, informativos, fasciculos e relatórios da empresa.

12. Consultando informaçōes disponiveis na intranet, busco compreender melhor as atividades que executo no trabalho.

13. Peço ajuda aos meus colegas de equipe quando necessito aprender algo sobre meu trabalho.

14. Quando estou em đúvida sobre algo no trabalho, consulto normativos e instruçōes editadas pela organizaçăo.

15. Para obter as informacōes de que necessito para o trabalho, leio informativos e matérias publicadas na agência de notícias.

16. Visando obter informaçōes importantes à execuçāo do meu trabalho, consulto a Internet.

17. Para aprimorar a execuçăo de minhas atividades, procuro compreender melhor cada procedimento e tarefa do meu trabalho.

18. Busco entender como diferentes aspectos do meu trabalho estão relacionados entre si.

19. Procuro obter nowos conhecimentos e informaçōes consultando colegas de outras equipes.

20. Consulto colegas de trabalho mais experientes, quando tenho dúvidas sobre algum assunto relacionado ao meu trabalho.

21. Para melhor execuçāo do meu trabalho, reflito sobre como ele contribui para atender as expectativas dos clientes.

22. Procuro compreender como o meu trabalho está relacionado aos resultados obtidos nas diferentes áreas da organizaçăo. 
23. Procuro aprimorar algum procedimento de trabalho, experimentando na prática novas maneiras de executálo.

24. Testo novos conhecimentos aplicando-os na prática do meu trabalho.

25. Busco compreender as relaçōes entre as demandas feitas por outras áreas da organizaçāo e a finalidade do meu trabalho.

26. Tento conhecer como as diferentes áreas da organizaçăo estāo relacionadas entre si.

Caso haja, destaque aqui as práticas mais utilizadas para aprender em seu ambiente de trabalho: 


\section{BLOCO CARACTERIZAÇÃO - Informaçőes do Participante}

Para caracterizar os participantes da pesquisa, favor informar alguns dados a seu respeito. Lembrando que as informaçōes aqui prestadas serăo analisadas de forma agregada e sem a identificação dos participantes garantindo seu sigilo $e$ anonimato.

* Idade

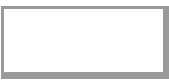

* Sexo

Masculino Feminino

* Formação

Ensino Fundamental

Ensino Médio

Ensino Superior

Pós-Graduaçāo

Outro (especifique)

* Em qual AABB você trabalha? (ex.: "AABB Săo Paulo", "AABB Juiz de Fora", "Satélite Esporte Clube")

Em qual Estado?

*

* A quanto tempo trabalha nesta Organizaçăo? (em anos)

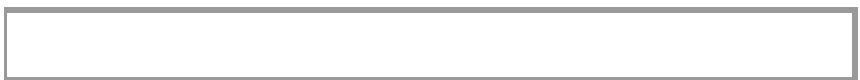


* Em qual área trabalha?

Administrativo/Financeiro

Desportes/Entreterimento

Alimentaçāo/Bar

Serviços Gerais (Limpeza, segurança, etc.)

Outro (especifique)

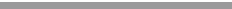

(2)

* Exerce cargo de chefia?

Sim

Nāo

Comentários ou sugestōes sobre a pesquisa:

Caso deseje receber o resultado da pesquisa, favor informar aqui o seu e-mail:

Agradecemos sua valiosa colaboração para essa pesquisa! 